\title{
INVESTIGATING EXIT-SEEKING INTERVENTIONS FOR RESIDENTS WITH ALZHEIMER'S DISEASE IN
}

\section{INSTITUTIONAL CARE}

\author{
by \\ Dea Attar \\ A thesis submitted to \\ the Faculty of Graduate and Postdoctoral Affairs \\ in partial fulfillment of the requirements for the degree of
}

\author{
Master of Design \\ in \\ Industrial Design
}

Carleton University

Ottawa, Ontario

(C) 2014, Dea Attar 


\begin{abstract}
The exit-seeking behavior of persons with Alzheimer's disease has been associated with a decline in the physical and emotional wellbeing of the residents and their caregivers in long-term care facilities. Recent studies in the field suggest that promoting safe wandering and adapting to the patients needs contribute for better exit-seeking management, which can be facilitated through the use of assistive technology. In order to investigate how the technology can be introduced to nursing homes to effectively deter this dangerous behavior, five research methods are utilized: expert, family and artist interviews, a co-design workshop and a visual survey. Noticing the attitudes of the research participants towards the use of technology and their interests in low-tech deterrents such as door camouflages, the study examines the rationale behind the effectiveness of various exit-seeking interventions in order to provide recommendations for the professionals involved in the development of such solutions. The research finds that an effective wandering management strategy requires a combination of multiple approaches that complement each other in terms of the purpose of use, and build on the residents' interests, understanding and backgrounds.
\end{abstract}

Keywords: Alzheimer's disease, exit-seeking interventions, assistive technologies, door camouflages, design recommendations 


\section{ACKNOWLEDGMENTS}

First of all, I would like to thank Prof. Lois Frankel for her tremendous support academically and emotionally, her dedication and her positive encouragement throughout the process. I really appreciate her effort in reviewing my lengthy drafts and unorganized chapters until they made sense as a whole. Thanks to Dr. Federica Goffi for her invaluable guidance throughout the development of this thesis and for her availability outside normal working hours. Without their advisory, this work would not have succeeded.

I am thankful for all participants in the interviews, the workshop and the survey, especially the family members who participated in the workshop. I truly respect your devotion to give back to those who cared for your loved ones during the stages of the disease and your motivation to expand the knowledge in the field. I would also like to thank the facilities in which the interviews and surveys were conducted, the organizations that introduced me to the right people and the Alzheimer's Society of Ontario with its local chapters for their willingness to help.

Thanks to the faculty and staff of the School of Industrial Design for their ongoing support and sincerity, and my MDES classmates for making this journey possible.

Finally, a special thanks to my parents, Rania and Hanna, and my brother Abdallah for their constant love and support and for believing in me from day one. My friends and family back home must also be thanked for showing me that one can overcome the hardest challenges. 


\section{TABLE OF CONTENTS}

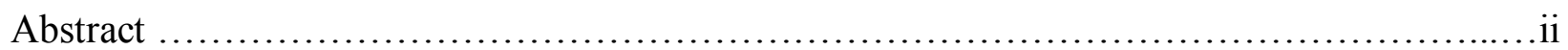

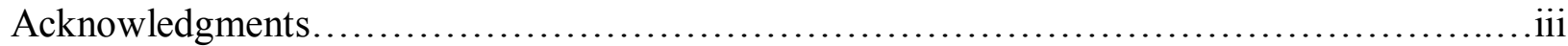

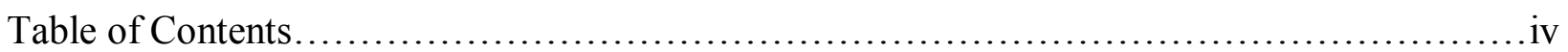

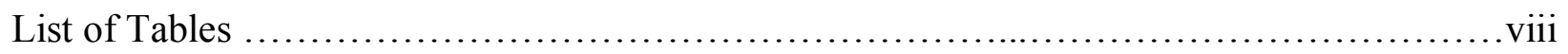

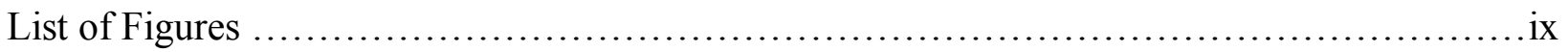

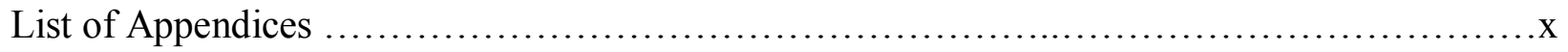

\section{CHAPTER}

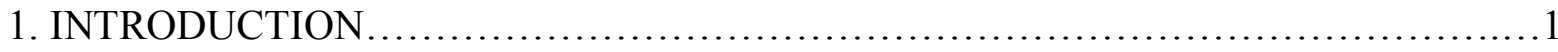

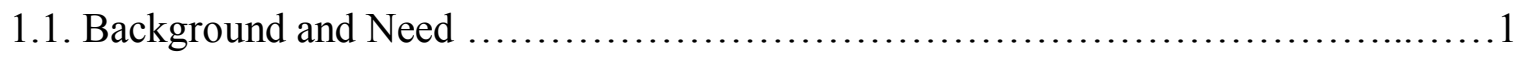

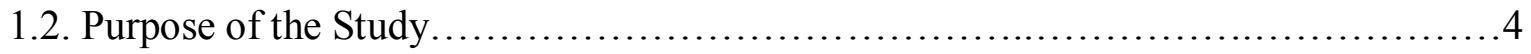

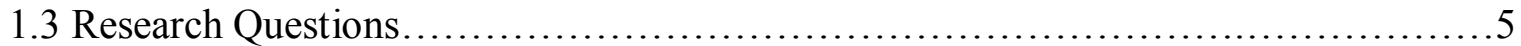

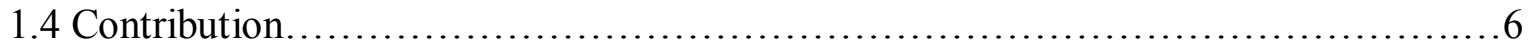

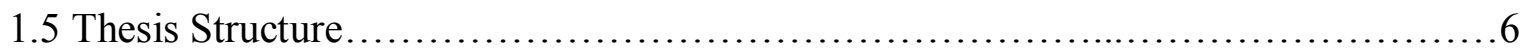

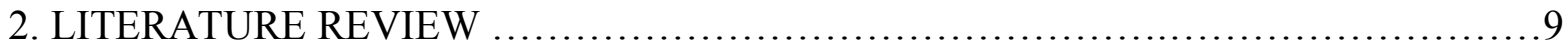

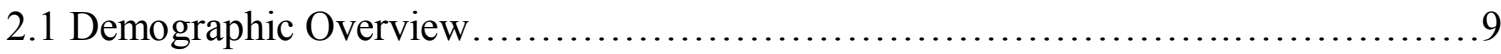

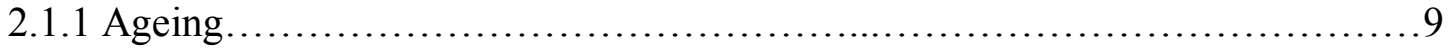

2.1.2 Alzheimer's Disease ................................................ 11

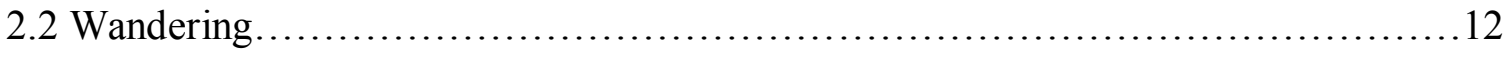

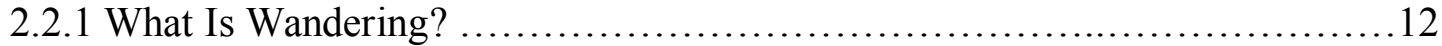

2.2.2 Wandering In Long-Term Care Facilities..................................16

2.2.3 Exit-Seeking and Wandering Away ......................................17

2.3 Traditional Approaches to Manage Wandering ..................................... 18

2.3.1 The Environment and the Wellbeing ..................................... 18 
2.3.2 Environmental Designs That Affect Wandering.............................20

2.3.2.1 Interior Architecture and Spatial Interventions.........................21

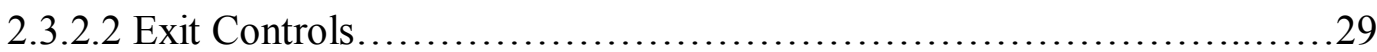

2.4 Technological Approaches to Manage Wandering..................................34

2.4.1 Technological Interventions................................................

2.4.1.1 Tagging and Tracking Systems.....................................35

2.4.1.2 Surveillance and Monitoring Systems................................38

2.4.1.3 Measurement \& Prompting Interventions............................ 41

2.4.2 Privacy and Ethical Concerns ..............................................41

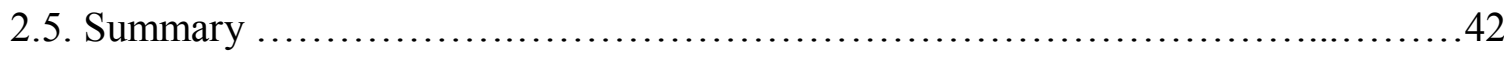

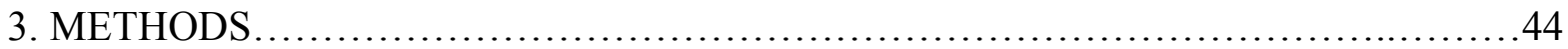

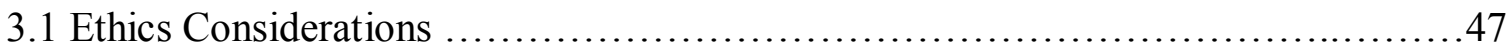

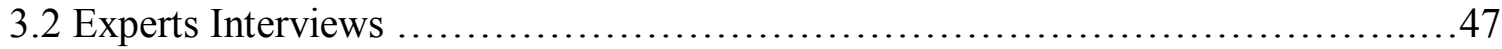

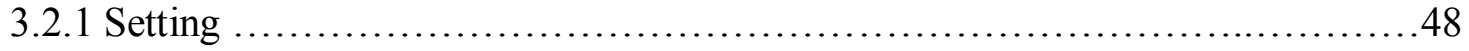

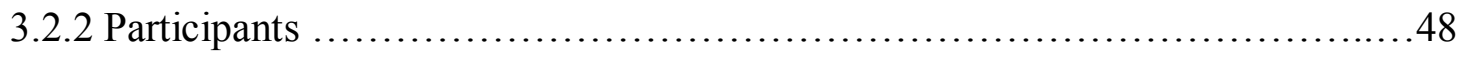

3.2.3 Data Collection Procedures .................................................... 49

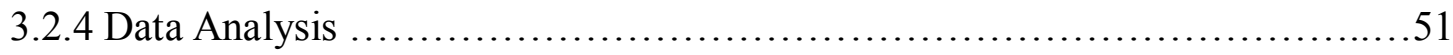

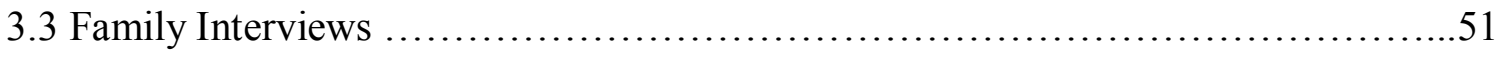

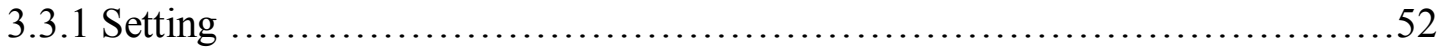

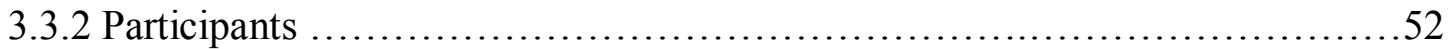

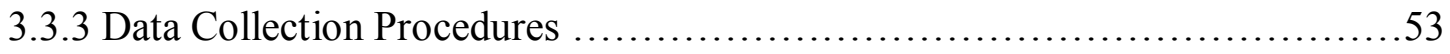

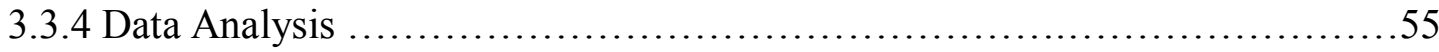

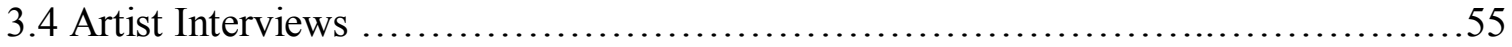

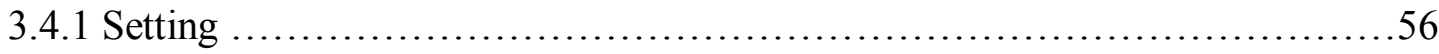

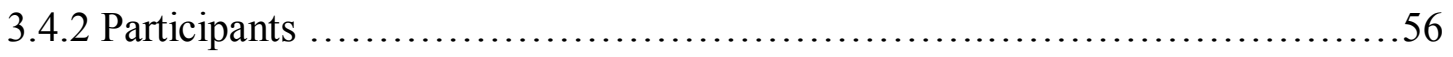

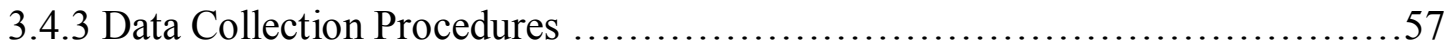

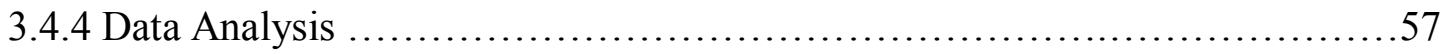

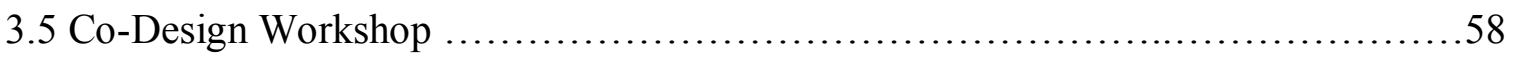

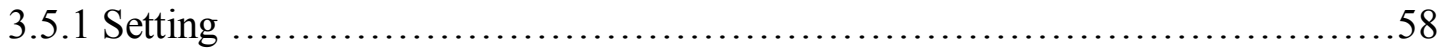

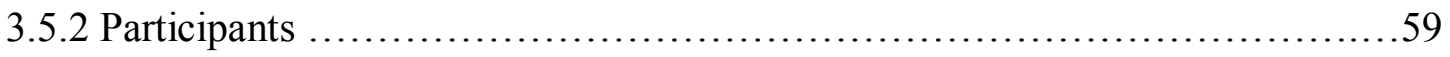


3.5.3 Data Collection Procedures …........................................60

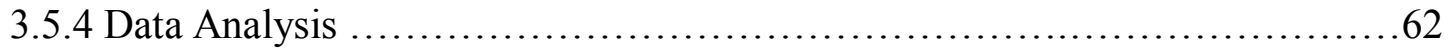

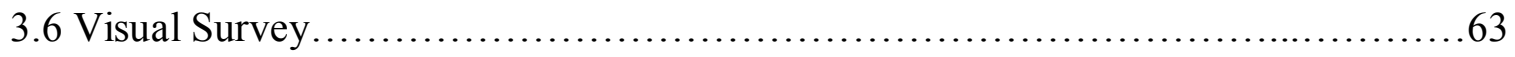

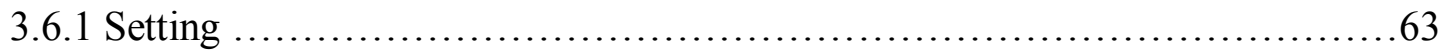

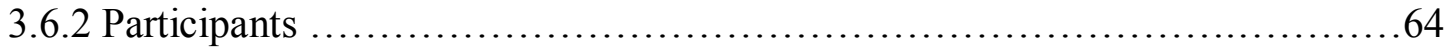

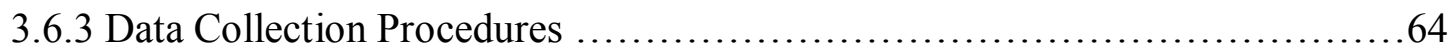

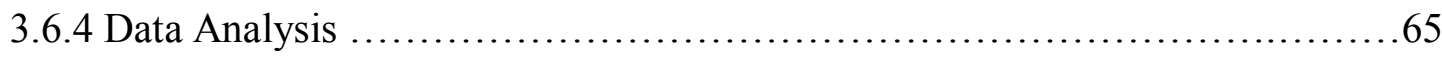

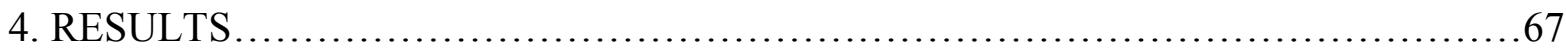

4.1 Instrument One - Semi Structured Interviews ..................................67

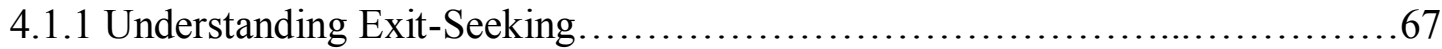

4.1.2 Understanding the Exit-Seeker.............................................69

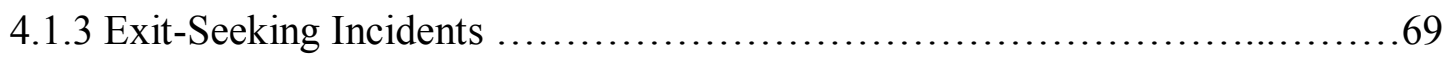

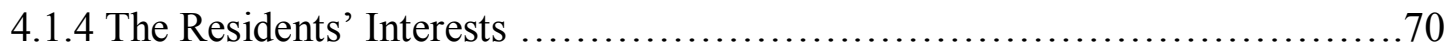

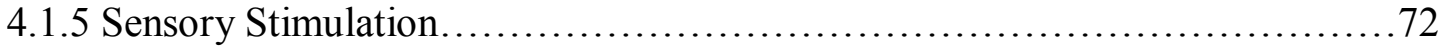

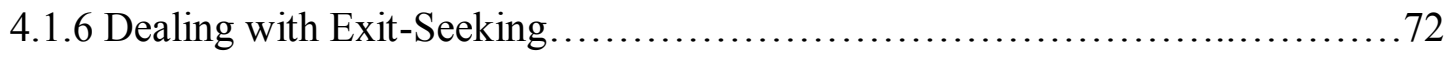

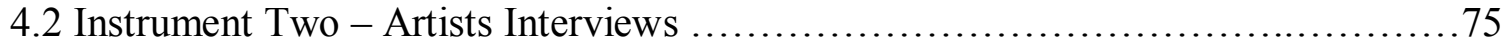

4.2.1 The Painting ................................................................... 75

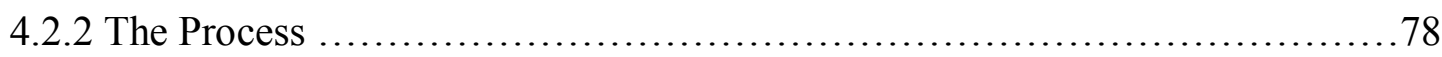

4.3 Instrument Three - The Workshop ............................................ 79

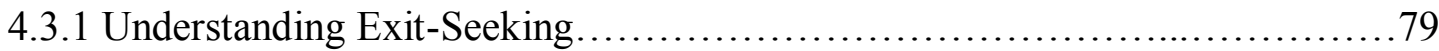

4.3.2 Understanding the Exit-Seeker........................................... 81

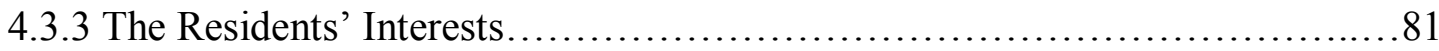

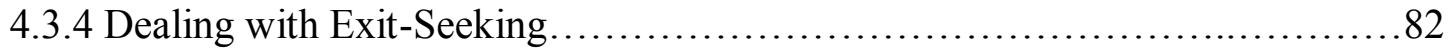

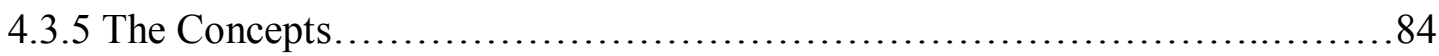

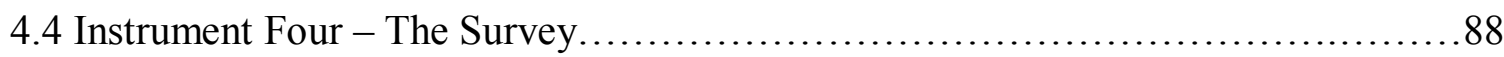

4.4.1 Survey Section One....................................................... 88

4.4.2 Survey Section Two ............................................... 92

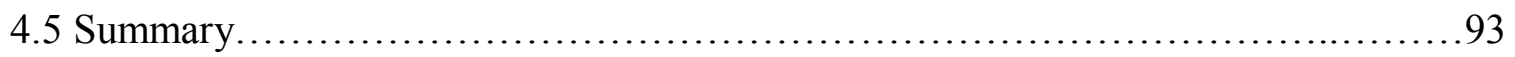




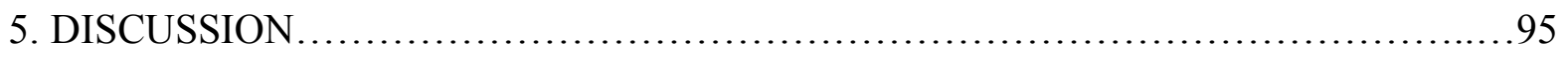

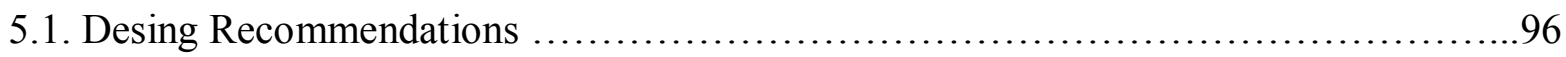

5.1.1 the Need For Muliple Interventions .........................................97

5.1.1.1 Direct Exit-Seeking Recommendations ..........................98

5.1.1.1.1 Visitors Alarm....................................................98

5.1.1.1.2 Doors Concealment............................................99

5.1.1.2 Indirect Exit-Seeking Recommendations..........................101

5.1.1.2.1 Engaging Distractions.......................................... 102

5.1.2 General Recommendations .............................................104

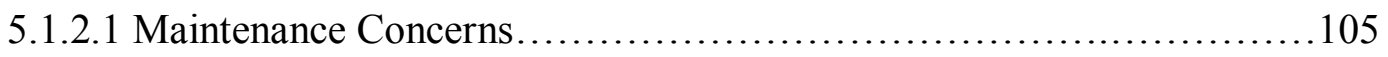

5.1.2.2 Relatable and Understandable Interventions.........................105

5.1.2.3 Disruptive Interventions Complications............................106

5.1.2.3.1 For the Caregivers............................................. 107

5.1.2.3.2 For the Patients............................................... 108

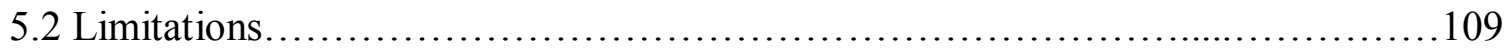

5.3 Recommendations for Future Research......................................110

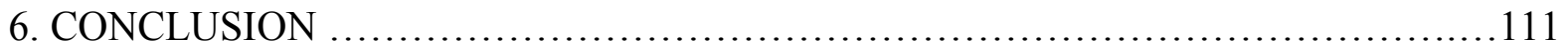

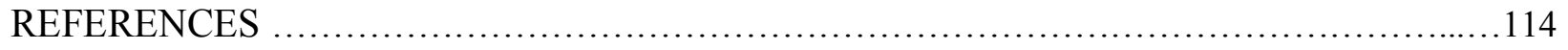

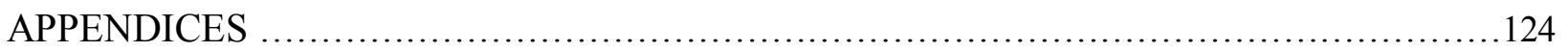




\section{LIST OF TABLES}

Table 1 - Level of staff training and supportive environment ..............................21

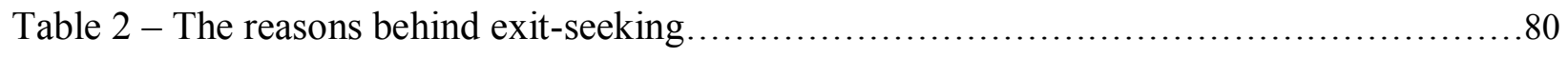

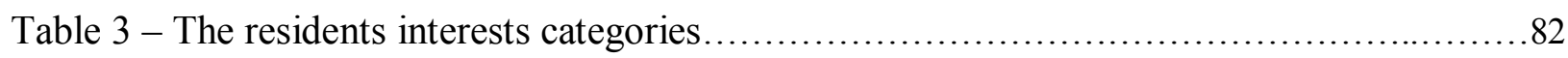

Table 4 - Video wall stations responses............................................ 89

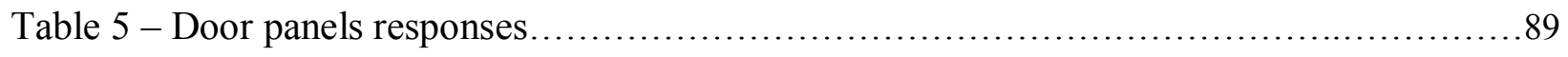

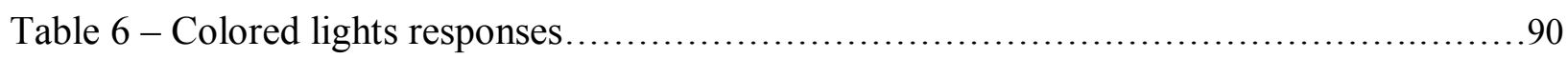

Table 7 - Video call responses..................................................... 90

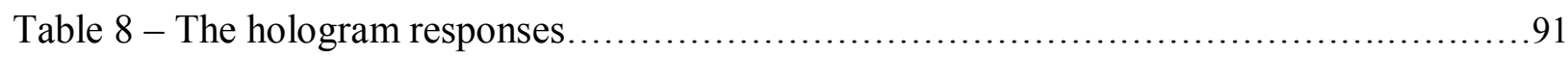

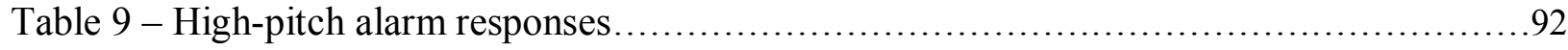

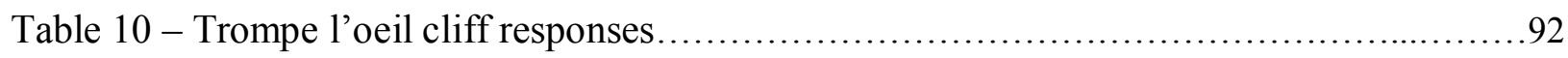

Table 11 - Interventions preference ranking .......................................... 93 


\section{LIST OF FIGURES}

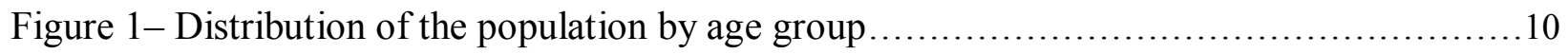

Figure 2 - Illustrations of wandering patterns........................................... 16

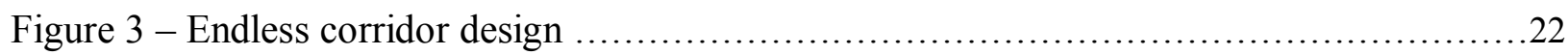

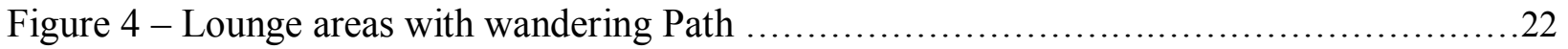

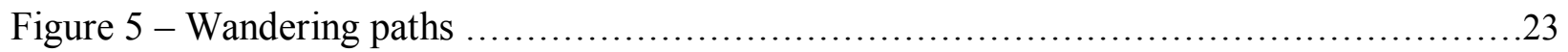

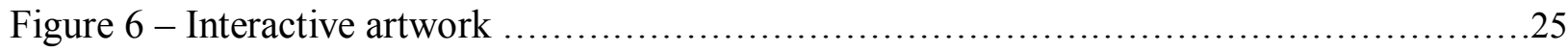

Figure 7 - Home environment and outdoor nature environment ............................27

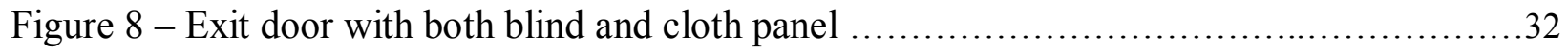

Figure $9-$ Bracelet $\&$ monitoring station and the pager.....................................

Figure 10 - Overview of the measurement environment ................................40

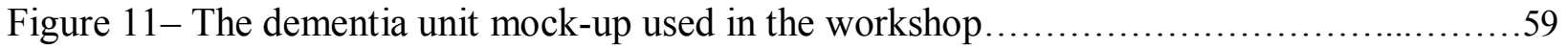

Figure 12 - Visualizing the interventions and their locations within the mock-up unit..........61

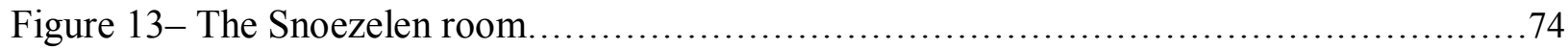

Figure14 - The Door Camouflage, before and after..................................... 77

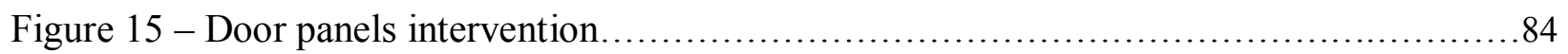

Figure 16 - Trompe l'oeil cliff intervention................................................. 85

Figure $17-$ The hologram intervention.............................................. 85

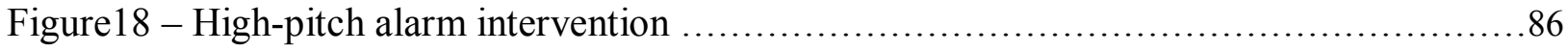

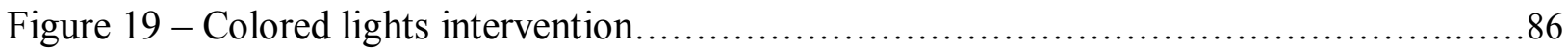

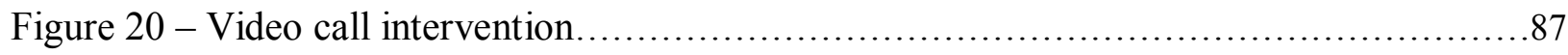

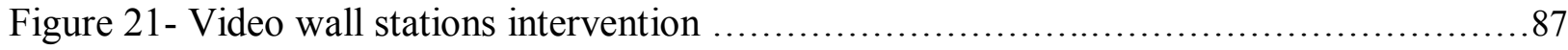




\section{LIST OF APPENDICES}

Appendix A - Experts Interviews.................................................... 124

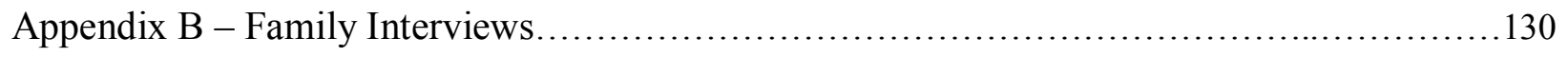

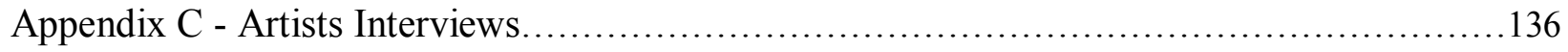

Appendix D - Co-Design Workshop............................................. 139

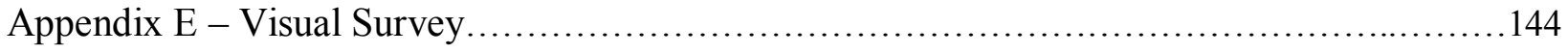

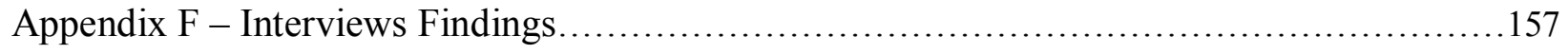

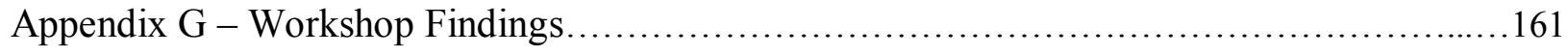

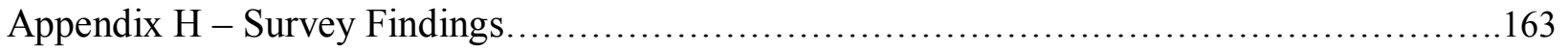




\section{CHAPTER 1}

\section{INTRODUCTION}

The ageing of the world's population and the increase in the number of older people goes hand-in-hand with an increase in the number of people with Alzheimer's disease (AD) and related dementia. These individuals suffer from cognitive impairments that result in various responsive behaviors, which are a major source of distress both to the persons who display them and their caregivers. One example of these troubling behaviors is wandering.

It has been established that the wandering behavior of people with $\mathrm{AD}$ is dangerous and can lead to increased risks of injury and death, even in nursing homes (Silverstein, et al, 2002, P.112; Aud, 2004). Therefore, in order to deter exit-seeking and prevent elopement, there is a need to provide effective wandering interventions in long-term care (LTC) settings. Moreover, assistive technologies have been found to have the potential to increase the physical and emotional wellbeing of both patients and caregivers.

This thesis focuses on how appropriate design of technological interventions could contribute to wandering management by exploring the nature of this disturbing behavior, as well as the needs and requirements of the dementia population and their care providers.

\subsection{BACKGROUND AND NEED}

Canadians are ageing at a fast rate. With the number of Canadians suffering from this disease doubling within a generation, $\mathrm{AD}$ is considered to be the most significant social and health crisis of the 21 st century (Alzheimer Society of Canada, 2012a). As the disease develops and affects different areas of the brain, symptoms become more severe resulting in changes in 
abilities and behaviors (Alzheimer's Association, 2013). Wandering behavior, among other responsive behaviors, is considered to be an outcome of the cognitive impairment that increases as dementia progresses (Alzheimer's Association, 2012). Those who wander become disoriented and unable to find their way; hence, they are believed to be in danger. The risks involved can contribute to death if the wandering episode is not seriously addressed within the first 24 hours. In addition, this disturbing behavior can be worrying and stressful for the patients' families and caregivers (Silverstein et al, 2002, P.76).

When persons with $\mathrm{AD}$ display uncontrolled wandering behavior that might jeopardize their safety, keeping them at home might no longer be an option. In fact, the consequences of wandering are dangerous enough to require persons with $\mathrm{AD}$ to be institutionalized (Melillo, 1998). Dementia patients are admitted to nursing homes with the assumption that an institutional environment will be safer. Safety, however, cannot be assumed (Silverstein, et al, 2002, P.112).Thus, it is important to find a solution that preserves the person's safety and dignity (Alzheimer's Society of UK, 2013). The approaches of managing the problem of wandering can be divided into three categories: physical and chemical restraints, traditional approaches and technological interventions. However, restraints are often associated with complications and dangerous side effects (Alzheimer Society of Canada, 2007; Wigg, 2010). Conversely, managing wandering should not compromise the physical and mental wellbeing of the residents, nor substitute for safe and well-designed environments ( Alzheimer Society of Toronto, 2013; Tilly \& Reed, 2006). Instead, proper wandering management recognizes that people with $\mathrm{AD}$ are no longer able to adapt, and that instead the environment must be adapted to the person's specific needs (Desai \& Grossberg, 2001). 
The assumed risks of wandering influence the interventions' design to accommodate the behavior rather than eliminating it (Wigg, 2010). Moreover, the design of the physical environment has been recognized in literature as an important aid in the care of people with dementia (Brawley, 1992; Zeisel el al, 1994). Accordingly, architectural modifications were suggested to allow the residents to wander in a safe environment and provide them with an opportunity to exercise (Heim, 1986; Coons, 1988). Such modifications include creating endless corridors were residents wouldn't reach a dead-end in their circulation around the facility (Dickinson \& Mclain-kark, 1996; Silverstein, et al, 2002, P.119). Other studies suggested that there is a connection between sensory stimulation and wellbeing. According to Coons (1988), a rich, stimulating environment can alleviate some wandering behaviors. In fact, it is argued that interesting environments can provide the necessary distraction to redirect exitseekers' attention. Thus, ideas such as group activities, interactive artwork (Dickinson \& Mclain-kark, 1996), sensory scenes (Cohen-Mansfield \& Werner, 1998) and different levels of light and sound (Yao \& Algase, 2006) were investigated in literature. Lastly, door interventions and exit controls have an important role in addressing the residents' need for coming in and out (Zeisel et al, 1994). These include door locks and alarms, visual barriers and signage, and doorway windows (Aud, 2004; Coons, 1988; Alzheimer Knowledge Exchange, 2010; Hamilton, 1993; Namazi et al.1989; Silverstein et al, 2002, P.115-118). Nonetheless, persons with $\mathrm{AD}$ still manage to elope or escape.

On the other hand, technological solutions have the potential to adapt to and create supportive settings to accommodate this disruptive behavior. The literature suggests that technologies can compensate for the shortage in staffing resources, lessen the burden on caregivers and extend the quality of care by responding to users' needs (Dorsten et al, 2009). 
Some studies examining technological solutions for LTC facilities investigated the use of tagging systems (Hughes and Louw 2002; Altus et al. 2000; Miskelly, 2004; Mulvenna et al, 2010). The goal of such systems is to provide the wanderer with more liberty and freedom inside and/or outside the nursing home while maintaining their safety. However, ethical issues as well as concerns about the patients rejecting the gadgets, forgetting to wear them and/or losing them arose in literature (Youssef et al, 2007; Wigg, 2010). Other studies focused on monitoring technologies that can examine actual situations by understanding the context in which the wandering is taking place, and consequently, detect possible elopements and alarm the staff (Diaz-Ramirez et al, 2013; Kim et al, 2009; Wigg, 2010).

Although wandering behavior has been a major concern and focus of AD research for the past three decades, no fully effective intervention exists. While, it is evident that technology holds promise for wandering solutions, most studies were not tested in real environments and/or do not reflect on the patients' and caregivers' needs and concerns. This gap may be an opportunity to better understand the potential use of technological interventions in LTC settings from the perspective of family members and formal caregivers; and therefore provide design recommendations and guidelines for creating and/or improving the features of such interventions to be used in real practice.

\subsection{PURPOSE OF THE STUDY}

The purpose of this study is to explore how appropriate design of technological interventions could effectively deter the wandering behavior of people with AD in LTC settings, while maintaining their wellbeing. Caregiving for dementia patients is often an overwhelming and burdening process. Additionally, many wandering prevention approaches 
have been associated with complications and dangerous side effects. Thus, a new philosophy in management of exit-seeking has evolved to promote safe wandering rather than restraining it. Moreover, assistive technologies have the potential to increase the physical and emotional wellbeing of both the patients and caregivers. However, there is still a lack of understanding of what caregivers are looking for in a wandering management solutions, and more importantly, what design criteria are appropriate for technological interventions considering the nature of the disease and the behavior. Therefore, and because the knowledge about this subject is scattered throughout different fields and disciplines such as healthcare, architecture and design, and technology, the goal of conducting this research is to provide recommendations and set up design guidelines for creating and/or improving the features of technological interventions to deter wandering.

\subsection{RESEARCH QUESTIONS}

In order to examine the problem of wandering and investigate how appropriate design of exit-seeking interventions can contribute to safer environments and improved wellbeing in nursing homes, the following question (Q) and sub-questions (SQ) will be explored through a combination of in depth interviews, a workshop and a survey.

Q- How can technology be introduced in the LTC environment to effectively deter the exit seeking behavior of dementia residents?

SQ1- Which dementia-related factors and caregiver issues need to be taken into account when designing assistive technologies to deter exit seeking?

SQ2- What are the tools and interventions currently available to deter wandering, how effective are they and why/why not? 
SQ3- Which objects, activities and elements of the physical environment can capture the exit-seekers' attention and provide a distraction?

\subsection{CONTRIBUTION}

The main goal of the this research is to serve as design tool or guide for the professionals involved in the development of assistive technologies concerned about dealing with the wandering behavior of persons with AD in LTC settings. By providing valuable insights into possible functions and attributes of the technological applications, this study aims to provide recommendations for creating and/or improving the features of such interventions that were not previously discussed in literature.

Furthermore, this study is intended to expand the interdisciplinary knowledge base about the issue of wandering and its effective management approaches. Thus, formal and family caregivers may benefit from the findings of this research by understanding how the technology would work in context and increase the physical and emotional wellbeing of the patients and the caregivers.

By the exploratory means of this thesis, the lessons learned in this study and the theory developed might provide groundwork for future research and indentify specific research areas to further investigations.

\subsection{THESIS STRUCTURE}

The thesis consists of six chapters, each containing several main sections and subsections. In this first chapter, the focus of the current research study is introduced by briefly discussing the niche of the thesis in relation to other similar studies. Moreover, the problem, the 
purpose, and the objectives of the study are indentified. The research questions that tackle the phenomenon of wandering are presented in addition to the significance and value of this research to interdisciplinary design research.

The second chapter is the literature review, which explores existing research that surrounds the topic of wandering of persons with AD. This chapter provides a descriptive profile of dementia patients and of their wandering behavior as discussed in literature. In addition, it sheds light on various approaches of dealing with the exit-seeking and its consequences that range from environmental to technological interventions.

The third chapter is concerned about data gathering methodologies used to answer the thesis main and sub-questions. The settings in which the data collection took place; the sample of the participants who took part in the study; the data collection procedures and data analysis process that followed are thoroughly described. Qualitative data was collected through the use of three sets of in-depth interviews and a workshop in order to collect information from a variety of perspectives. Also, a mixed methods strategy (visual surveys) was conducted to collect both quantitative and qualitative data.

The forth chapter is dedicated to presenting the research results, which consist of both qualitative and quantities findings. Data collected were organized according to themes that evolved in the data analysis process. The results from each method are presented separately.

The fifth chapter is an interpretation of the research findings. It is dedicated to understanding the actual meanings behind the results of this study in relation to wandering management. Also, the data is compared with similar investigations found in literature, with the aim of answering the research questions. A discussion acknowledging the limitations of this study and suggestions for future research initiatives are included in this chapter. 
The sixth and last chapter is the conclusion of the extensive analysis conducted in the study. The significance of the results and the four major contributions of this research are clearly defined and discussed in this chapter. 


\section{CHAPTER 2}

\section{LITERATURE REVIEW}

This chapter provides a review of the relevant literature addressing the phenomenon of wandering of persons with AD in LTC settings. The following sections set up the basis from which the research questions evolved. Stemming from various disciplines, the information gathered is summarized and condensed into four main topics. The first section provides an overview of the demographic changes affecting society, calling attention to the problems arising from the growing numbers of elderly in general and persons with AD in particular. The second section explores the issue of wandering including the causes, the types and the possible consequences of this disruptive behavior. The third section introduces the traditional approaches of dealing with wandering in LTC facilities that range from architectural and spatial modifications to exit controls. Finally, the last section addresses the research about technological interventions as discussed in literature.

\subsection{DEMOGRAPHIC OVERVIEW}

\subsubsection{Ageing}

As the first wave of the so-called baby-boomer generation starts to experience the first signs of ageing, the structure of the Canadian population will be changed significantly over the next fifty years. The Parliament of Canada (2012) predicts that the number of seniors could double between 2011 and 2033, rising from about 5 million to close to 10 million. Among these statistics, the proportion of the "very elderly" (80 and over) would increase from $27 \%$ to $38 \%$ between 2011 and 2061. The reasons behind the population growth rate are associated with two 
main factors: the declining birth rates and rising life expectancy. Figure-1 demonstrates the percentage of the population in relation to age since 1971 and projects the future until 2061. In the view of that, the dependency ratio of seniors (number of seniors per person of working age) would increase from 0.21 to 0.43 between 2011 and 2061 (Library of Parliament, 2012). As a result, this transition will transform the society on multiple levels including the economy and healthcare systems (Morchadze et al. 2009; United Nations, 2004).

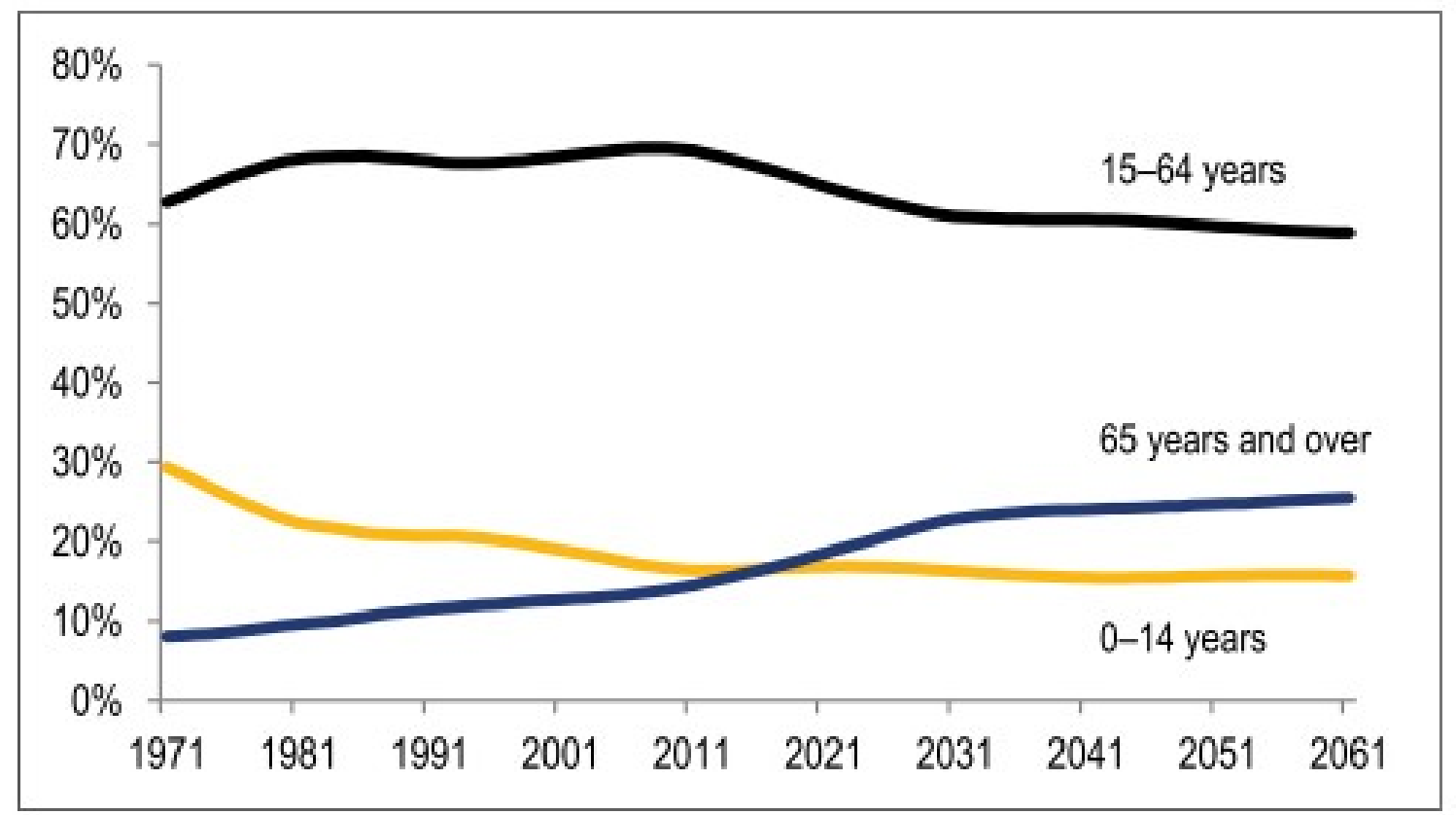

Figure 1- Distribution of the population by age group, adapted from André Léonard, Library of Parliament, 2012, from http://www.parl.gc.ca/content/lop/researchpublications/2011-63-e.pdf

As people get older, their needs and expenses gradually increase then they rise sharply towards their senior years (Library of Parliament, 2012). While a greater share of the Canadian population is becoming comprised of the elderly, the number of disabled people will also increase. These demographic changes will amount for an intensive burden that could encumber the general population and the healthcare sector. In fact, among the elderly, persons with chronic conditions are the most frequent and costly users of health care services (Library of 
Parliament, 2012). These individuals require excessive help and continued monitoring. One example of these illnesses is Alzheimer's disease (AD).

\subsubsection{Alzheimer's Disease}

Alzheimer's disease (AD) is the most significant social and health crisis of the 21st century and has the potential to overwhelm Canadian families and health-care systems (Alzheimer Society of Canada, 2012a). Although its causes are not yet fully understood or recognized, ageing is considered the major risk factor of $\mathrm{AD}$. In fact, this progressive, disabling, chronic illness is affecting 5\% of all people above 65 and over $40 \%$ of those over 90 years of age (Fratiglioni et al., 2007). This country can expect a massive rise in the number of dementia sufferers which corresponds with the increase in the number of elderly. Currently there are 500,000 Canadians suffering from this disease, and this number is expected to double within a generation (Alzheimer Society of Canada, 2012a, Ontario Retirement Communities Association, 2009). In addition, it is the most common form of dementia with $64 \%$ of dementia patients suffering from it. For all these reasons, it is referred to as the "plague" of the twentyfirst century" (Mulvenna et al., 2010).

$\mathrm{AD}$ develops in various parts of the brain and can impair the brain self-repair abilities. Losing brain tissues affects learning, short and long-term memory and behaviors. Persons with AD gradually experience difficulties of learning, remembering information and/or disorientation in time and space (Mulvenna et al., 2010, P.32). This type of dementia has no cure yet, however, current treatments can slightly slow its progression. As it worsens over time, this degenerative illness increasingly affects those who endure it and their companions. Because $\mathrm{AD}$ changes the way a person feels and acts, and causes problems associated with thinking and 
judgment, patients can no longer take care of themselves and face difficulties performing their daily activities. This can place an extra burden on caregivers who try to accommodate patients' needs and increase their quality of life (Alzheimer Society of Canada, 2013c; Alzheimer Association, 2013).

As their brains deteriorate, persons with $\mathrm{AD}$ gradually lose control over what they think or do. These factors challenge the sufferers, their families, and healthcare systems and lead to increasing disability and dependence in everyday life (Wimo et al., 1999). While the philosophy of caregiving for individuals with $\mathrm{AD}$ focuses on enhancing their declining well-being, facilitating it when the patients can no longer communicate or make decisions is challenging. Therefore, instead of focusing on the remediation of impairments, maintaining a good quality of life is often achieved by adapting to the new conditions (Nygard, 2004; Gori et al., 2001).

\subsection{WANDERING}

\subsubsection{What Is Wandering?}

Behaviors associated with $\mathrm{AD}$ are a major source of distress both to the person who is presenting the behavior and to those who experience them (Alzheimer Society of Canada, 2013b). One example of these troubling behaviors is wandering. It is commonly associated with dementia and publicly defined as:

An aimless or purposeful motor activity that causes a social problem such as getting lost, leaving a safe environment or intruding in inappropriate places (Alzheimer's Association, 2013).

In scientific literature, however, the definition of wandering is still hazy (Price et al., 2000). One reason for this vagueness is that multiple disciplines and professions, as well as diverse people dealing with wandering or its consequences, view it from different perspectives and 
attribute varied meanings to the word (Algase et al, 2007). To map the maze of terms and definitions associated with dementia-related wandering, Algase et al (2007) proposed the following definition:

A syndrome of dementia-related locomotion behavior having a frequent, repetitive, temporally disordered and/or spatially-disoriented nature that is manifested in lapping, random and/or pacing patterns, some of which are associated with eloping, eloping attempts or getting lost unless accompanied (Algase, et al, 2007).

Moreover, a recent study by Huston et al (2011) addressed the perception of wandering in the lens of caregivers. The research conducted interviews with informal caregivers and members of the International Consortium on Wandering and Missing Incidents, and resulted in this shared agreement about statements used to describe wandering: Aimless walking, disorientation/confusion, forgetting destination, leaving without telling anyone, getting lost, elopement, pacing, roaming, not returning home, leaving when they shouldn't, unrealistic/odd location, continuing on a path past destination. However, for the sake of this research, the definition proposed by Thomas (1995) will be adopted:

Wandering is a purposeful behavior that attempts to fulfill a particular need (from the context of the wanderer), is initiated by a cognitively impaired and disoriented individual, and is characterized by excessive ambulation that often leads to safety and/or nuisance-related problems (Thomas, 1995).

Changes in the brain can cause a person with dementia to become confused and disoriented, even when in a familiar place. This behavior is an outcome of the cognitive impairment that increases as the disease progresses and it may occur at any stage and at any time of the day or night (Alzheimer Association, 2012). Of course, brain deterioration affects the persons' cognitive mapping and thus their abilities to find their way from one point to another (Flaherty \& Scheft, 1995). While the causes of wandering have not been fully explored, 
the literature states numerous hypotheses explaining why patients with $\mathrm{AD}$ might wander or get lost. Some argued that causes of wandering include past lifestyle patterns of activity; current needs; and reactions to environmental stress (Thomas, 1997; Algase, 1999). Others suggested that it could be the outcome of casual factors such as confusion; inability to recognize familiar people; places or objects; fear arising from misinterpretation of sights and sounds; or a desire to fulfill a former obligation such as going to work and looking after a child (Peter et al, 2004). In their book, Silverstein et al (2002, P.33-35) summarized unsafe wandering as being due to the following reasons:

- A substitution for social interaction

- An expression of agitation, anxiety, sleep disorder, or unmet physiological needs

- A result of boredom, excess energy, lifelong habits, or an attempt to escape crowds or noise

- A result of experiencing fear, seeking exercise or companionship, looking for a childhood home, or trying to get to a former workplace

According to Algase et al (2007), however, wandering goes beyond perseverance and has an underlying drive or motivation. Yet, this perseverance (in terms of entailing an inability to stop or interrupt one's own behavior) may be a factor in a wanderer's overshooting a goal or getting stuck in a path.

In itself, wandering is not a harmful behavior, but it might have serious consequences especially if the person ends up wandering out of his residence (Alzheimer Society of Canada, 2012b). Algase and her colleagues (2007) emphasized that wandering as a scientific term should not be interchanged with its potential consequences such as elopement and getting lost. While these may be unfortunate outcomes of this disruptive behavior, they don't necessarily 
have to be. In fact, when able to wander freely in a safe and secure environment, the patients can enjoy a healthy outlet for feelings of anxiety, distress or restlessness (Alzheimer Society of Canada, 2012b). Nonetheless, wandering has been found to lead to institutionalization, increased risk for injury and sometimes death (Rubin et al, 1987). While AD doesn't affect the patients' physical capabilities, a sufferer might continue wandering until they are no longer capable to. According to Namazi et al (1989), wandering involves extended periods of movement without full awareness of one's behavior. Moreover, data indicates that more than $60 \%$ to $70 \%$ of those with $\mathrm{AD}$ will wander away from their residence at some point during the course of the disease (Flaherty \& Scheft, 1995). If this behavior is not seriously addressed, these individuals have only a 50\% chance of survival if not found in the first 24 hours (Alzheimer's Association, 2013). The risks associated with this behavior are presented in section 2.2.3.

Concerns for the safety of wanderers living in the community, as well as the burdens associated with dealing this disruptive behavior are recognized as important determinants of nursing home admission (Teri 1997; Braekhus et al. 1998; Melillo, 1998). In fact, for dementia alone, the number of family caregiving hours is expected to more than triple by 2038 (Alzheimer Society of Canada, 2010). Therefore, when persons with AD display uncontrolled wandering behavior that might jeopardize their safety, admission to a nursing home becomes almost guaranteed. This is based on the belief that their needs cannot be met with any combination of caregiving, and therefore, living at home is no longer possible (Community Care Access Center, 2013). 


\subsubsection{Wandering in Long-Term Care Facilities}

Due to the constant supervision, the risks associated with wandering in LTC facilities are limited in comparison to those of home based caregiving. However, according to Sternberg (2009, P.149), persons with AD express stress and anxiety when moving to assisted-living facilities; they feel completely lost when the illness affects their memory of place and thus they fail to remember the landmarks of the new space. The adjustment of moving to a new and unfamiliar place is difficult and special precautions should be taken during the first few days of a resident's move into a facility (Silverstein el al, 2002, P.151). It is important to note that $45 \%$ of elopements occur within the first 48 hours of admission (Rodriguez, 1993).

In a study conducted by Martino-Saltzman et al (1991), researchers tracked behaviors commonly referred to as wandering by videotaping the residents and analyzing their patterns of locomotion. Four primary types of motion were identified (Figure-2):
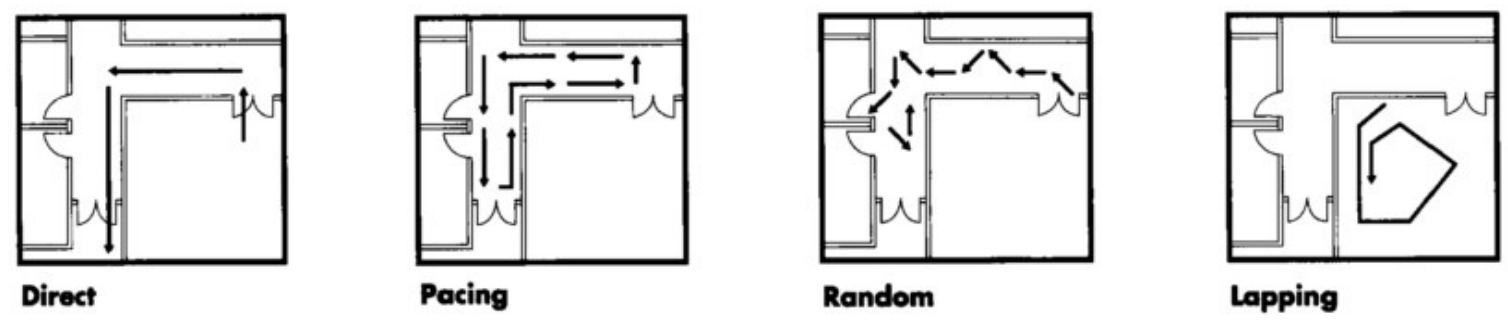

Figure 2- Illustrations of wandering patterns - Adapted from Martino-Saltzrnan et al., 1991 as cited in Dickinson \& Mclain-kark, 1996

- Direct travel (in which the resident moved from one place to another without diversion)

- $\quad$ Pacing (walking back and forth repeatedly)

- $\quad$ Random travel (seemingly aimless locomotion)

- $\quad$ Lapping (repetitive locomotion in a circular pattern) 


\subsubsection{Exit-Seeking and Wandering Away}

The caregiver makes this decision of the last resort with the assumption that an institutional environment will be safe for the individual with dementia. Safety, however, cannot be assumed (Silverstein, et al, 2002, P.112).

Data regarding the prevalence of institutionalized dementia patients who wander from nursing homes range from estimates of $11 \%$ to $24 \%$ (Lai, 2003). In histories of successful elopements, staff efforts to prevent elopement failed and a resident succeeded in leaving the facility, or a secured area within the facility, without an appropriate escort. In some cases, the nursing home employees were surprised at the return of the resident because his absence had not been noted (Aud, 2002). In fact, wandering away is difficult to predict. Therefore, all cognitively impaired residents who are ambulatory are presumed to be at risk. This group includes those who have not attempted to elope in the past, even if they are mobile with assistive devices (e.g. wheelchairs) (Foxwell, 1993-1994). It is worth noting that as the brain deteriorates, exit-seeking attempts become more prevalent (Silverstein et al, 2002, P.32). Yet, this relationship has a peak, after which it begins to reverse. Hence, when ambulatory ability is lost, wandering becomes less likely.

Because the residents have little insight into their present circumstances and believe that they still have responsibilities, exit-seeking wandering behavior can be prompted out of confusion, frustration, or anger (Lucero, 2002). In view of that, two different types of exitseekers were identified by Hussain et al (1985): elopers and runaways. They differ in their emotional states, their perception of why they are in LTC setting, and their reasons for wanting to leave. Elopers adjust well to being admitted to a long-term care setting because of their belief that they are just visiting, their desire to leave is driven by a wish to accomplish their 
responsibilities. Runaways have a very difficult time as they continuously try to escape throughout the first two days and nights (Lucero, 2002).

When wandering around becomes wandering away, older adults with dementia are presumed at high risk of injury (Aud, 2004). When AD wanderers pass beyond the boundaries of safe environments, they could be faced with dangerous conditions and environmental risks. All of these are made more hazardous by their impairments in memory, judgment, path-finding ability, spatial disorientation, safety awareness and problem-solving ability (Aud, 2004; Lucero, 2002). In her revision of notices of noncompliance about 62 elopements incidents in LTC facilities in Missouri, Aud (2002) reported that roads were the most common hazards mentioned in $52 \%$ of the notices, followed by the outdoor temperature in $27 \%$ of the incidents. Also, $32 \%$ of the residents who eloped were injured, all because of falls. Furthermore, wandering involves emotional distress and exceptional levels of stress for the patients who wander and become lost, and for their families and formal caregivers (Silverstein et al, 2002, P.31).

As it is the nursing home's responsibility to use adequate precautions and enhance the safety of residents with dementia, this type of wandering behavior is a significant risk management problem for LTC providers.

\subsection{TRADITIONAL APPROACHES TO MANAGE WANDERING}

\subsubsection{The Environment and the Wellbeing}

The most significant evolution in research over the past decades is a shift from an almost exclusive focus on challenging or disruptive behaviors to a more inclusive approach that also explores positive emotional states and wellbeing (Calkins, 2009). 
Interactions between the users and their environment are spontaneous and unavoidable. While these interactions can be positive or negative, a good interior space is about harmonizing all the physical, environmental and cognitive elements to make the space feel right, functionally and emotionally. The most important element that has to be considered in an interior space is the "user" (Reddy et al, 2012). In LTC, the primary users are the residents who suffer from AD and related dementias in addition to caregivers and other occasional users.

The design of the physical environment is increasingly recognized as an important aid in the care of people with $\mathrm{AD}$ and other dementia. It is now being viewed more than simply decorative (Day el al, 2000). A number of studies have addressed the role of physical environment in the care and wellness of nursing home residents in general and those suffering from dementing disorders in particular. In effect, the design of dementia-specific environments is regarded as a therapeutic resource to promote well-being and functionality, and support dignity and autonomy (Day el al, 2000; Algase el a,1 2010). Hence, the physical environment is called the "silent partner" in caregiving (Noell, 1995/1996). According to Van Hoof \& Kort (2009) the term physical environment has the following two meanings:

1- The architectural environment or interior as a whole

2- The whole of the thermal, visual, and acoustical environment and indoor air quality Creating supporting environments is a non-pharmacologic approach to adapting to the patients' specific needs, as they are no longer able to adapt (Desai \& Grossberg, 2001). In general, an optimum space balances between the users' safety and convenience (Reddy et al., 2012). Yet, older adults with dementia pose great challenges in terms of creating appropriate, healthy and supportive living environments where they can perform optimally and be compensated for decreasing vitality and overall health status (Cohen-Mansfield \& Werner, 
1998). While a good living environment can reduce confusion and agitation, and improve wayfinding, poor environments can increase confusion and problem behaviors (Fleming et al, 2003).

In addition, the interwoven effects of the numerous discrete and interconnected elements of an environment cannot be extricated. According to Lawton (1984):

The change in the treatment locale subsumed an immense variety of components whose effects are unquestionably related to one another in very complex ways.

In fact, Lawton's work was the foundation of research addressing the role of design as an active component of treatment in nursing homes. The behavior, as described by Lawton (1975), is represented by the following equation: $\mathbf{B}=\boldsymbol{f}(\mathbf{P}, \mathbf{E},(\mathbf{P x E}))$. This suggests that the behavior (B) is not just the function of the person $(\mathrm{P})$ and the environment (E), but also of the unique interaction between the persons and their environments (PxE). Thereafter, modifications of the physical environment have been considered an important focus for intervention to address dementia-related behavior such as wandering (Algase et al, 2010).

\subsubsection{Environmental Designs that Affect Wandering}

How well a facility can manage wandering behavior is based on two important factors according to Silverstein et al (2002): i) the physical environment ii) the level of staff training (Table-1). This indicates that the ultimate goal of nursing homes is to place well-trained staff in a therapeutically dementia-friendly environment. Similarly, Zeisel et al (1994) argue that supportive environments can be therapeutic for wandering by improving the resident's wellbeing or quality of life rather than curing any disease-related dysfunction. This can be 
facilitated through reduced environmental or organizational stress enabling a normal response (e.g. walking instead of pacing).

\begin{tabular}{|c|c|c|}
\hline & $\begin{array}{c}\text { Not Supportive } \\
\text { Environment }\end{array}$ & $\begin{array}{c}\text { Highly Supportive } \\
\text { Environment }\end{array}$ \\
\hline Minimally Trained Staff & Poor & Good \\
\hline Well-Trained Staff & Good & Best \\
\hline
\end{tabular}

Table 1- level of staff training and supportive environment - adapted from to Silverstein et al 2002, P.113

The following sections are an overview of different wandering environmental modifications and interventions addressed in literature.

\subsubsection{Interior Architecture and Spatial Interventions}

Designing and constructing a building result in a static physical object, the way that people perceive, use, react to and in other ways interact with that object takes place over time, dynamically (Zeisel, Hyde, \& Levkoff, 1994).

\section{Wandering Paths}

According to Calkins (1988), the more acceptable response is to accommodate the behavior by allowing residents to wander in a safe physical environment. In fact, wandering can be positive in terms of providing the patients with an opportunity for exercising, which can improve circulation and oxygenation, and reduce stress, boredom and agitation (Heim, 1986; Coons, 1988). One approach to facilitate this is by providing wandering paths in which a resident never reaches a dead-end. An endless corridor is the one that allows the residents to circulate around activity areas (Figuer-3). Another approach applied in space saving plans is to have a shared living space at the end of the corridor to provide a destination for the wanderer (Figuer-4) (Dickinson \& Mclain-kark, 1996). Residents' frustration and agitation associated 
with encountering a dead-end may decline and the wanderer may be encouraged to stop and join the ongoing activities (Calkins, 1988).

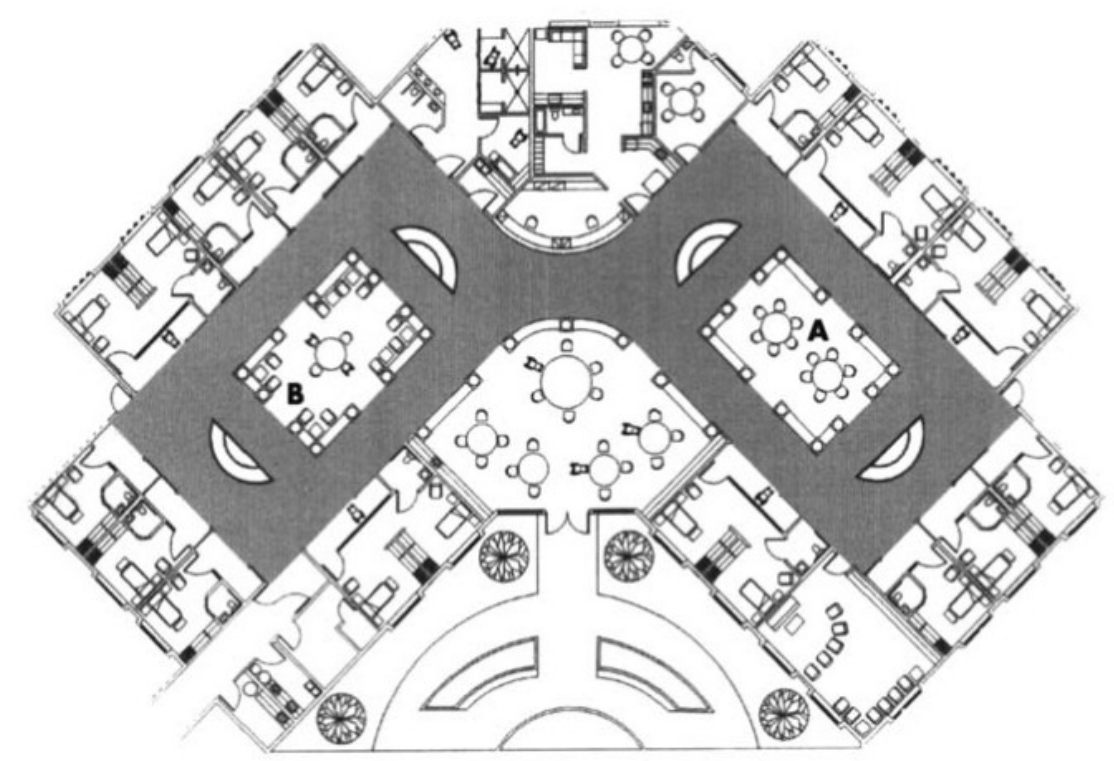

Figure 3 - Endless Corridor Design - Adapted from Virginia Tech graduate student Claire Hamilton, 1992 as cited in Dickinson \& Mclain-Kark, 1996

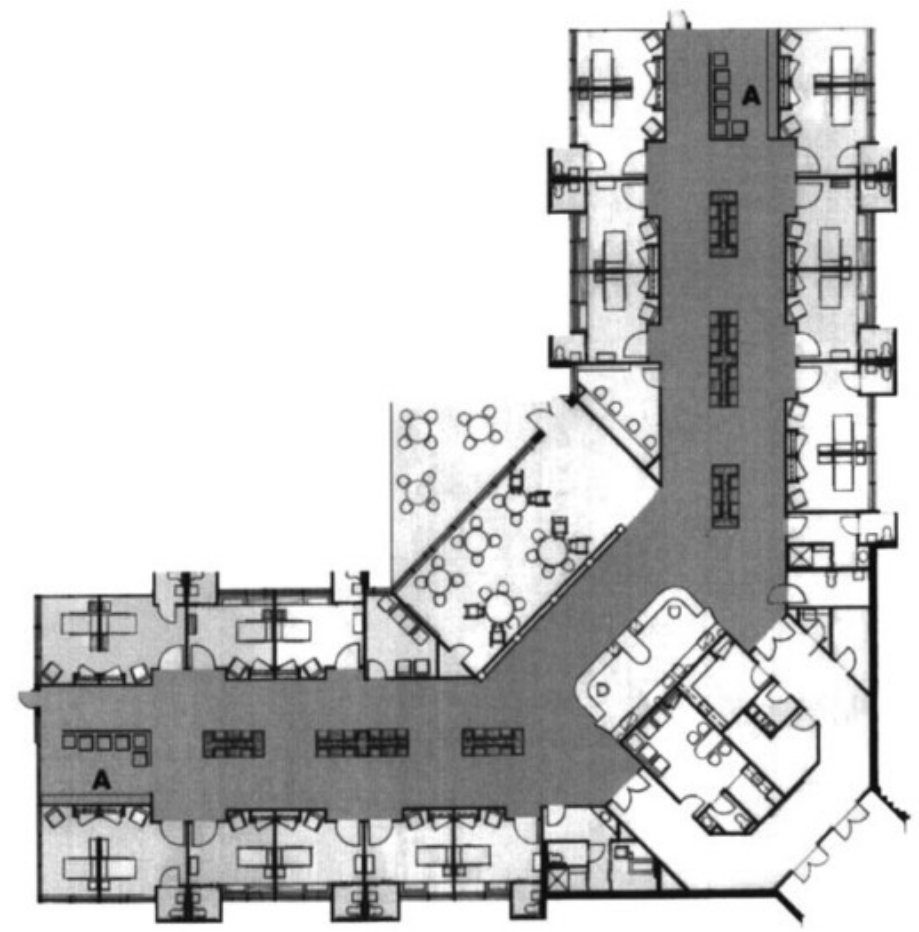

Figure 4 - Lounge Areas with Wandering Path - Adapted from Virginia Tech graduate student Joan Dickinson, 1992 as cited in Dickinson \& Mclain-Kark, 1996 
In fact, the degree to which the shape of a wandering path reduces the number of decision points (the clear path to a second destination) is of vital importance in supporting therapeutic wandering according to (Silverstein et al, 2002, P. 119). Figure-6 represents several shapes of corridors ranked from 1 (the lowest in accommodating wandering) to 8 (the highest).

1- Straight corridor

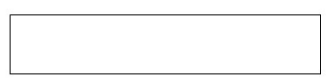

2- Straight with alcoves

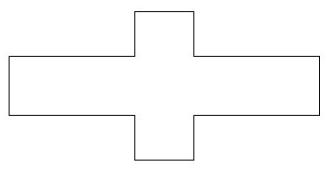

3- Small corner alcoves

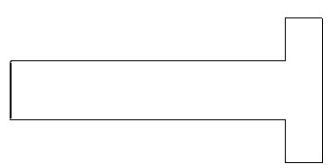

4- "T"shape

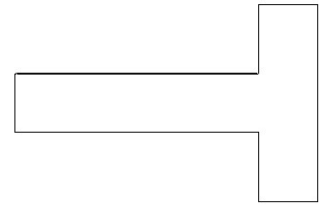

5-Square

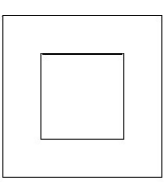

6- Centipede

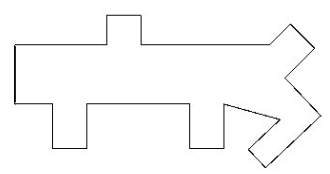

7- Inside/outside square

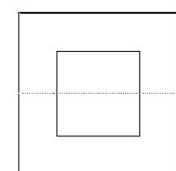

8- Circle/oval

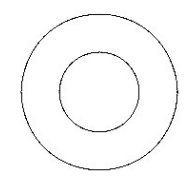

Figure 5 - Wandering paths design - adapted from Silverstein et al, 2002, P.119-120

Moreover, in their E-B Model for dementia friendly care units, Zeisel et al (1994) indicated that a positive environment is the one that accommodates therapeutic walking among the residents and support the residents' ability to have a sense of pathway as a place. A facility with a high value on wandering paths is one in which corridors and other pathways in the unit and in any enclosed resident outdoor space are: 


\section{1) Easy to use}

2) Represent a continuous trip

3) Provide residents using corridors and pathways with understandable visual cues and interesting events that support therapeutic walking.

A cue can be a sign indicating directions or behaviors, and can be more discrete such as a change in floor covering to help the residents sense a difference between different areas with different purposes. Thus, it is important to include sensory cues and events that interest, engage and orient the residents in space without necessarily indicating a future destination. On the other hand, low value for wandering paths within a unit would be assigned to an institution with a limited and uninteresting corridor as the only place wandering residents can use to walk (Zeisel et al, 1994).

\section{Sensory Stimulation in Spatial Interventions}

As previously discussed, the more elements of interest along the pathway (views, artwork, objects), the more interesting the trip is for the residents. This in turn provides the patients with the motivation to stop and attend to an object, or view outside the window, and eventually move to another destination along the pathway (Silverstein et al, 2002, P.119). Dickinson \& Mclain-Kark (1996) add the suggestion of including activity areas (dining areas, lounge areas, art activities, gardening) within the corridor space to encourage the wanderer to rest and perhaps join a group. Accordingly, the impact of architecture on wellbeing can be positive when the space supports and enables an activity or negative when it curtails or restricts it (Torrington, 2006). In addition, people with AD suffer from a loss in their cognitive capabilities, yet, they can still perceive the surrounding space with their senses (CBC News, 
2011). Hence, the sounds residents hear, the visual images, the smells and kinesthetic experiences that they understand make up their sensory comprehension (Zeisel et al, 1994). Therefore, it is important for the residents' well-being to design a physical environment that supports activities by providing opportunities for them to happen, and provide settings that are recognizable at a multi-sensory level and appropriate for their function (Yao \& Algase, 2006).

A rich, stimulating environment can potentially alleviate some wandering behaviors (Coons, 1988) as well as reduce the boredom and restlessness associated with wandering (Cluff, 1990). In fact, the use of design elements and activities could provide a distraction which is considered the best intervention for the exit seekers (Dickinson \& Mclain-Kark, 1996). Their therapeutic value can be observed when wanderers stop and interact. For instance, interactive artwork (Figure-6) is one source of visual and sensory stimulation that could add the necessary interest to the environment and benefit the self-stimulator wanderers (Dickinson \& MclainKark ,1996). It is advised to offer artworks, along with other activities, that build on lifetime experiences such as dusting, folding towels, or sorting envelopes.

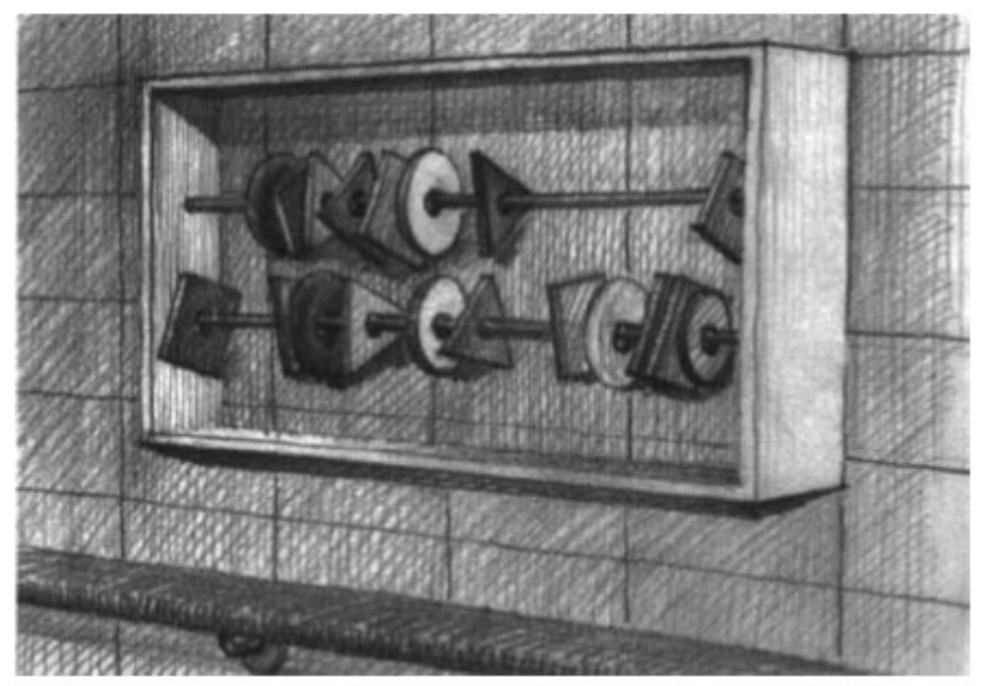

Figure 6 - Interactive Artwork - Adapted from Calkins, 1988 as cited in Dickinson \& MclainKark, 1996 
Similarly, the Alzheimer's Knowledge Exchange (2010) recommends using positive cueing and redirection with stimuli to reduce anxiety and consequently reduce exit seeking. This can be facilitated by leading dementia patients' attention away from doors and engaging them with another area. For example, redirection can be as simple as offering sensory cues (e.g. the smell of freshly baked breads, vanilla, or coffee), making pleasant seating / special interest areas available in areas away from exit doors, and creating aquariums and bird watching areas. Another approach sought to enhance the well-being of older nursing home residents who pace and wander by enriching their nursing home environment was implemented by Cohen-Mansfield \& Werner (1998). They have incorporated visual, auditory, and olfactory stimuli to simulate two types of environments: a home environment and an outdoor nature environment (figure-7). The residents were observed before and after the installation. The researchers marked a significant increase in the level of the participants' pleasure as the patients spent longer amounts of time and demonstrated improved mood in the corridors when the scenes were on. Furthermore, participants were consistently observed sitting more and manifesting less trespassing and exit-seeking behaviors at the corridors with the enhanced scenes than at corridors without the scenes. 

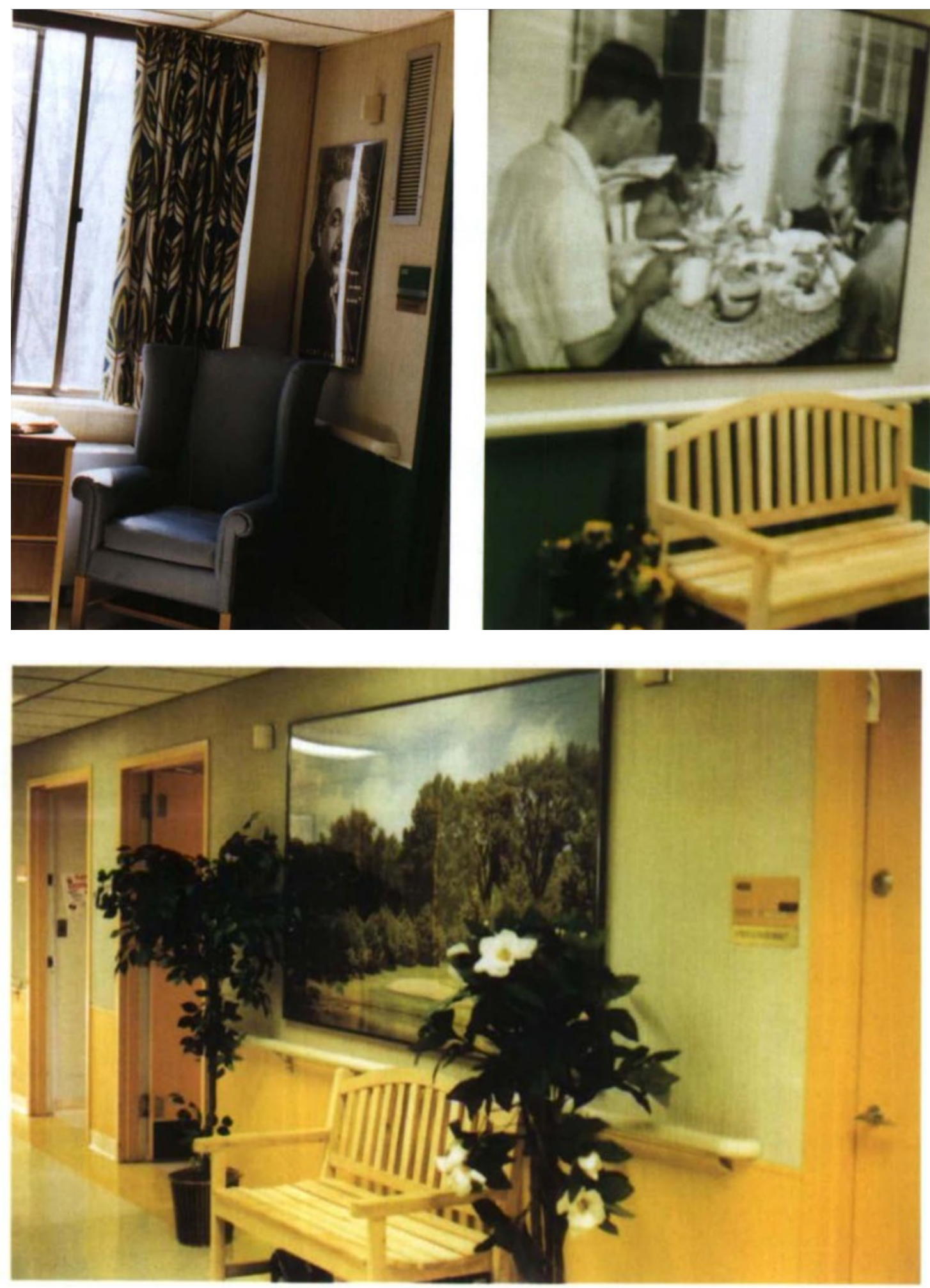

Figure 7 - Home environment and outdoor nature environment scenes - Adopted from CohenMansfield \& Werner, 1998 
In a more recent cross-sectional study, Yao \& Algase (2006) explored the relations between enviromental ambiance and locomotion behavior. The researchers found that the physical environment varies in important ways in relation to the occurrence of wandering and that differing aspects of the environment were significant for different types of wanderers. For instance, they found that brighter light, more variation in sound levels, and a higher engaging quality of the environment were associated with wandering. On the other hand, the patients were less likely to wander when surroundings have soothing qualities. They also noted that the single purpose use of a space (bathroom vs. activities area) may promote function of people with dementia. Accordingly, a facility's design can increase or decrease wandering. For example, if reducing wandering is the goal, then modifying environmental conditions to soothing areas is beneficial. Conversely, if the goal is to attract or contain wanderers without affecting the amount of wandering, then access to a well-lit area fitted with engaging materials or actives may be more appropriate.

While the previous studies build on the recognition that environments have the abilities to engage people through cognitive and emotional channels (two separate processing pathways) (Yao \& Algase, 2006; Zajnoc, 1980), providing moderate amount of sensory input that all residents can understand in the context of their past and current experience in LTC is utmost importance (Zeisel et al, 1994). People with AD face difficulties with sensory over stimulation, which may increase the distraction, agitation and confusion associated with dementia. At the same time, sensory deprivation has been identified as a potential problem in many dementia care environments. In fact, design guides call for appropriate levels of sensory stimulation, striking a careful balance between overstimulation and deprivation (Day et al, 2000). 


\subsubsection{Exit Controls}

Promoting the wellbeing of residents with dementia can also be facilitated by addressing their interests in going in and out of doors. These individuals do not lose this interest, however, they may lack judgment as to what will happen if they do enter or exit from one area to another (Alzheimer's Knowledge Exchange, 2010). Persons with AD who desire to look or go outside can experience great anxiety and frustration if they are not able to satisfy this need, which may result in increased risks and danger if they actually go outside. Ideally, facilities should be designed to avoid drawing attention to exits. Yet, this is not always possible, especially when the location of the doors influences the chance of residents noticing them. For instance, the exit door that is at the end of a straight hallway is likely to beckon the individual forward as it is a clear destination. In contrast, an exit door that is in a common room off of the main hallway, where residents can find an activity or destination as they exit, may be less of an attraction. In addition, exit doors on busy, well-travelled hallways pose a greater threat to the patients than the ones on less frequently travelled hallways. Staff and visitors going into and out of the unit are constantly drawing attention to the door and may be inadvertently inviting residents to follow them (Silverstein et al, 2002, P.115). To accommodate the previous scenarios, exit controls are needed.

Exit controls are defined by Zeisel et al E-B Model, (1994) as follows:

The immediacy of control over ways to get out of the unit via locks, alarms, surveillance or other methods, and the lack of awareness among residents of their ability to get out (exit controls unobtrusiveness).

Accordingly, the guidelines that define the performance of exit controls are based on the relationship between the immediacy of control and the unobtrusiveness. In other words, a special care unit with high value on exit control will: 
1) Have signals and other control devices, such as keypad openers, that keep the exits well controlled with few delays in warning signals.

2) Doors, door handles and security devices will be minimally visible, or unobtrusive, thus not providing residents with a visual invitation to leave the unit or facility.

This means that residents in such units are i) safe ii) minimally frustrated by visual invitations to leave. On the other hand, the residents in an institution that places low value on exit control would be aware of the lack of exit barriers and would be retrieved by staff when they try to elope. (Zeisel et al, 1994).

\section{Door Locks and Alarm}

In care units, some LTC residents actively test locked doors and express a desire to leave; hence, locking devices and alarms can be used on exit doors to prevent elopements. Some nursing homes use no locks or alarms, while others use a combination of both. Where less exit controls are used, the responsibility is on the staff to retrieve residents who elope. In a content analysis of elopements reports, Aud (2004) found that the use of alarm devices failed to alert staff to elopement attempts; thus, alarms were regarded ineffective. Also, the sensitivity of the alarm and the signal delays vary from one facility to another and range from 15 seconds to immediate activation every time the door is opened or touched (Silverstein et al, 2002, P:117118). While alarms may lessen the incidence of injury, these devices are disruptive, waste valuable staff time, and increase agitation of the residents (Coons, 1988).Thus, the goal is to have signals that are meaningful to staff but do not cause disruption for residents. Ideally, the alarm signal should have no sign, noise or visual signal apparent to residents (Silverstein et al, 2002, P.117-118). For that reason, it is recommended to incorporate door and elevator code 
pads into visual redirection adaptations. For example, keypads can be a part of a bookshelf design or wall painting, and can be flipped upside down. Such strategies can provide unobtrusiveness and meet fire regulations by still being visible (Alzheimer's Knowledge Exchange, 2010).

\section{Visual Barriers}

Since the 1980 's, visual barriers have been studied for their potentials to deter exiting. A visual barrier is defined as "one that appears to be an obstruction but does not impede egress through the door" (Namazi et al., 1989). It is important to note that city fire regulations may dictate or ban a certain type of intervention such as signage, locking devices and windows on exit doors.

In normal settings, the exit doors should stand out in an environment and look different than other doors. However, when designing for a dementia unit, the egress door should look like any other door, and like the surrounding walls if possible. Otherwise, the door will attract attention like a magnet (Silverstein et al, 2002, P.115). The Alzheimer's Knowledge Exchange (2010) published a document with strategies for camouflaging the door. They suggested painting or covering the exits with the same shade/pattern as the surrounding walls. Also, they recommended covering the handles and panic bars with a cloth apron of the same color/ pattern so they would blend visually and not attract wanderers. Dickinson et al (1995) found that a cloth barrier over a panic bar reduced exiting by $96 \%$ (Figure-8). However code officials may not allow a panic bar to be concealed in this way. Yet, painting the bar the same color as the door could also succeed in camouflaging it and might not be considered concealment. In fact, the regulations dictating the appearance of the panic bar can only serve to draw more attention 
to an exit door. The more its appearance stands out, the more dangerous it will become for individuals with dementia. Likewise, the hardware on an exit door that is made of shiny metal or elaborate designs may become an object of interest and attract the residents (Silverstein et al, 2002, P.116).

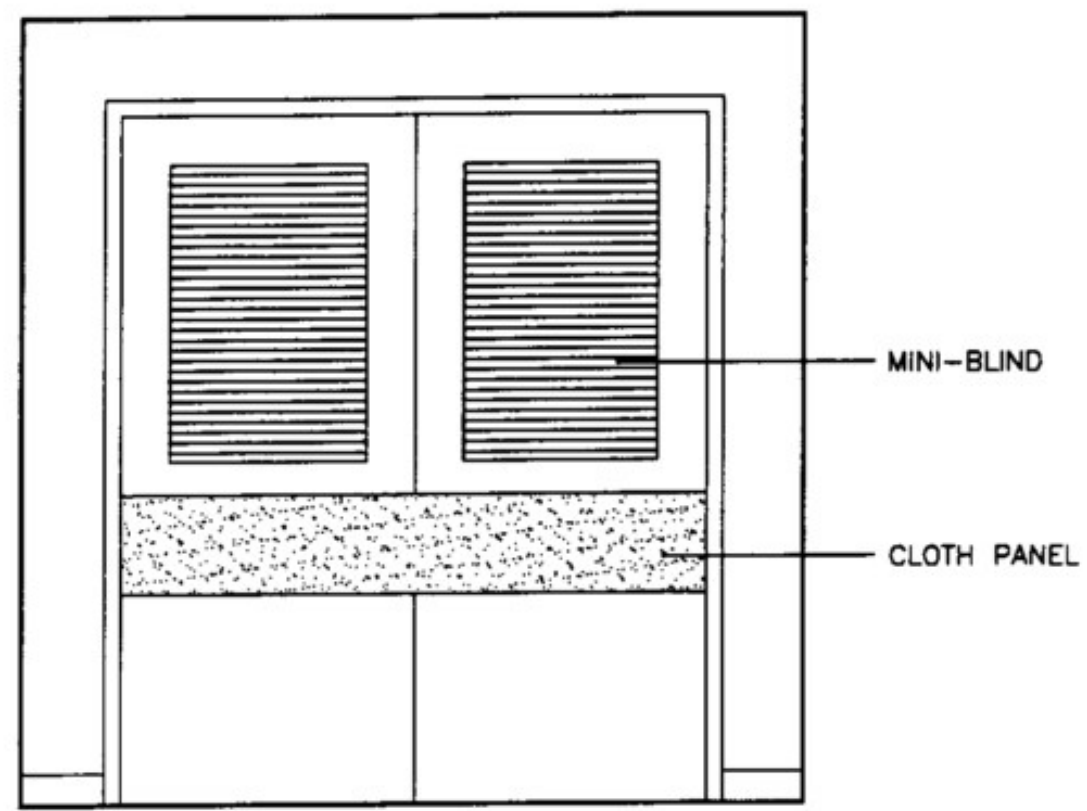

Figure 8- Exit door with both blind and cloth panel - Adapted from Dickinson \& Mclain-kark, 1995

It has been observed that patients with Alzheimer's disease appear to be affected by certain visual stimuli that do not affect other non-demented people such as perceiving twodimensional patterns as three dimensional objects. Hussain and Brown (1987) used progressively increasing numbers of floor stripes in different orientations as a visual barrier. They found a $42 \%$ reduction in exiting attempts by using beige masking tape grid patterns. However, other studies had contradicting results and concluded that this approach is an ineffective intervention (Hamilton, 1993) and increases exit-seeking attempts (Namzi et al., 1989). Yet, in a latter experiment conducted by Hewawasam (1996), black insulation tapes in 
two different grid configurations were laid out in an attempt to prevent patients wandering through exit doors. It was found that the use of a horizontal grid reduced exit door contact by up to $97 \%$ for participants with a diagnosis of $\mathrm{AD}$. However, the grid was less effective for patients with other types of dementia. Nevertheless, inherent dangers associated with this approach were also reported.

In addition, signage on egress doors has been recommended by the Alzheimer's Knowledge Exchange (2010). They suggested using large stop signs or a sign that states "[the name of resident] this is not your room" in front of exit doors and/or to off limit rooms to decrease their use. However, too many signs on the door would make it a center of attention and may encourage the individual to approach it (Silverstein et al, 2002, P.116).

\section{Doorway Windows}

Residents will be drawn to whatever is on the other side of an egress door. Thus, the ability to see through a door window, for example, will attract residents to exit doors. It is preferred to make the doors all solid with no opening or glass panels so that light or view does not attract a wanderer (Silverstein et al, 2002, P.116-117; Dickinson et al, 1995). When it is not possible, wandering can be addressed by adding blinds or other window coverings to doorway windows. Also, it is recommended to use translucent film/glazing that shows shadows but not details (Alzheimer's Knowledge Exchange, 2010). 


\subsection{TECHNOLOGICAL APPROACHES TO MANAGE WANDERING}

\subsubsection{Technological Interventions}

Assistive technologies are relatively novel tools for research and care in LTC facilities. These technologies are emerging at a rapid rate to compensate for the shortage in staffing resources that is combined with the burgeoning of the cognitively impaired population (Dorsten et al, 2009). Assistive technologies are defined as follows:

Any item, piece of equipment, product or system, whether acquired commercially, off-the-shelf, modified or customized, that is used to increase, maintain or improve functional capabilities of individuals with cognitive, physical or communication disabilities (Marshall, 2000).

Ideally, these technologies should sense and respond to users needs, adapt to the changing situations and compensate for the physical or cognitive deficits (Dorsten et al, 2009). These solutions have the potential to lessen the burden on caregivers, improve the quality of care and extend the patients' independence.

The assistive technologies available in LTC settings include alarm systems worn by the residents to alert professional caregivers of potential dangers, wearable "smart sensors" that record relevant health data and "pervasive" or "environmental" electronic devices that are integrated into the everyday environment to monitor health and behavioral status (Sixsmith et al., 2007). One of the behaviors that requires sufficient amount of control is wandering. Because controlling the consequences of this behavior poses serious practical problems, protecting the individuals from getting lost, injured or from death is of the utmost importance (Hughes \& Louw, 2002). Thus, to improve the life of the patients and their carers, the goal is to develop a technology that can automatically recognize, classify, and quantify human behaviors, and detect aberration or abnormal patterns of activity (Chen et al., 2008). It is important to 
understand how the technology can be used to facilitate the wellbeing of people with AD. Therefore, the following is an overview of the research conducted in this area.

\subsubsection{Tagging and Tracking Systems}

Tagging and tracking technologies can offer an opportunity to maintain the safety and welfare of persons with AD. While the environmental approaches described earlier in this chapter are useful in reducing elopements, none guarantees its elimination. Therefore, the main objective of tagging and tracking approaches is to lessen the consequences of wandering instead of confining it. Hence, these technologies aim to provide the residents with more liberty and freedom while, at the same time, improve their safety and reduce the carers' stress (Cash, 2003).

The concept of tagging itself is not a new one. However, with the advancement of technology, tagging has become more sophisticated. For instance, the Alzheimer's Society of Canada partnered with the Medic-Alert Foundation to provide the Safely Home program. With this program, persons with $\mathrm{AD}$ will be registered with the police and provided with wearable identification accessories (Figure-10). These accessories can aid the police in identifying the wanderers in case they are reported to be missing (Alzheimer's Society of Canada, 2013a). The advanced type of tagging involves placing a surveying device on an individual who wanders, to be able to locate the person through wireless technology (Hughes and Louw 2002; Altus et al. 2000). This new format of electronic tagging and tracking can better manage crisis situations by locating the wanderer efficiently. In addition, the researchers recognize that the least restrictive environments help modify the unusual behaviors (Fisher \& Swingen, 1997; Buchanan and Fisher, 2002). For these reasons, information technologies such as Global 
Positioning System (GPS), Global System for Mobile Communication (GSM) and Geographic Information System (GIS) have been used in mechanisms and systems for locating dementia patients outdoors (Lin et al., 2006). In other words, these worn (e.g. watches \& bracelets) or attached (e.g. sewn into clothing) devices are used to increase the residents' freedom and autonomy while minimizing the risks involved by determining the wanderers' locations (Miskelly 2004; Welsh et al. 2003).

In a study conducted by Miskelly (2004), equipment derived from prisoners tagging systems were tested in three different settings (a hospital, a nursing home and the community). Four wandering residents qualified for the study in LTC facilities. The residents' worn bracelets transmitted radio signals to nine monitoring stations installed throughout the facility. These stations passed the information to a central base station which then transmitted warning signals back to pagers worn by staff (Figuer-9). All pager messages included the name and location of the residents as well as the cause of the alert.
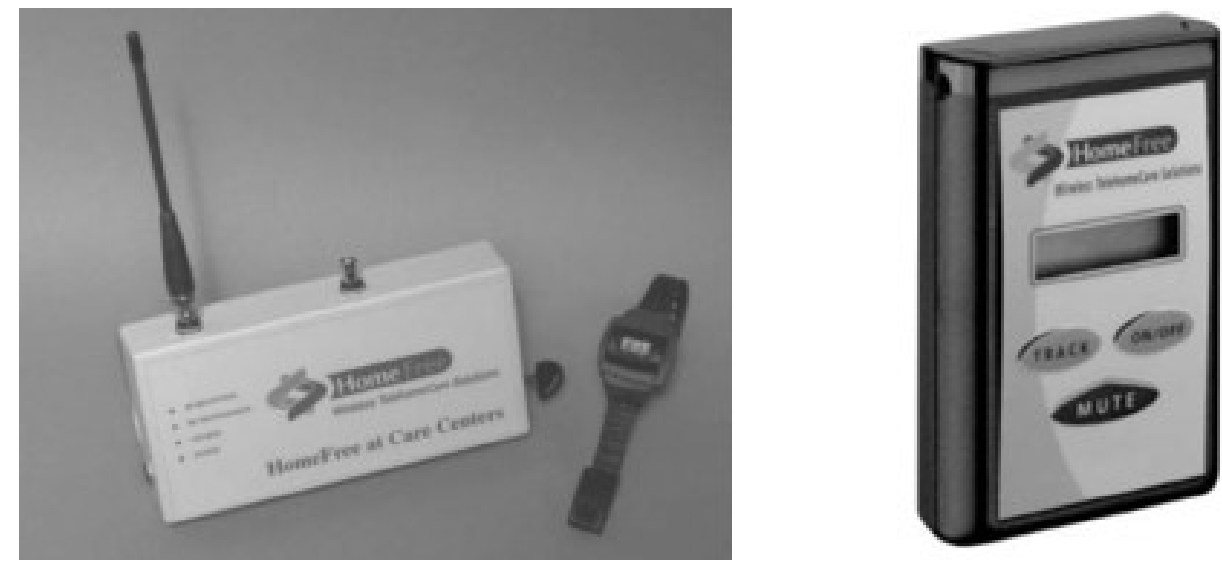

Figure 9 - Bracelet \& monitoring station and the pager - Adopted from Miskelly, 2004

In the six month trial period, the residents had the ability to wander freely on their own, but an alarm was paged to caregivers when they entered a fire escape or tried to leave via the 
front door. Two episodes of elopement were discovered immediately and fifteen internal wandering to an "at-risk area" were daily detected by the system. No wandering events were missed. However, there were a few false alarms due to the bracelet losing contact with the skin for a period of greater than 60 seconds, usually due to the resident falling asleep with their arm in an unusual position. In addition, one resident ( $25 \%$ of participants) managed to remove the bracelet which was designed to require two hands for its removal. Regardless, the ability to intervene early prevented wandering events from developing into a dangerous situations. Thus, the system provided a sense of safety and reassurance to staff and relatives.

The Mobile Locator is an electronic device designed to help caregivers to quickly locate a person who has eloped. The study was conducted with formal and informal care providers and other rescue workers in two settings (Community and LTC facilities). The main components of the Mobile Locater are the transmitter and receiver. While the user wears the miniature transmitter in a wrist, ankle, or belt holder, the caregiver uses a receiver with a directional antenna to locate the wanderer. To use, the caregiver dials the unique frequency of the wanderer's transmitter. While the transmitter does not give out an audible sound, it does emit a constant radio signal that the receiver is able to locate for up to one mile on the ground and several miles by air (Altus et al, 2000). A total of three hundred and fifty two respondents participated in the opinion survey and on average the respondents agreed that the device would improve their ability to locate wanderers, improve user safety, increase user freedom and reduce caregiver stress. The surveys were followed by a trial in a nursing home facility where four residents were provided with the Mobile Locator. Although staff members did not have occasion to use the Mobile Locater receiver (no elopement incidents took place during the 
course of the study), those who took part in practice sessions felt that the device was easy to use and improved their peace of mind.

Similar tracking devices are used for detecting the locations of those who are still living in the community, mainly because these individuals require more freedom and independence. For example, Windsor-Essex Project Lifesaver is system that is comprised of wearable GPS and on-duty officers who can be contacted to search for the wanderer (Windsor-Essex Project Lifesaver, 2013). The COGKNOW is a mobile device and home based sensors and actuators that combine the tracking and monitoring technology. This European research project takes into account location of lost elders and the possibility of showing them the way back home. Users could also be helped in making a call to emergency contacts (Mulvenna et al, 2010, P.32).

While most of the interventions described in literature require the use of physical devices attached to the person who is being monitored or tracked, dementia patients tend to reject noticeable gadgets (Wigg, 2010). Alternatively, the attach-free type of transmitters must be carried all time and may become lost. Also, the battery of the transmitter must be changed (Nishigaki et al, 2013). Thus, when dealing with this population, a device-free passive localization is needed to detect and track those who do not carry any device (Youssef et al, 2007).

\subsubsection{Surveillance and Monitoring Systems}

Every course of action is highly dependent upon their material and social circumstances, "focusing on moment-by-moment interactions between actors, and between actors and the environments of their action" (Suchman, 1987, P.179). This suggests that when designing technology for the field, it is necessary to carefully examine 
the actual situations, how all the actors act in practice, and how situational and organizational factors fit into the cognitive process (Muller et al, 2013). When using activity recognition technologies it is important to know people's behaviors in context; when, how and what they do (e.g. distinguishing running from walking \& sitting from standing and lying) (Kim et al, 2009). Therefore, real-time monitoring systems for institutionalized settings have the potential to contribute towards improved safety, especially for those who have a tendency to elope (Greiner et al, 2007).

In a study conducted by Wigg in 2010, a motion detector alerted staff when someone entered and exited the front deck space of a nursing home by emitting a buzzing sound. The facility regarded wandering as a therapy that deserves recognition and support; a regular walking routine to reduce anxiety levels among elders with dementia. When a resident exits the unit, a noise will alarm the caregivers of the situation. To ensure the wanderer's safety and return, staff members observe or join the residents on their excursion. In addition, by comparing between an unlocked and a secured facility, the researcher reported the benefits of recognizing the human need to move beyond confines of enclosed space, not locked behind or struggling to open a locked door. Although, the unlocked approach can decrease the residents' stress, the patients are presumed at higher risk. Thus, to create dementia friendly unlocked facilities, incorporating technologies and increasing staff-residents ratios can accommodate the need for staff to wander with residents.

A non-intrusive sensor network was developed by Diaz-Ramirez et al (2013) to monitor dementia patients. Using high availability and low cost binary sensors, the proposed model has been designed to determine, in real-time, the location of a patient, and to emit alerts if one leaves a secure place. Although this pervasive computing model can efficiently sense when a 
patient leaves a room without supervision, it was not tested in real life environments such as nursing homes. Yet, the system has the potential to detect events in more complex scenarios with minor algorithmic modifications and more sensors.

A novel support system based on image processing technology using fluorescent dye was developed to prevent the wandering of elderly people with dementia (Nishigaki et al., 2013). A simple rectangular shape is painted on the clothes of elderly people with dementia using fluorescent dye. The fluorescent color becomes visible by irradiation with a long wavelength of ultraviolet light, not under regular light. Therefore, the patient wouldn't be aware of the dye. In addition, a 3D video camera was used to acquire a 3D image and detect the simple shape. When people pass near the video camera, black light is emitted, and the video camera captures a sequence of images. If fluorescence is detected by the system, the person is identified as the patient. Then, the system can inform the caregiver that the patient has left the premises before serious trouble can occur (Figure-10).

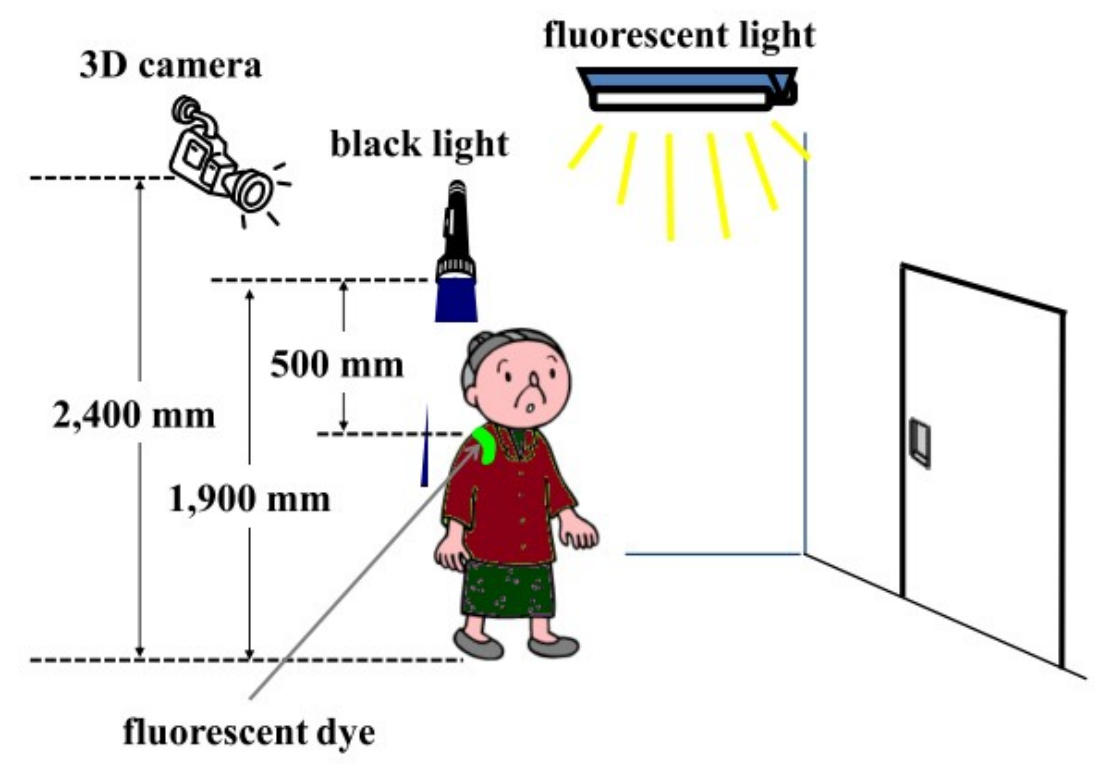

Figure 10- Overview of the measurement environment - Adopted from Nishigaki et al., 2013 
In this study, the relationship between the color of the dye and the cloth was investigated. The results indicate that the proposed method extracts green fluorescence dye from different colored cloths. Although the system has great potential to be implemented in LTC, it was not actually tested in a real environment.

\subsubsection{Measurement \& Prompting Interventions}

Videotaping, biomechanical and sensors have been used to measure the wandering behavior of institutionalized people with dementia and to identify patterns, frequency and amount of movement. In addition, modern technology has enormous potential to help people with $\mathrm{AD}$ in their daily tasks by monitoring their progress, prompting them into the next step and providing feedback or calling for caregiver assistance if needed (Algase, 2003 ; Carswell et al., 2009; Carrillo et al, 2009; Hoey et al., 2011). However, these types of systems and interventions are beyond the focus of the thesis.

\subsubsection{Privacy and Ethical Concerns}

The mere existence of surveillance technologies is morally neutral. Rather, it is the use to which it is put which has the potential for good or bad (Welsh et al., 2003).

Proponents of technological interventions have met with considerable resistance and opposition. Technology has been perceived as contrary to human dignity and freedom with its connotation of criminal surveillance. It can compromise the patients' privacy or dignity (Welsh et al., 2003). More importantly, in LTC settings, the patient-caregiver interaction is very necessary (Tellis-Nayak, 2007). Therefore, the technology might jeopardize this relationship as 
professionals become more occupied with computers and less oriented towards the patients (Ludwick \& Doucette, 2009). In other words, it could deprive some people of the necessary resources rather than enhance their freedom. For instance, if caregivers can relax their observations and be lulled into a false sense of security by the attachment of bracelets to residents which set off an alarm when they leave, or, worse still, if already low staffing levels are cut further, then electronic tagging might lead to increasingly little need for human contact, and resources (Welsh et al., 2003). In addition to the previous, concerns regarding costs, maintenance, and increased opportunity for errors have been marginally mentioned in the literature (Carrillo et al, 2009; Dorsten et al, 2009).

\subsection{SUMMARY}

This chapter has provided an extensive review of the pertinent literature related to the issue of wandering of persons with $\mathrm{AD}$. Dealing with wandering has been the center of research for the past couple of decades due to its possible harmful outcomes. There were two major categories - traditional \& environmental and technological approaches- that covered different interventions addressed in literature. In summary, the first section focused on environmental designs that ranged from architectural to exit-controls. The second section discussed the technological and advanced interventions to manage wandering. While both sections focused on deterring wandering, the second category presented approaches to deal with this disruptive behavior after it has occurred (the consequences).

Based on the literature review, it became clear that the extent to which the technology can be employed to deter exit-seeking hasn't been fully explored. The researcher has identified an opportunity for more investigation regarding the use of technology and its applications in 
LTC settings. Moreover, there is a need to provide recommendations for designing inclusive solutions stemming from multiple disciplines to deter wandering. Indeed, the findings from the literature framed the decisions made regarding the methodology of this study. More importantly, the key subjects that emerged from this exploration guided the elaboration of questions that could possibly be addressed by this research. Hence, the main question that this thesis is addressing is how can technology be introduced in the LTC environment to effectively deter the exit-seeking behavior of dementia residents. Accordingly, in order to explore the full potential of technology, there is a need to understand what is currently being used in institutional care to manage wandering and what sort of attributes and functionalities caregivers and family members are looking for in an intervention. On the other hand, previous research suggested that interesting surroundings could alleviate some wandering behaviors. Therefore it is important to understand what sort of distractions (objects, activities and elements of the physical environment) can capture the residents' attention and provide a diversion. This in turn could help in identifying possible roles/functions of technology in providing interesting environments and reducing the job requirements of caregivers. 


\section{CHAPTER 3}

\section{METHODS}

It has been established that wandering can jeopardize the physical and emotional wellbeing of persons with AD. Previous research showed that assistive technologies could contribute to better wandering management. However, haziness surrounding the design criteria of these interventions, considering the nature of the disease and the context in which the technology will be deployed, persisted in literature. Therefore, this study was conducted to investigate how appropriate design of assistive technologies could serve in better addressing wandering. Because of the exploratory nature of this user-centered research, the chosen methodology was predominantly qualitative. This allowed the researcher to form a holistic understanding of the issue of exit seeking from the viewpoint of caregivers and family members. Yet, the results from the exploratory process of data collection led the researcher to utilize a mixed methods approach.

According to Creswell "The key idea behind qualitative research is to learn about the problem or issue from participants and engage in the best practice to obtain information. This involves reporting multiple perspectives, identifying the many factors involved in a situation, and generally sketching the larger picture that emerges" (Creswell, 2013, P.47).

The objective of this study was to provide recommendations and guidelines for professionals involved in the development of technology based interventions to deter the exit seeking behavior of persons with AD in LTC settings. Therefore, the following question and sub-questions were addressed:

Q- How can technology be introduced in the LTC environment to effectively deter the exit seeking behavior of dementia residents? 
SQ1- Which dementia-related factors and caregiver issues need to be taken into account when designing assistive technologies to deter exit seeking?

SQ2- What are the tools and interventions currently available to deter wandering, how effective are they and why/why not?

SQ3- Which objects, activities and elements of the physical environment can capture the exit-seekers' attention and provide a distraction?

The research questions suggested a need to identify meanings that different subjects hold about the issue of wandering. Therefore, a multidimensional view and diverse standpoints related to the problem were required. Similarly, failing to recognize the uniqueness of participants in the study by statistical or quantitative measures did not fit the problem (Creswell, 2013, P.48). Therefore, the chosen research strategy was appropriate to such qualitative research questions. To report a holistic image of the phenomena being studied, inductive-deductive logic was applied in this research. This involved "working inductively from particulars to more general perspectives, then, working deductively to gather evidence to support the themes and interpretations" (Creswell, 2013, P.53). In fact, the design of the research methods was intended to explore the complex issue of exit seeking from different angles, and also to sustain the findings by triangulating the collected data from different methods as explained by Creswell:

Triangulation is a process that typically involves corroborating evidence from different sources to shed light on a theme or perspective (Creswell, 2013, P.251).

Correspondingly, the following research methods were applied in order to obtain the perceptions of different participants: experts', family members' and artists' interviews, a codesign workshop, and a visual survey. The mixture of qualitative and quantitative approaches 
was used in the last method to tackle the research problem with a larger audience to refine the themes that emerged from the preceding methods.

In the first stage of data collection, two sets of semi-structured in-depth interviews were conducted with caregiving experts and family members of patients who experienced wandering, one set for each group. These interviews focused on gathering descriptions of their shared experiences in subjective as well as objective manners. This description consists of what they experienced and how they experienced it (Moustakas, 1994). These interviews were analyzed across cases, with the significant statements from transcripts clustered into emergent themes.

Information from the interviews led the researcher to conduct another set of interviews with three artists in the field. These painters were identified by LTC providers and had designed door camouflages, a low-tech intervention to deter exit-seeking, for dementia units' main exits. These interviews shed light on the process and challenges of designing and implementing a diversion into an institutional environment.

Findings from the interviews informed the development of the co-design workshop that followed. While the workshop plan was defined prior to data collection, the exercises were altered based on the interview results. Thereafter, the analysis of the ideas generated in the workshop yielded a need to reach for a larger pool of subjects to enrich the investigations of the research problem by sharing their thoughts about the concepts suggested in the workshop.

The final contribution of this study was a result of triangulated analysis of the results from all methods and an overall theme abstraction that cuts through all the collected data. This chapter describes each of the used methods in terms of the setting, participants, data collection procedures, and data analysis. The methods are described in chronological order in the following sections. 


\subsection{ETHICS CONSIDERATIONS}

The research study was reviewed and cleared by the Carleton University Research and Ethics Board. It was concluded that this study involves emotional risk to the participants, considering the nature of topic investigated. Protective measures have been taken to reduce the risk involved. The sensitivity of the topic addressed was acknowledged with participants prior to collecting data. Subjects of the research were informed about the purpose and the process of the study. In addition, an emphasis was placed on the role of the researcher as a knowledge seeker, not a judgmental individual. As the participation of the subjects was completely voluntarily, participants were informed of their right to take breaks, decline to answer any question and participate in any activity, and withdraw from the study. Lastly, the research and the university ethics board contacts were provided to all respondents in case they wanted to follow up. Moreover, the data collected from all methods was kept confidential and stored in a secured key for the duration of two years. The results of the study were presented collectively and no individual participant was identified.

\subsection{EXPERTS INTERVIEWS}

Interviews are a fundamental research method for direct contact with participants, to collect firsthand personal accounts of experience, opinions, attitudes, and perceptions (Hanington \& Martin, 2011, P.101).

In the first stage of data collection, the researcher conducted semi-structured interviews to gain useful information from individuals with specialized experience in caregiving for dementia patients. The choice of approach was based on the need to i) collect comparable data in terms of the objectivity of the phenomenon studied, ii) provide some flexibility in addressing several subjective views of the participants. The interview script was pilot-tested with volunteer 
participants and reviewed by the thesis co-supervisors in order to make appropriate adjustments (Appendix A).

\subsubsection{Setting}

The interviews were conducted in three different care facilities in Ottawa, except for one, which was conducted by phone. Five interviews took place at LTC facility of 90+ dementia patients. One interview was held at another nursing home, which is the residence of $125+$ individuals with dementia. Another interview was conducted at an Outreach day program where $100+$ patients are being taken care of weekly. Because the in-person interviews took place within the participants' working hours, their location was chosen by the interviewees or facility management. Thus, these conversations were performed under natural, nonmanipulative settings. Most interviews were held in an office located inside the dementia locked unit, two interviews were conducted in a management office on site, one interview took place in the kitchen, another in the meeting room, and one took place in the Special Behavior Unit main living room area.

\subsubsection{Participants}

For this set of interviews, a convenience sampling was chosen to include subjects who are available and accessible that time (Creswell, 2013, P.143). Yet, the sampling was purposive since it specifically targeted individuals with a background in providing care to persons with AD and related dementias. A number of LTC and senior housing organizations were contacted, however, only those who expressed an interest in the subject of the thesis led to contact with individuals from inside the facility. The sample of participants included four caregivers (both 
day and night personnel), one activity coordinator, and two program managers. The phone interviewee was a founder of an Oakville based enterprise specialized in providing education and support for dementia carers. This participant was first contacted by email through the enterprise website. Thus, a total of eight interviews were conducted with one male and seven females whose years of expertise ranged from two to thirty years. The diversity of the informants' positions allowed the researcher to gain a multi-layered understanding of the research problem and capture the different meanings participants have about the issue of exitseeking.

\subsubsection{Data Collection Procedures}

The data was collected through one-on-one interviews with experts in the field. Each person was interviewed once. The conversations were held within the individuals' working hours and in different rooms of the workplace, based on the time of the day and the activities taking place in the care facility. One interview was conducted by phone. The interviews lasted from 30-60 minutes, based on the participants' availability and the length of their answers.

Before conducting the interviews, participants were informed about the purpose of the study and the process of the interview. They were given an opportunity to ask questions and inquire about the thesis and the interview session. They consented to have their perspectives recorded on the premise of preserving the data anonymity and confidentiality, and to have quotations by them published under a made-up name or number. Lastly, the researcher and the university ethics board contacts were provided to the informants in addition to instructions on how to withdraw from the study in case the interviewees wished to do so by a certain date. 
Upon receiving the signed forms in person or by email (Appendix A), the interviewing session began.

Five open-ended questions formed the main script of the interviews which allowed the participants to expand on their answers and provide additional details. The questions were also general, and focused on understanding the central phenomenon of the study (Creswell, 2013, 163). This approach was a good fit for the qualitative nature of the research as it provided an opportunity to explore key ideas from the standpoint of caregivers. Also, the questions were only asked when appropriate to the conversation flow. This allowed the interviewees to reflect more on the areas they thought were important rather than constantly changing the questions and limiting the explorations of each topic. However, unplanned questions were used as probes to dive deeper into a particular answer or to elicit more specific information.

To make the in-person interviews more engaging, cards of different elements, activities and wandering prevention solutions were introduced in a number of questions (Appendix A). This approach increased the productivity of the conversation and provided a constant reminder about what is left to be addressed. Also, it allowed for a continuous comparison between the content of each set of cards.

All interviews were audio-taped using a smart phone application to enable the researcher to focus her attention on the conversation. This strategy reduced the researcher's need to take notes throughout the session, while preserving all the details of the discussion. At the end of each interview, the recording was imported to a password protected hard-drive where it was kept for future use. 


\subsubsection{Data Analysis}

Because of the large amount of data accumulated in the interviews, the researcher's goal was to cluster the information into a manageable and a comprehensive manner. Thus, the audio recordings of the interviews were first transcribed into written copies. The transcripts were then reviewed alongside with the interview recordings in order to ensure the accuracy of the written records obtained. After revising and correcting the conversations' scripts, relevant participant quotations were labeled with codes in relation to the research questions. Afterward, these codes, together with the interviewees' passages, were arranged into an affinity diagram (Appendix F). The data analysis involved reorganizing the codes within clusters of similar concepts. Each group of codes was rearranged in a hierarchical way and was given a title that portrays its fundamental nature. For example, the codes "looking for home", "looking for someone" and "looking for something" were given the title "goals" to refer to the reasons behind exit-seeking. Doing so allowed the similar concepts, relevant to the research questions, to surface and helped in understanding the relations between all these significant themes. The emergent themes were compared to those of the Family Interviews described in the next step, to grasp a bigger understanding of the thesis problem. The result of this comparison was a table with the themes and codes identified in the affinity diagram.

\subsection{FAMILY INTERVIEWS}

The second set of interviews targeted the family members of those who suffer from AD and related dementias, specifically, those who were the main care providers at home. To delve profoundly into the participants' experiences, the interviews had to be semi-structured and the questions had to be open-ended. This approach is of vital importance in the early stages of the 
research to explore salient issues for further investigation (Pickard, 2007, P.175). The questions (Appendix B) asked in this method aimed to gather insights about the families' major concerns and worries, patients' routines and behaviors, and the family and patients' familiarities with technology. The transition from experts' to families' interviews helped in understanding the exit-seeking behavior in more specific contexts and within individual scenarios. Also, it introduced an additional human-centered layer to the previous results because of the nature of the relationship the informant had with the patients.

\subsubsection{Setting}

Considering the sensitivity of the topic addressed, the family informants chose the time and location of the interviews. This allowed the interviewees to feel more comfortable in a place of their choice so they could share their own experiences and tell their own narratives in a relaxed atmosphere. Hence, all interviews were conducted in person and in a number of locations around the city of Ottawa. One meeting took place at the café of a nursing home, two at Carleton University and the other two in different coffee shops.

\subsubsection{Participants}

Because it was impractical to ask dementia patients what they think, feel, and remember about events (due to the nature of the disease), the researcher sought answers from individuals with immediate contact with these people. Thus, for this approach, participants were recruited purposively based on their history of experience in providing care for a family member who suffered from dementia and developed wandering tendencies. To preserve their privacy, family members were contacted by the nursing home staff and were informed about the research taking 
place. The identity of those who showed interest in the thesis topic was then revealed to the researcher along with their contact information, so that the researcher could contact them at a later time. The initial contact between the participants and the researcher was made by phone or by email depending on the interviewees' preferred method of communication. A meeting time, date and location was scheduled based on the participants' availability to listen to their stories narrated in their own words.

This sample of interviewees included one respondent whose mother is still living in LTC and was admitted to the facility because of a number of exit-seeking incidences. Also, two siblings whose mother was diagnosed with $\mathrm{AD}$ and has experienced wandering participated in the study. Their mother was deceased at the time of the interview. One participant who volunteers in LTC facilities, and whose mother suffered from Vascular Dementia and was also deceased at the time of the interview took part in the research. The last informant was the widow of an $\mathrm{AD}$ patient who managed to escape several times from the LTC. In total, five family members were involved in the study, three of whom were females and the other two were males. Prior to taking the step of sending a loved one to an institution, all informants had been taking care of their family member by living together in the same place, alternating shifts with other relatives and caregivers, and/or constantly visiting the patient at home.

\subsubsection{Data Collection Procedures}

All interviewees were informed about the subject of the research prior to agreeing to participate. All interviews were conducted in person so that nuances of personal expression and body language would be recognized in the conversation (Hanington \& Martin, 2011, P.101). 
The meetings ranged in length from 1-3 hours, based on the informants' availability and the time taken to address the researcher's questions.

Upon meeting with the interviewees, the researcher explained the focus of her thesis, the process of the session and the interview's goal of gathering answers for the research problem. Then, the family members were handed a consent form (Appendix B) on which they agreed to participate in the study and have their stories audio-recorded. The consent form also addressed the participants' rights of taking breaks, not answering questions and withdrawing from the study during the interview or after and by a specific date. The researcher addressed all participants' inquiries before starting the interview.

Because of the exploratory nature of the study, family interviews consisted of seven semi-structured questions that allowed for flexible detours in the conversations. These questions were structured in natural order to allow the researcher and the participants to follow a logical thought process (Pickard, 2007, P.173). Also, they were used as a guide to remind the researcher of the remaining questions and their order when the conversations drifted from one topic to another. Ad-hoc questions were posed as probes when needed throughout the course of the interview to gain a growing understanding of the informants' feelings and thoughts about a particular issue. Following this approach would capture the uniqueness of each experience. Some of the topics addressed were supplemented with cards of keywords found in the literature and were used as additional probes for discussion (Appendix B). This provided an opportunity to collect comparable data on two levels; between participants within the family group, and between the family and experts interviews.

Audio-taping the conversation was achieved by using the researcher's tablet. This minimized the need for note taking and granted the researcher a chance to concentrate on the 
interviewees, their responses and their narratives. The recordings were eventually transferred to a password protected hard-drive where they were stored for future use.

\subsubsection{Data Analysis}

Similarly to the experts' interviews, the audio recordings of family interviews were transcribed into written copies. After revising the transcripts for accuracy purposes, the researcher analyzed each interview solely searching for statements relevant to the main research questions. These significant statements were coded, mostly in accordance with codes identified in the caregivers' interviews with added new found codes. The coded quotations from the transcripts were arranged in an affinity diagram (Appendix F) and structured into emergent themes. In fact, the extended conversations the researcher had with the family members in comparison with those of the formal care providers provided new information about key subjects that the researcher didn't have a chance to cover in shorter interviews. Consequently, the emergent themes from this analysis were compared to those of the previous method.

\subsection{ARTIST INTERVIEWS}

Through listening to diverse opinions and perceptions about the thesis problem, the researcher identified a new trend that was becoming very popular in LTC. The door camouflage technique was one favored solution for disguising the main entrance of dementia units to deter exit seeking. The researcher first spotted a camouflage painting when visiting a nursing home to conduct an interview. Then, in a subsequent interview, the researcher was informed about a couple of artists in southwestern Ontario who specialized in transforming egress doors into artworks. The researcher was interested in understanding more about the concept of door 
camouflage, since it seemed to be a fairly successful wandering deterrent. The interviews were scripted to gain an understanding about the logic behind this technique, the process of the design phase, and the implications of setting it up. The objective of this approach was to build on the artists' experience to create a list of guidelines for professionals concerned about designing wandering preventions for LTC.

\subsubsection{Setting}

One interview was conducted by phone and the other one was in person. Participants were first invited by email and informed about the study. Then an interview time and date was scheduled. The in-person interview took place at a nursing home café in Ottawa and during the participant's work hours. The meeting time and location was chosen based on the artist's convenience.

\subsubsection{Participants}

The artists were selected based on their experience in disguising egress doors as works of art. One interview was done by phone with a couple of artists residing in southwestern Ontario. These individuals made painting their main profession after demand for their services increased over the last 3 years. Since then, they have disguised 60-70 doors. An expert who had participated in an interview as part of this investigation and had strongly recommended their camouflages as wandering deterrents to various LTC facilities contacted them. The other interview was conducted with a local artist who took on this profession as a hobby. This interviewee specialized in caregiving for dementia residents in LTC facilities and had over nine years experience. The initial contact with the artist was facilitated through the management of 
the nursing home in which she works. The participant was then contacted by the researcher in order to set an interview meeting time, date and location.

\subsubsection{Data Collection Procedures}

All artists were informed about the goal of study when invited to participate in the interviews. Because two of them worked together on every camouflage project, it was more appropriate to interview them together at the same time. Thus, a phone call was arranged with both artists on one end, and the researcher on the other end. After addressing the informants' inquiries, the researcher obtained their oral consent agreeing to be part of the study. The third interview was conducted in person; thus, the consent was in written format (Appendix C). As with other interviews, all participants were informed about their rights of not answering questions and withdrawing from the study.

Sixteen questions were posed to the participants, covering six main areas: pre-design analysis, painting styles, camouflage application, design challenges, maintenance and camouflage effectiveness (Appendix C). Questions were asked when appropriate to the conversation flow, which provided some flexibility and succession/continuity. Other questions were added on the spot to probe further into unclear answers and concepts. Both interviews were completed in 35 minutes and recorded using a smart-phone application.

\subsubsection{Data Analysis}

The audio tapes were transcribed and coded into emergent key points. Participants' noteworthy statements with their codes were arranged in an affinity diagram. Afterwards, they were grouped into relevant themes and re-arranged in a hierarchical order. The data analysis 
provided guidelines for introducing similar diversions in the entrance area of care units, which will be discussed in the next chapter.

\subsection{CO-DESIGN WORKSHOP}

After carrying out the interviews and learning about the disease and the behavior, the researcher needed to closely examine the interests of different groups of individuals (family members and caregivers) simultaneously in order to explore what sort of deterrents they would consider ideal for LTC environment. Therefore, a group of individuals was selected based on their experience to contribute to the research by designing a concept for a "magic" intervention that would hypothetically deter exit-seeking. This workshop followed the co-design principles of qualitative design research as all participants engaged in collaborative activities and added inputs to the design process (Appendix D).

\subsubsection{Setting}

The workshop took place in a mid-sized room on the Carleton university campus. The room was set up with two tables, one for each group. The tables were arranged with enough distance in between to provide the participants with the ability to join open discussions and at the same work separately in groups without distraction. In between the tables, a mock-up of a dementia unit (Figure-11) was positioned, so that both groups could have easy access to it throughout the workshop exercises. 


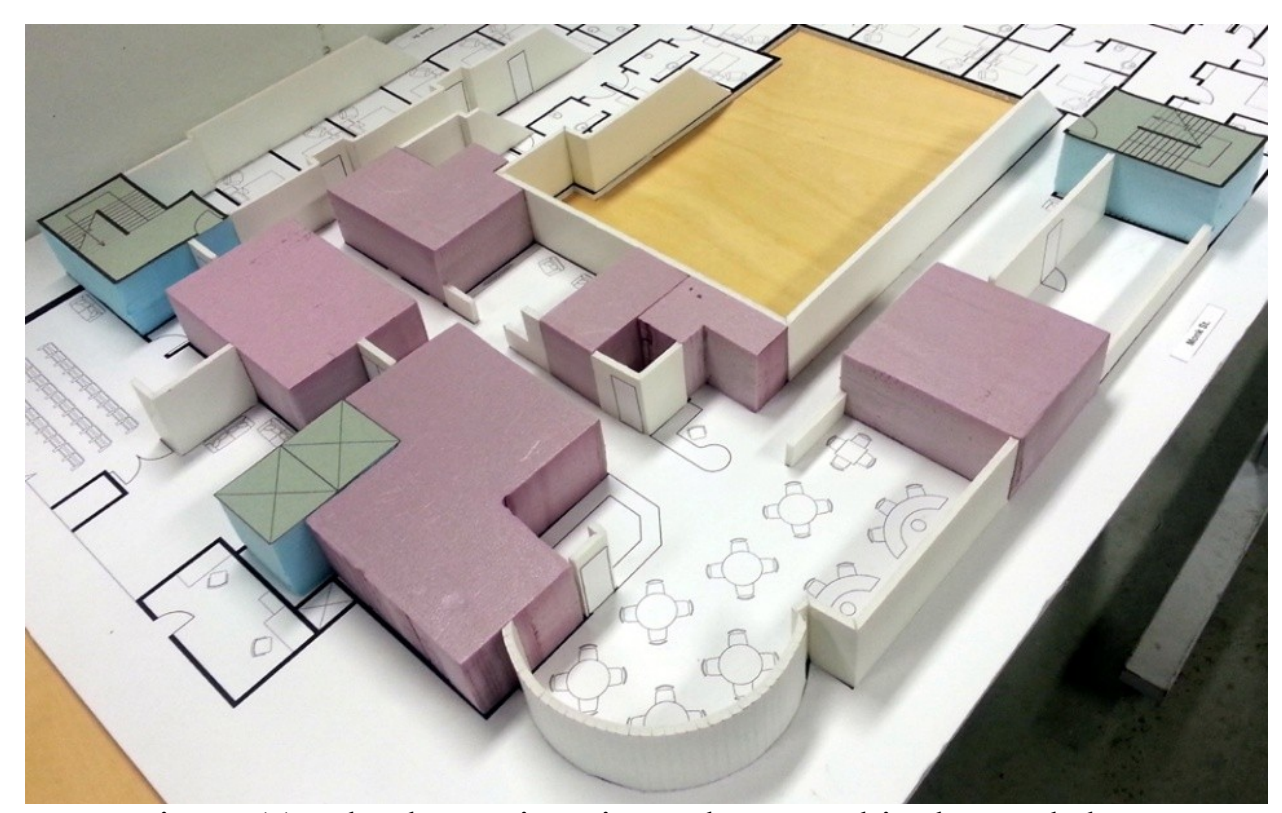

Figure 11- The dementia unit mock-up used in the workshop

\subsubsection{Participants}

Four individuals were contacted for this workshop. The sampling approach was purposive. All participants were family members of people who suffered from AD and related dementias and portrayed exit-seeking behaviors. All participants have had family members residing at the same nursing home; three in a dementia unit and one on a general floor. Three of the informants were chosen from the interviews' pool of participants and were already familiar with the research problem (the one who had a mother suffering from vascular dementia and the two siblings). They were directly contacted by the researcher. One participant was new to the study. She was a formal caregiver in LTC and family care provider to a grandmother who suffered from $\mathrm{AD}$. The new informant was contacted by the volunteer management at the institution. Also, two of the participants were volunteer care providers at the same location. In total, two males and two females participated in the workshop. 


\subsubsection{Data Collection Procedures}

The workshop was conducted with the four participants at the same time. It lasted about 2.5 hours. The subjects were informed about the purpose of the workshop when they were contacted by the researcher. They were also reminded about the research problem at the beginning of the workshop. The participants consented to have the session videotaped (Appendix D). This was of a vital importance as it was used as a reference for data analysis. It kept a record of the participants' interactions, comments and expressions. Also, it provided an opportunity for the researcher to focus on the discussions and to facilitate the workshop without worrying about note taking. Video recording was accomplished by using two video cameras; one aimed at each group.

The informants were grouped into two groups of two. To have diverse discussions within each group, the researcher made sure that the siblings were not collaborating together. The workshop included four separate exercises that were modified based on the interview findings (Appendix D). The first exercise focused on identifying the reasons behind exitseeking. The second exercise aimed to understand how the patients exit-seek. The third exercise was concerned about the elements and objects that persons with $\mathrm{AD}$ can relate to. The forth exercise included collaborative tasks to design possible concepts for technological interventions. These participatory exercises started with verbal discussions and ended with artifact design. The answers to each task were used as key elements in the subsequent task. The first and third exercises were intended to abstract the interview results in one collective layer, while building on the perceptions of several people at the same time. The second exercise asked the participants to act out how dementia patients exit-seek within the confined walls of a dementia unit. The informants had the choice of either using the small mock-up unit to illustrate 
their scenes and map the behavior within the unit or impersonating a patient and acting out his or her behavior. Providing options allowed the participants to be relaxed by choosing a comfortable approach to fulfill the task requirements. Also, the mock up unit was a recreation of the dementia floor at the nursing home, which all informants were already familiar with from their experience. The use of the mock up unit was inspired from a project conducted by Sanders (2008) where the nurses (users) were regarded as experts of their own experience. The project's participants co-designed the ideal patients' room using a three-dimensional toolkit for generative prototyping.

The last exercise asked the participants to conceptualize a "magical" intervention that could deter the wandering behaviors they've previously described using the key elements they had pointed out as effective. Using the term "magic" allowed the participants to unleash their creativity and imagination and picture a design that could successfully deter the exit seeking behavior of the patients, given its futuristic technological nature. Later, they were asked to visualize these solutions by drawing or using the craft materials provided (figure-12), and to finally act out the new scenarios.

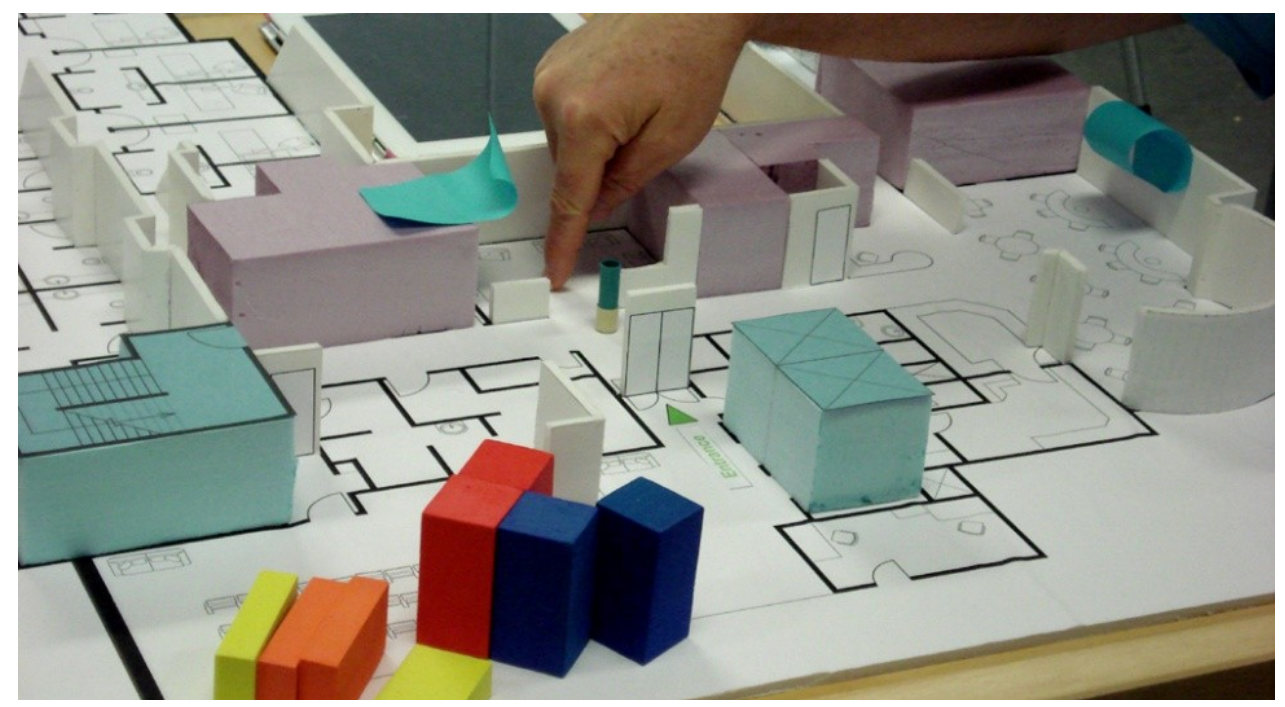

Figure 12 - Visualizing the interventions and their locations within the mock-up unit 
After the workshop, pictures of the generated drawings and artifacts were captured. Then, they were transferred to a password locked drive along with the video records.

\subsubsection{Data Analysis}

Video recordings were transcribed and participants' reactions were noted as well. Informants' statements were coded in relation to the research questions. Because the workshop exercises were designed to make meaning from the interview findings, the emergent codes were relevant to the codes of the interviews. Thus, they contributed to a better understanding of the interview results. These helped in clarifying the previously identified themes and meanings and in simplifying the interviews' complex results. For example, in the interviews, agitation, frustration and anxiety were considered to be negative feelings that can cause exit-seeking. However, in the workshop, it became clear to the researcher that these feelings persist with wandering. Consequently, they might escalate the behavior but are not direct causes for it. The results of these new findings led to an updated version of the previously mentioned tables.

The "magic" tool exercise created concepts for possible solutions that matched the expectations of those who participated in the workshop, and at the same time, these conceptualizations were built on findings from the interviews. The data analysis focused on discovering real motives behind the interventions arose from the workshop, in order to revisualize them with current technological capabilities. The emergent codes and themes helped in pointing out key guidelines for potential deterrents. 


\subsection{VISUAL SURVEY}

Seven different solutions were identified in the workshop. However, these interventions represented the opinions of only four participants. Therefore, to consider the targeted populations more adequately, the researcher sought for a larger group of informants.

The purpose of survey research is to gather and analyze information by questioning individuals who are either representative of the research population or are the entire research population (Pickard, 2007, P.95).

Hence, the decision to contact LTC caregivers and nurses at a local senior housing organization followed. By questioning this sample of participants, their answers could possibly be generalized to the wider population.

The survey questions were designed with the intention of gathering opinions about and attitudes towards the seven wandering interventions (Appendix E). Participants were surveyed in an attempt to support or refute the suggested preventions based on three categories synthesized from the research findings. This approach was mainly quantitative with a limited qualitative element. Prior to data collection, the questionnaires were pilot tested with volunteer participants and were reviewed by the research co-supervisors. They were then amended to better serve the research goals.

\subsubsection{Setting}

The surveys were conducted in person at one of the LTC facilities where the experts' interviews took place. They were held at two different dementia units. Participants were surveyed inside the first dementia suite and in a meeting room that has direct access to the 
second unit. The surveys were held over the course of three days based on the informants' availability during three shifts: morning, evening and night.

\subsubsection{Participants}

Eighteen experts were surveyed to obtain satisfactory numbers of responses. The sample included ten personal support workers, six registered nurses, and two healthcare assistants. All of whom were specialized in working with people with $\mathrm{AD}$ and related dementias. Their years of experience in this field ranged from 1-35 years. The informants work hours ranged from morning, evening, to night shifts in both locations. In total there were twelve females and six males. With their educational background and professional titles, this group of participants was considered non-purposive sample.

\subsubsection{Data Collection Procedures}

Each participant was surveyed once in person. Some were surveyed individually and others in groups of 2-4 based on the informants availability and patients' schedule. The participants were contacted and informed about the study by the facility management. Upon meeting with the subjects, the researcher explained how the presented interventions had been conceptualized. The meetings were audio recorded to capture the informants' comments as they went though the questions. Also, participants were asked to think aloud while answering to make sure that i) they comprehended the questions ii) they were not responding in an arbitrary manner. Before starting the session, they agreed to participate in the research by singing the consent forms (Appendix E). 
The survey was designed to be completed in 15 minutes and was divided into three main sections. The first one included general questions about the informants such as occupation, years of experience and familiarity with the technology. The second section was designed based on the workshop findings. Each wandering prevention approach was re-created in 2D graphics and presented to the participants in story grids. Then experts were asked to rank each intervention using a Likert scale and based on three different categories: effectiveness, ease of use, and suitability to the environment. They were also prompted to suggest changes for further improvements. The last section asked the informants to rank these seven ideas in order of preference. In some cases, unplanned questions were posed to inquire further about a specific comment or answer.

\subsubsection{Data Analysis}

After fully completing the data collection stage, participants' responses were compiled into one document. These answers were organized and summarized in tables in accordance with the survey questions. The data of the interventions' section was first analyzed on a detailed level; the number of responses in rating scales was displayed in charts for each question and in each category. On a more abstract level, calculations were used to sum up every category's answers in simple figures. Thus, matrices were applied to replace the Likert scale for each category in numbers. To better understand the emerging data, it was presented visually in simpler charts. Likewise, the data of the ranking section was analyzed quantitatively, and presented in percentage charts.

As for the recordings, the participants' comments were transcribed and coded in relation with the survey questions. The codes of each question were clustered into relevant concepts. At 
the end, the emergent concepts and quantitative charts were compared and contrasted in order to get a holistic picture of the participants' collective perspectives.

The findings of this survey were compared with those of the interviews and workshop. The results of this comparison are presented in the next chapter. 


\section{CHAPTER 4}

\section{RESULTS}

The results of the exploratory research conducted are presented in this chapter. An analysis of the data gathered from the interviews, the workshop and the survey revealed answers to the research questions. The study findings are ordered according to the categories evolved during the data compilation and analysis. The results from each method are presented separately.

\subsection{INSTRUMENT ONE - SEMI-STRUCTURED INTERVIEWS}

In the first stage of data collection, two types of interviews were conducted with a total of thirteen participants from two backgrounds: Expert care providers and family members of patients who experienced wandering. Because of the similarity of the topics addressed, the data of both sets of interviews were analyzed simultaneously and across cases. In total, five major themes surfaced from the coded data, as well as hierarchical and organizing relationships between them. These themes are presented through "thick description" (Bui, 2009, P.285) and illustrative charts in the following sections.

\subsubsection{Understanding Exit-Seeking}

To design effective solutions to deter wandering, it became clear that there is a need to understand this troubling behavior from the standpoint of those who provide care for the patients. One expert noted, "the first thing you need to ask when developing a design strategy is why, why is the behavior occurring. So that would be the first part of your problem solving”. 
Thus, the nature of wandering and the reasons behind it were explored in the interviews (Appendix F).

Goals. While family members defined wandering as the dangerous walking that can result in wandering away, there was a distinction between the term wandering and exit-seeking from the LTC caregivers' perspective. When asked about the goals of this behavior, wandering was considered aimless walking (pacing), while exit-seeking was goal-oriented. According to an expert interviewee, "wandering is aimless; exit seeking is towards the exit". Hence, pacing was overlooked as it is not the focus of this study. The participants indicated that residents often seek unattainable destinations such as a childhood home; unreachable individuals such as deceased parents; past-life routines/habits. Other less common goals are looking for stuff or fulfilling a need.

Triggers. Triggers associated with exit-seeking were addressed in the interviews. Most of which were associated with the outside such as seeing the egress door; watching visitors and caregivers coming in and out of the dementia unit or wearing outdoor clothing; and hearing others talk about their desire to leave (this is also known as the chain reaction).

Boredom and the State of Mind. The participants identified boredom as another origin of wandering. A family member stated, "I am bored, what am I doing here! So if I go outside, maybe it will be familiar, maybe I will have something to do". It is worth noting that the negative feelings such as agitation, frustration, confusion and anxiety were stated as causes and outcomes of exit seeking concurrently. According to a family caregiver, "when everything around them is unpleasing they wanna go back home, so they would be seeking an image that they have of their childhood home". 
More importantly, identifying the reasons behind exit-seeking is difficult and not always possible according to the interviewees. Furthermore, accommodating some needs (e.g. seeing a deceased parent) is not feasible.

\subsubsection{Understanding the Exit-seeker}

The interviewees reported that persons with $\mathrm{AD}$ do not make for a homogenous population. As the disease progresses, memory impairment will become more evident. Therefore, the patients relate to their past experiences better than their current lives. They relive their childhood or early adulthood memories, which are distinct to each individual. In addition to the disease, these people suffer from ageing symptoms such as visual impairment and hearing loss. More importantly, the population of patients presented in a long-term care facility at a given time is constantly changing as people come in and out. They have different personas and different interests, thus, they relate to different interventions. Furthermore, the desire of some exit-seekers to elope can be very powerful. The informants recalled stories of patients who stand by the exits, try different doors, try to trick visitors and new staff, and act aggressively to egress the facility. As described by an expert, "you will see people waiting by the door, waiting for an opportunity to happen, they [some patients] would push a caregiver coming through the door to go out".

\subsubsection{Exit-seeking Incidents}

Although dementia units are secured, caregivers and family members reported a number of successful elopement incidents. Some residents managed to get out to the parking lot or the reception area of LTC facilities, without outdoor clothing on. The patients managed 
doing so by following visitors and new staff or by tricking them into thinking that they are also visiting, even though the facilities have posted pictures of wanderers on main exits of the dementia unit. One family member noted, "they become cunning and play games"; "He didn't look like a patient so one person allowed him to leave". Other patients found alternative exits to get out of the secured floor (e.g. service doors). According to an expert, "when there is a will there is a way, I strongly believe that". Fortunately enough, the attentive staff and reception personnel managed to notice the run-away patients before they got very far. However, being $100 \%$ attentive is not an easy task for the caregivers due to the limited numbers of staff in comparison to residents $(1 / 6-1 / 12)$. In one case, the staff hadn't noticed the elopement of a resident, not until he waved at them from the outside window.

\subsubsection{The Residents' Interests}

Interactions. Because of living in the confined spaces of LTC, the residents lack interaction with other people, especially healthy ones. As stated by a family interviewee, "this is not home, these are all strangers, I shouldn't be here"'. Therefore, one-on-one time with caregivers is essential. Yet, with the limited staff numbers $(1 / 6-1 / 12)$, it is not frequently possible. Also, the interviewees reported that as the time passes, people with $\mathrm{AD}$ fail to recognize the relationship they have with their family members. One family member stated, "he [the patient] didn't remember anything about us getting married". However, a person who smiles and addresses the patients by their name is presumed to be an acquaintance in their eyes. One family caregiver said, "I would say it [patient's name] with a smile that would tell her that we are friends". Similarly, the patients love kids, animals, and babies. Caregivers reported that even those who cannot dress themselves would spontaneously approach children and interact 
with animals. According to a formal caregiver, "it is more like reacting to moving object like cats and dogs and small children, rather than objects sitting there". In relation, persons with AD treat baby dolls as if they are real babies. An expert noted, "when you see the way they are holding them and talking, they got a chance to live it and it [their maternity]".

Activities. All participants indicated the patient's interest in an activity is based on his/her personal taste. In fact, there is a wide range of activities that patients can enjoy, most of which are based on their personalities, preferences and what they used to do before getting diagnosed with AD. One expert caregiver stated, “if a patient didn't like gardening when he was younger and healthier, chances are, he is just not gonna do it when living in LTC care". In any case, two to three weeks of observational assessment is required to indentify the interests of the new resident. In addition, patients usually need to be prompted in order to do an activity. They require explicit instructions as they can't remember series of actions. Yet, activities that connect to the residents past such as folding the laundry can be spontaneous. According to a formal caregiver, "content is more about something that they can relate to". One caregiver advised that activities should provide a challenge and certainly a success. In addition, activities have to be safe and patients are advised to sit while doing them. Also, family photos are considered important when a patient first moves to LTC. But, as the disease progresses, the resident loses the ability of recognizing the people in the picture. It is worth noting that activities and patient's interests are used to alleviate boredom, create a purpose and provide a distraction for exit-seeking (section 4.1.5) (Appendix F). 


\subsubsection{Sensory Stimulation}

Audible Stimulation. The interviews revealed that individuals with AD are very sensitive to sounds and noise. An expert interviewee stated, "music is universal language; I have not met someone who does not enjoy music". While music (including religious rhythms) is considered the only stimulation that every resident can enjoy, the noise can get the patients very agitated. Hence, constant monitoring is essential to prevent sound over-stimulation. Also, the informant reported that out of curiosity, patients might look for the source of the music in a facility. In addition, music can be used to calm wanderers; one LTC caregiver noted, "I will take them away from the door, have them sit in the living room area and turn the music on".

Olfactory Stimulation. Little controversy was noted regarding the participants opinion about the sense of smell. While they all agreed that residents can't notice bad smells, no two opinions were the same about nice scents such as perfume or cookies. One expert noted, "the sense of smell usually disappears on some people", while a family member stated, "she [the patient] loved the smell of perfume".

Visual Stimulation. The participants indicated that light is important for the overall wellbeing of the residents. Having adequate amount of lighting is needed to eliminate visual illusions and prevent falls, especially at night.

\subsubsection{Dealing with Exit-seeking}

Technology. Most family members have considered tagging the patient when they were living at home. This is because there was a need to track and locate the wanderers if they were to get lost. Although the interviewees have acknowledged the issue of privacy \& dignity versus safety, they found tagging more dignifying that experiencing wandering away. An expert said, 
"but if someone leaves home in middle of night in winter, how dignified is that?". Moreover, because persons with $\mathrm{AD}$ were reported to have a tendency to take off visible tags and lose their belongings, a couple of informants postulated that inserting an electronic chip under the skin of the patient might be the only solution. On this note, all family members stated that their loved never took of their wedding band. In addition, most family members used medic-alert services and registered the patient with the police. On the other hand, LTC facilities have occasionally used bracelets that alarm the staff about wandering incidents. However, this approach wasn't favorable. As stated by a caregiver, “at the moment I don't think anybody is with a bracelet on right now, touch wood". At night, LTC staffs have reported the use of monitoring camera to keep a watchful eye over the facility hallways. However, technology requires maintenance, which seemed to be an issue in nursing homes according to family members. One family interviewee noted, "there are a lot of things that can be modernized but there is no one to maintain them".

Exit Doors Concealment. Because the door itself is considered a major exit-seeking trigger, caregivers are constantly trying to hide it. An expert interviewee said, "what can we use on the doors to stop people from exit seeking". The door camouflage was reported to be a successful method to deter wandering by three expert-interviewees. One of them indicated, "camouflage will prevent them from exit seeking when they are not busy". However, one participant indicated that door camouflage can turn into a point of attraction if it is visually appealing. Similarly, another family member noted that her loved one lost interest in the camouflage when the final colors turned out very dark. Also, one interviewee articulated that the topic of the disguise painting can trigger different unexpected behaviors, "because it is a trigger that brings back memories of something else". Thus, choosing the right topic can be 
tricky. In addition, using stop signs to conceal the door is another approach to deter wandering. However, there was a controversy regarding their effectiveness. Moreover, curtains covering the doors have been used to eliminate room trespassing and reported to be more effective than stop signs. Though curtains cannot be used on egress doors for fire related concerns by law.

Distractions. Formal and informal caregivers have indicated the use of verbal distractions, such as reminiscing about happier times, to divert the patients focus away from the doorway. According to a family member, "and as a caregiver I will try to distract you cause this is all I got as a weapon". Also, they reported that redirecting these individuals by providing them with a new purpose (such as food, coffee and activities) can be very effective. However, care providers need to know the residents' interests in order to suggest enjoyable activities.

The Snoezelen Therapy. A multi-sensory therapeutic environment filled with light, sound and other elements (e.g. fiber optic lights, lava lamps, music, toys) that can be adjusted to suit a patient's preference. A couple of participants have recommended the use of this room as a therapy for those who display wandering, restlessness and calling out behaviors (Figure-13).

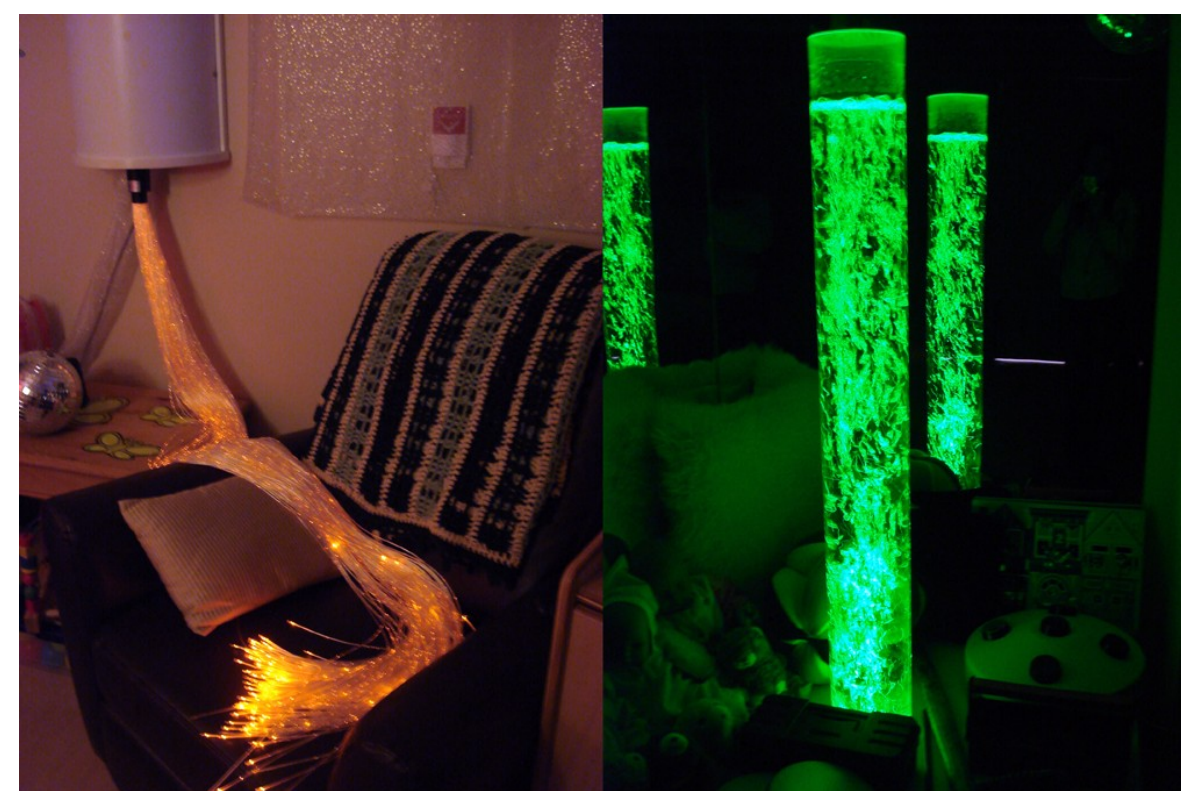

Figure 13- The Snoezelen Room 
Multiple Solutions. Because each patient is unique, it is hard to find a solution that would work for all. One expert noted, "but sometimes it has to be 2 or 3 solutions and bits and pieces in the actual practice". Accordingly, if one solution didn't work, the other would. One family member suggested having several comfortable activity areas to keep the residents busy for hours "If there were longer period where they are engaged in activities that they are comfortable doing, then they are not thinking: oh I don't know where I am". When patients are content they wouldn't think of going back home; home is where a person feels happy, relaxed and loved.

\subsection{INSTRUMENT TWO - ARTISTS INTERVIEWS}

The knowledge gathered from the first methodology led the researcher into conducting interviews with the artists who perform door camouflage to disguise egress doors in LTC facilities (Figure-14). Two semi-structured interviews were conducted with three artists in the field. Although these artworks are not technological solutions, it was important to understand the reasons behind their effectiveness and build on the artists' experience to provide recommendations.

\subsubsection{The Painting}

Uninviting Topics. The whole idea of the camouflage is to take away the understanding that it is the way out, which is ultimately what the exit-seekers are looking for. All participants indicated that choosing a topic that would meet every patient's need in LTC is not easy. Yet, the topic of heavy pieces of furniture (e.g. wall units, bookshelves \& buffet and hutches) seemed to be the right fit. One artist stated, "everyone knows that you can't walk through a 
bookcase for example. So this is inviting people not to leave through a bookcase". The topics used/tested by the interviewed artists are variations of the furniture pieces and a wall of brick. An artist interviewee said about the topics of the camouflage, "not flowers or cats so they just wouldn't go there". One of the artist approaches was to create a wall of brick painting on the egress door, and flowers ornaments on a nearby wall to redirect the residents' attention.

Unattractiveness. All artists reported that they try to make the camouflage as unattractive as possible. They have also indicated that they aim to make the camouflage belong to the space, so that people can pass by and not interact with. Accordingly, they used similar colors to the nursing home. One participant stated, "I didn't want it to stand out; instead I wanted it to blend with the background". The same applies to the detail of the artwork. For example, the artists painted big volume books and ornaments with an illusion of being behind glass. They explained, "we made them [books] big and clumsy so they wouldn't go to pick them up and lift them if you are old or maybe not so strong". However, in one interview, the artists reported that balancing between the need of LTC officials and residents is challenging. They noted, "it is a fine line between what the home wants which is something attractive but ideally something that the people would not be drawn to and not wanna interact with".

Effectiveness. Doors trigger persons with AD into exiting; however, covered doors wouldn't invite people to leave. According to the interviewed artists, the camouflages are an effective deterrent and they work immediately with most residents. One interviewee indicated, "if the camouflage is done properly, it can be 9 out 10 effective". However, the trick doesn't work on every resident. In fact, an artist noted, "some people will have a memory of going to this place no matter what is there". 
Connection to the past. In one interview, the artists recommended checking the backgrounds (e.g. ethnicity \& occupation) of the residents before deciding on the topic of the camouflage, hence, creating styles that patients can relate to. For this reason, their styles of painting are similar to lines and designs of mid 1900's. One artist reported, "patients remember themselves 20-30 years old, so we create things that they can recognize".
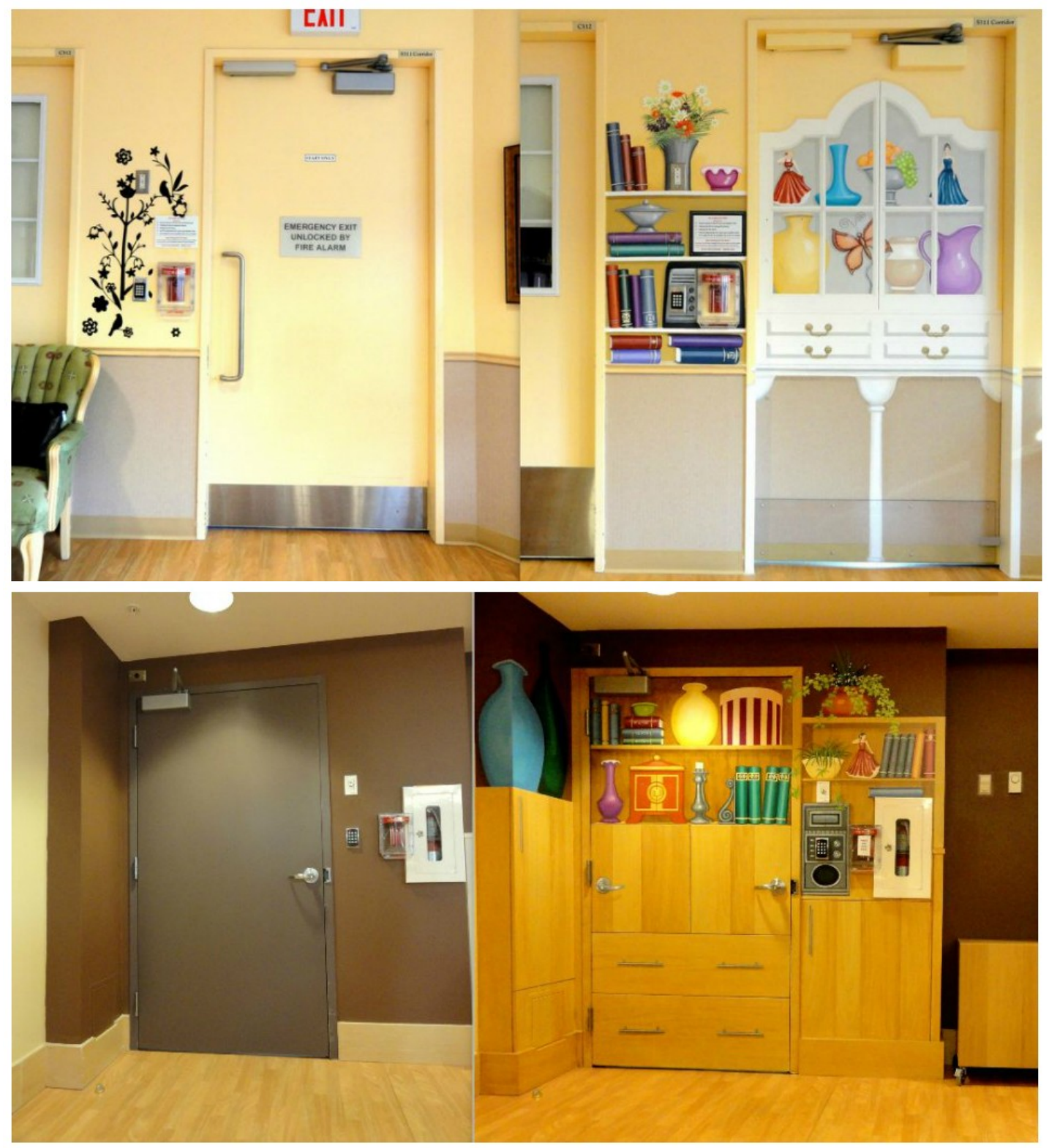

Figure 14 - The Door Camouflage, before and after, from http://bkrcarteffects.com/content/exit-diversion 


\subsubsection{The Process}

City Laws. The main challenges facing the artists who paint the camouflages are the city laws for fire regulations. While there is no standard in Canada regarding these applications, it is the local chapter of the fire department that makes the related decisions. Because there are no specific regulations, the artists are frequently asked to take the materials down or change the design.

Door elements. Egress door windows are troublesome, as they allow the residents to see the outside and strengthen their desire to leave. Thus, covering the door glass is essential. Yet, it is not always possible for safety reasons. One artist noted, "I can cover the window, but I have to leave enough space for safety reasons so people would know who is coming and going. And you have to by law". Also, because disguising the door handle is not allowed by the fire department, the artists incorporate a painted second handle in the design of the camouflage. According to them, creating multiples of one element would make it less noticeable. A couple of artists highlighted the importance of modifying the rectangular shape of the door frame using visual illusions from the top and sides. They said, "we'll put a decorative top that kind of create an illusional upper furniture piece". Lastly, since exit-signs cannot be disguised, the artists try to incorporate them into the design as much as possible

Maintenance. On the contrary to huge size posters, no maintenance is needed for the camouflage, except of a couple of retouches to deal with the wear and tear. Also, cleaning, if required, can be done by using a dry cloth. 


\subsection{INSTRUMENT THREE - THE WORKSHOP}

Based on the findings of the interviews, a workshop was organized with family members and caregivers of those who suffer from AD. The workshop exercises helped in mapping the wandering behaviors of the residents, in understanding the required functions and attributes of wandering interventions and in identifying the possible locations of the solutions.

\subsubsection{Understanding Exit-Seeking}

Throughout the workshop discussions, it became clear that exit-seeking can be categorized under two labels: direct and indirect. Because the workshop exercises were built on the interview findings, the reasons behind wandering were in accordance with those of the interviews. However, the participants indicated that upsetting feelings often accompany wandering, but they weren't identified as contributors to it (Table-2).

Indirect Exit-Seeking. According to one group, some patients wander randomly in all directions. This can result in an unconscious exiting. Moreover, boredom can contribute to indirect exit-seeking when the patients' main motive is to find something to do.

Direct Exit-Seeking.it is the wandering behavior that is caused by triggers or goals as discussed in the interview section. However, the participants pointed out that it is not the feeling of being trapped that triggers the residents to exit-seek. Instead, it is the need for freedom and the liberty to do what they want as they please. One participant noted, "it is not the nourishment they are looking for...”, then another participant continued “... yes it is going and buying my food". 


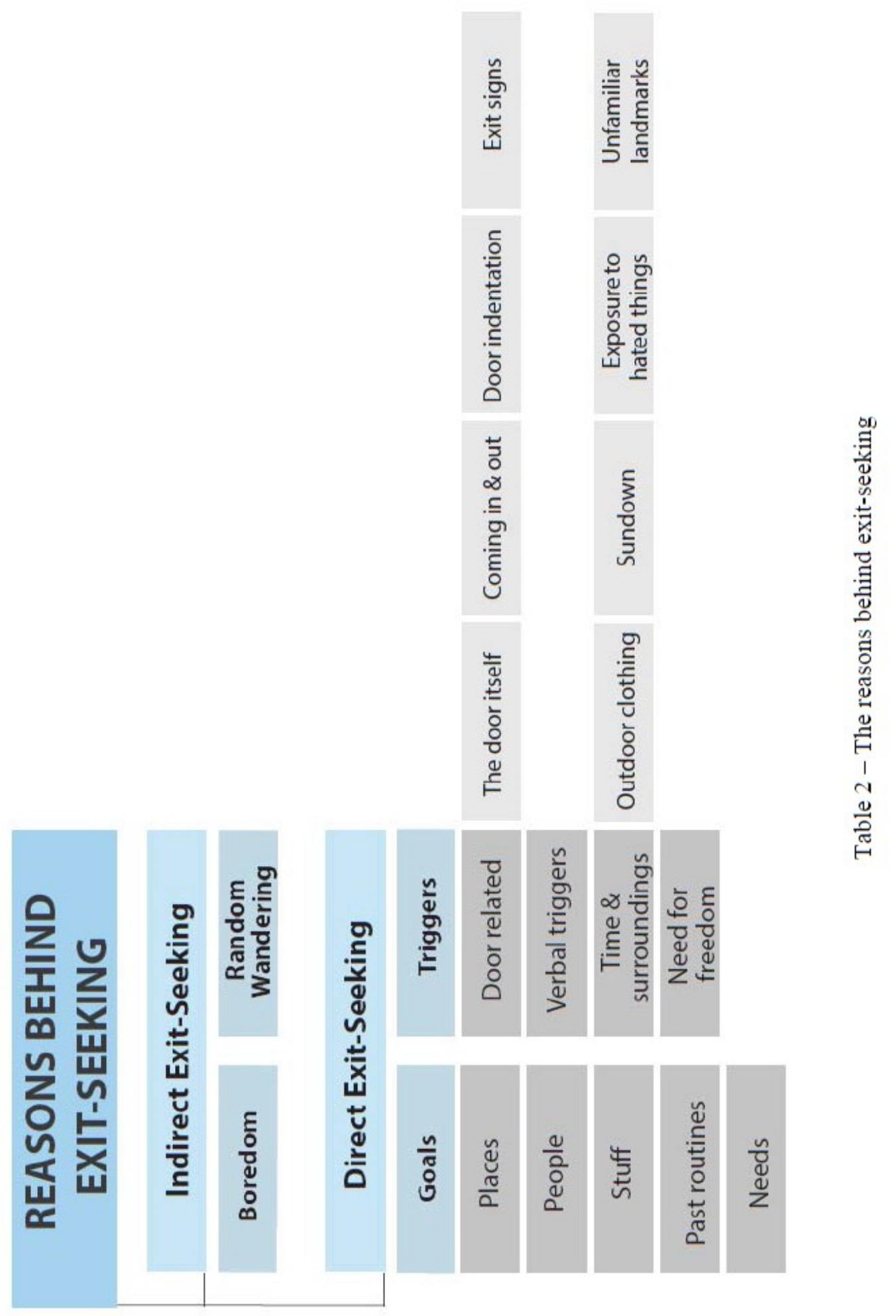




\subsubsection{Understanding the Exit-Seeker}

The workshop participants indicated that the patients exhibit different behaviors when exit-seeking. These behaviors range from passively sneaking into elevators and open doors to actively jiggling door handles and tricking the visitors to elope, even when they're wheelchair bound. One participant noted, "so mom will go to him [a visitor] and say: well I was just visiting, can you let me out". In fact, the reported successful elopements demonstrated the residents' intelligent thinking and ability to learn with time. One group pointed out that dealing with patients' needs of going out fast is more efficient. One member said, "when she [a patient] is at the door, everything is reinforcing. So you have to distract her and deviate her before she reaches that point [the door]". Also, the participants agreed that dealing with early stages participants is harder as they are smarter, more determined and physically more capable.

\subsubsection{The Residents' Interests}

Building on the workshop discussions, the residents' interests can be divided into three categories: Spontaneous (such as socializing, playing with pets or pet plush, baby dolls and kids), somehow spontaneous in that a caregiver needs to turn on the trigger (such as odor, light, and music), and require guidance (such as meaningful and/or routine activities, and personal

hobbies) (Table-3). While all proposed interests were selected based on the interview findings, the workshop groups found four objects/activities that patients wouldn't normally relate to, especially in the mid-to-late stages (such as reminiscing, family photos, memory boxes and sings). In fact, one participant noted, "memory boxes are for families, visitors and caregivers but not for patients". 


\begin{tabular}{|c|c|c|c|}
\hline Spontaneous & $\begin{array}{c}\text { Somehow } \\
\text { Spontaneous }\end{array}$ & Require Guidance & Do Not Relate To \\
\cline { 1 - 1 } Socializing & Odor & \multirow{2}{*}{$\begin{array}{c}\text { Meaningful and/or } \\
\text { past routine activities }\end{array}$} & Family photos \\
\cline { 1 - 2 } Pets or pet plush & Light & Memory boxes \\
\hline Baby dolls & Music & Personal hobbies & Signs \\
\hline Kids & & & \\
\hline
\end{tabular}

Table 3 - The residents' interests categories

\subsubsection{Dealing with Exit-Seeking}

Technology. Technology should be adaptive and tailored to different residents' profiles.

Although caregivers wouldn't favor the use of wearable technologies because they need to be tracked, there was an understanding among the participants that the deterring system would eventually include some sort of tagging devices. However, considering the patients' habits of taking off or losing various articles (even their critical stuff such as hearing aid devices \& dentures) and the indignity of chipping human beings (as stated by one informant "we don't wanna chip no one!’), the participants suggested the use of facial ID tracking or creating systems that would track the visitors or caregivers instead. It worth noting that the participants kept on coming back to the idea of wearable devices throughout the exercises. Their goal was to provide the residents with the ability to wander beyond the locked unit and walk around the facility. Furthermore, in their suggestions, tracking provided more functions than only indentifying the wearer's location and flexibility to evolve over time to facilitate more tasks. As stated by one participant, "bracelets can turn on a lot of things! We start small and then we kind of grow into bigger ideas because it has intelligence". In the "magic" exercise, a participant suggested developing an ink based soluble technology that can be used in tagging. In addition, the participants tackled the issue of technology maintenance by reporting a story of a 
dysfunctional stairway lock. Although this door can affect the safety of the residents, no step has been taken to fix the issue.

Door Concealment. Discussions took place about the effectiveness of physical barriers in preventing the residents from getting to egress doors. The participants suggested the use of door panels that can fully hide the exits. However, concerns regarding the function of this intervention were exhibited. One informant noted, "a physical door is dangerous because when sliding it can closes on people's hands".

Distractions. One Group suggested distributing the distractions and the patients gathering spaces around the facility, especially in the corners of the hallways. This is because of the confusion residents experience in corridors corners, as they have to decide where they should go next. Hence, they enter other residents' rooms. By placing distractions and activity areas around the facility, the wanderers can simply move from one station to another and join the activity taking place. Accordingly, ideas about the purpose of the stations were presented. However, the negative ones (e.g. alarms) didn't receive support by all members. The surprise of one participant was noted and her body language showed disagreement or negative attitude as another informant explained the purpose of the alarm. She commented, "well you scared the geebees out of them!"

Multiple Solutions. The participants seemed to understand that no solution will be $100 \%$ effective. Every patient is unique in the triggers and objects that attract him/her. Moreover, each person will relate to different triggers as he/she goes through different stages of the disease. A workshop informant stated, "when you think about one person you think of it one way, but when you consider them all you can't really say I can only deal with those people and I will let these go. And they can also be in this clump today and move to the other clump 
tomorrow". Thus, it is the nursing home's responsibility to provide various deterrents to accommodate the needs of all patients and in different stages.

Staff Concerns. According to the participants, any intervention to be used in the facility has to accommodate the staff work and responsibilities. For example, any solution that could delay the staff movement or add extra demands to their responsibilities would be disabled in a short period of time. As stated by a participant, "to me the system shouldn't rely on people or it will be disabled". More specifically, door interventions should take into account accommodating the different uses of the egress doors (e.g. furniture moving, emergency medical services). In addition, the interventions shouldn't deceive the staff. One informant noted, "system tricks can be anything that it wouldn't work on staff".

\subsubsection{The Concepts}

Building on workshop exercises, the participants designed the following concepts for exit-seeking interventions (Appendix E):

Door Panels. Wall panels that cover the door so it would look like a wall. This could prevent the wander from finding the door and thus eliminating the door trigger and avoiding elopement (Figure-15).

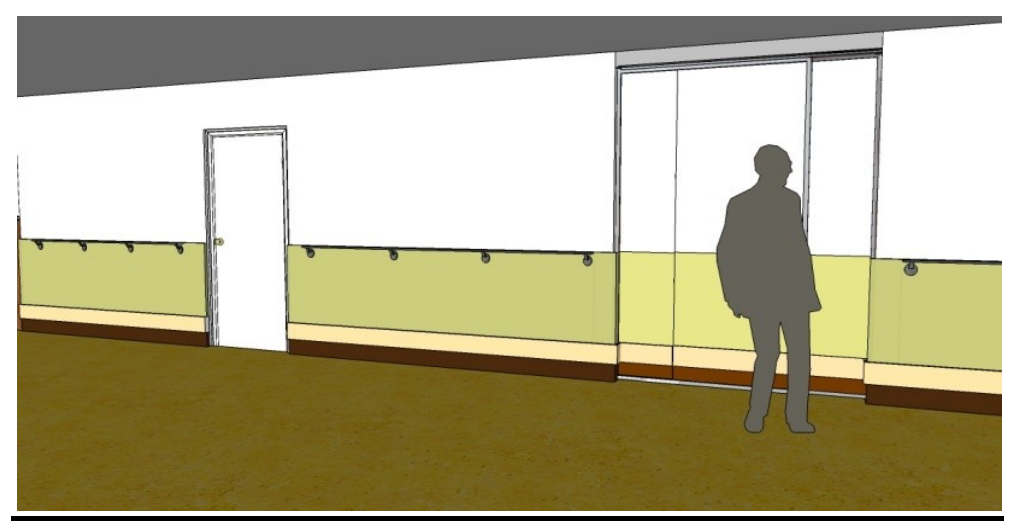

Figure 15 - Door panels intervention 
Trompe L'Oeil Cliff. A projection of a cliff by the egress door to provide the illusion of inaccessibility (Figure-16).

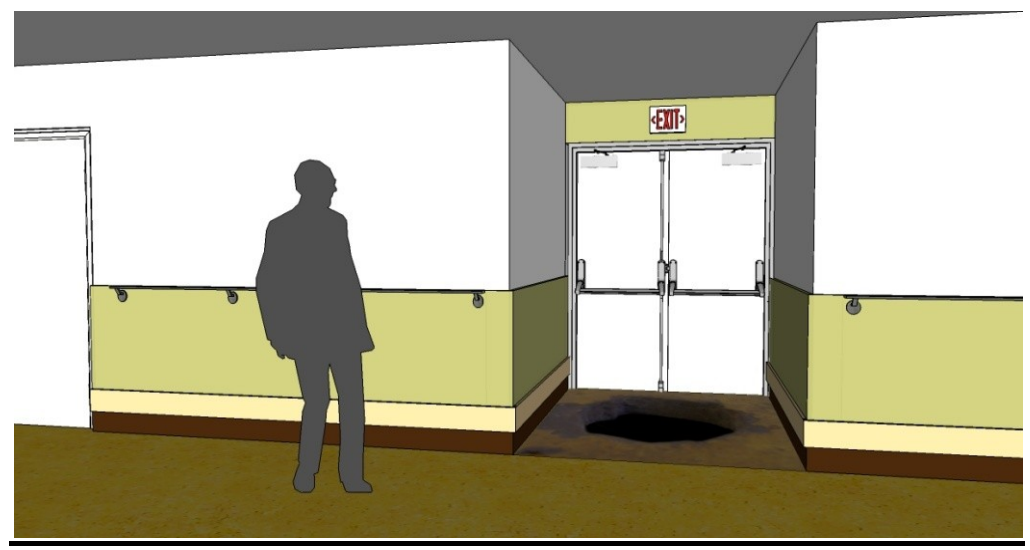

Figure 16 - Trompe l'oeil cliff intervention

The Hologram. A hologram of a nurse that could start conversations with the exitseekers and talk them out of their desire to leave, in the same manner of the LTC facility caregivers (Figure-17).

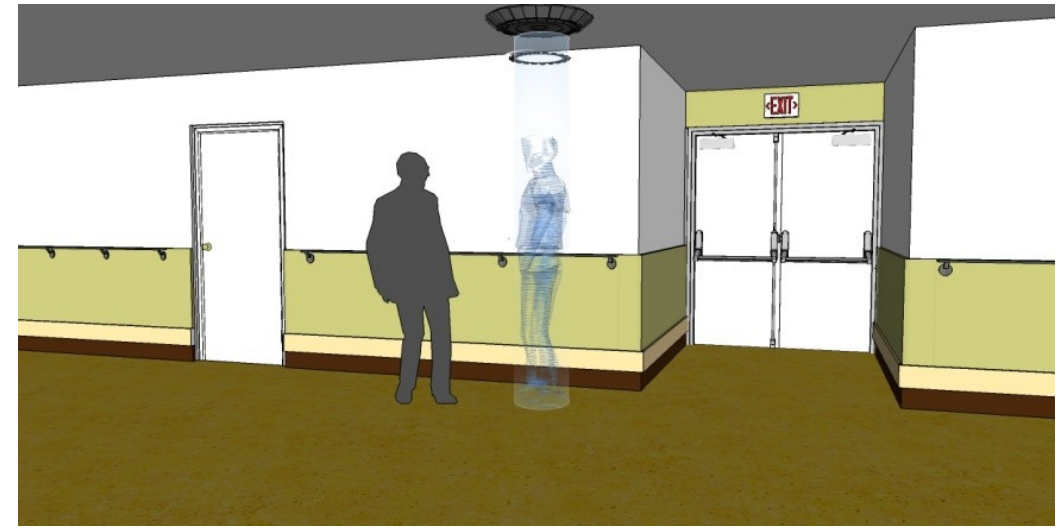

Figure 17- The hologram intervention

High-pitch Alarm. An alarm or loud noise that could frighten the wanderers when getting near the door, hence preventing elopement (Figure-18). 


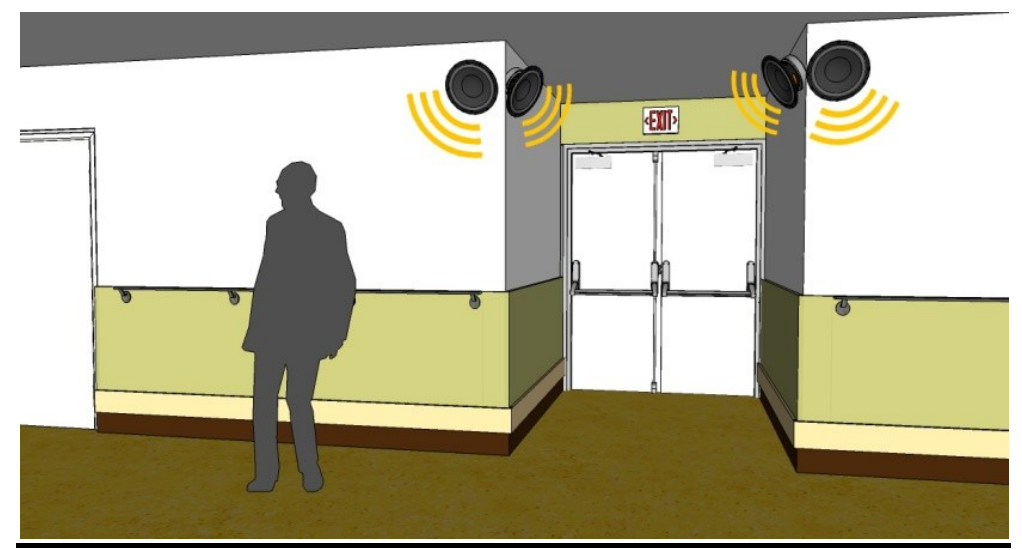

Figure18- High-pitch alarm intervention

Colored Lights. This is not a deterrent, but instead, it is a system that could notify visitors and caregivers of the presence of an exit-seeker by the door using colored lights. Consequently, their discretion is advised on both sides of the door (Figure-19).

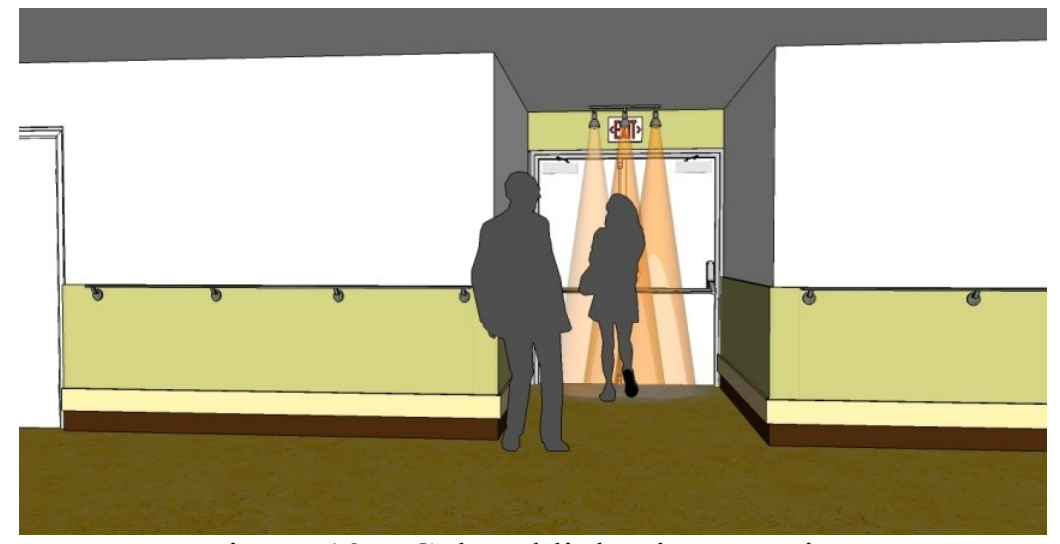

Figure 19 - Colored lights intervention

Video Call. Once the exit-seeker reaches the door, an automated system (video \& audio) would initiate a conversation to deter the wanderer. If the patient didn't respond, the system will connect him/her with the nursing station in a live video call (Figure-20). 


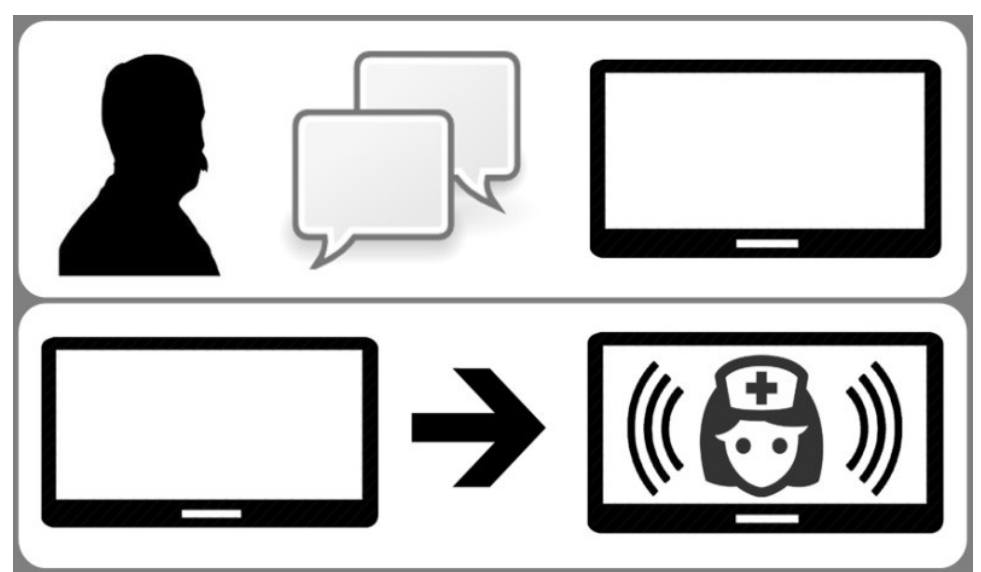

Figure 20 - Video call intervention

Video Wall Stations. Multiple stations distributed around the dementia unit in different conducive spaces. Each unit is composed of a couple of seats, a large size TV screen and other several objects. The system can understand different languages and project different stimulus (audible, visual and olfactory) that would attract the patients to sit and enjoy. Thus, it can provide the patients with a continuous trip of distractions and new purposes. Possible scenes to be projected could include: pop-up band, huge size Snoezelen, a nursery, a party, a wedding or a restaurant (Figure-21).

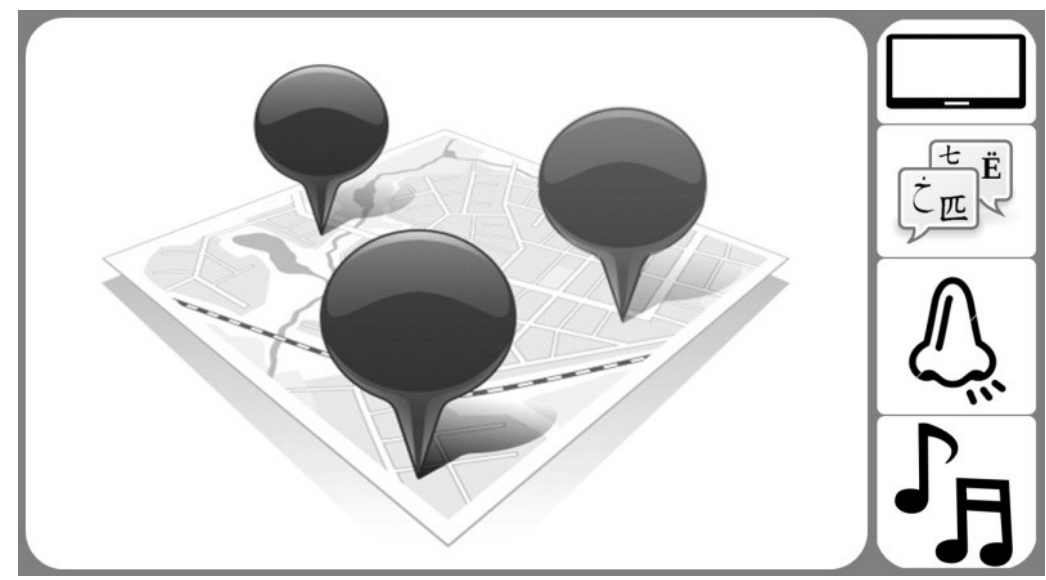

Figure 21- Video wall stations intervention 


\subsection{INSTRUMENT FOUR - THE SURVEY}

Eighteen LTC caregivers, social support workers and nurses were surveyed about their opinion in the design concepts generated in the workshop. The following is the result of the quantitative data collected.

\subsubsection{Survey Section One}

Five-point Likert scale grids were used in the survey. Each intervention was ranked based on three categories that emerged in the interviews and workshop findings: i) Effectiveness to answer the thesis main question, ii) ease of use to support the caregivers needs and their time constraints, iii) suitability to the environment to accommodate the staff movement and maintain the residents wellbeing. The number of responses received for each answer option (n), and the percentage of respondents to this option from the total number of the answers received per category (\%) are presented in the following charts. Each point along the Likert scale was assigned an integer value from one to five (ie: one for strongly disagree, five for strongly agree), from which the sample mean $(\overline{\mathrm{x}})$ and standard deviation $(\sigma)$ were calculated. The participants' suggestions and comments are also presented in the following sub-sections.

Video Wall Stations. The assessment criteria for this intervention were high. The last two categories received equal numbers of responses in strongly and somehow agree options. Also, the answers had the lowest standard deviations $(\boldsymbol{\sigma}=\mathbf{0 . 8} \& \mathbf{0 . 9})$, indicating a higher degree of agreement. Most respondents supported the use of this intervention. One participant suggested the use of more elements and to have something for every patient in each station. Some warned about over stimulation and suggested using neutral elements/stimulus, while others suggested making it specific to each individual. Olfactory stimulus and negative 
projections (someone asking for help) weren't favored by a number of respondents, because of their possible negative effects.

\begin{tabular}{|c|c|c|c|c|c|c|c|c|c|c|c|c|}
\hline \multirow[t]{2}{*}{$\begin{array}{l}\text { Assessment } \\
\text { Criteria }\end{array}$} & \multicolumn{2}{|c|}{$\begin{array}{l}\text { Strongly } \\
\text { Agree (5) }\end{array}$} & \multicolumn{2}{|c|}{$\begin{array}{l}\text { Somehow } \\
\text { Agree (4) }\end{array}$} & \multicolumn{2}{|c|}{$\begin{array}{l}\text { Neither Agree } \\
\text { or Disagree } \\
\text { (3) }\end{array}$} & \multicolumn{2}{|c|}{$\begin{array}{c}\text { Somehow } \\
\text { Disagree (2) }\end{array}$} & \multicolumn{2}{|c|}{$\begin{array}{c}\text { Strongly } \\
\text { Disagree (1) }\end{array}$} & \multirow[t]{2}{*}{$\overline{\mathbf{x}}$} & \multirow[t]{2}{*}{$\Sigma$} \\
\hline & $\mathbf{N}$ & $\%$ & $\mathbf{N}$ & $\%$ & $\mathbf{N}$ & $\%$ & $\mathbf{N}$ & $\%$ & $\mathbf{N}$ & $\%$ & & \\
\hline \begin{tabular}{|l} 
Effectiveness \\
\end{tabular} & 7 & 38.8 & 5 & 27.7 & 6 & 33.3 & 0 & 0 & 0 & 0 & 4 & 0.8 \\
\hline Ease of use & 6 & 33.3 & 6 & 33.3 & 5 & 27.7 & 1 & 55 & 0 & 0 & 3.9 & 0.9 \\
\hline \begin{tabular}{|l|}
$\begin{array}{l}\text { Suitability to } \\
\text { environment }\end{array}$ \\
\end{tabular} & 6 & 33.3 & 6 & 33.3 & 5 & 27.7 & 1 & 5.5 & 0 & 0 & 3.9 & 0.9 \\
\hline
\end{tabular}

Table 4 - Video wall stations responses

Door Panels. The majority of respondents indicated that door panels are somehow effective and agreed that they would be easy to be used and suitable for the environment. The participants predicted malfunctions in technology that could place the residents in danger and increase their agitation. Most participants preferred the panels to be closed all time and to have the ability to open them when needed. One informant noted, "what if other people are trying to come in, it works for me if I can force the door to open". Also, one caregiver compared the door panels with the camouflage in terms of hiding the way out.

\begin{tabular}{|c|c|c|c|c|c|c|c|c|c|c|c|c|}
\hline \multirow{2}{*}{$\begin{array}{l}\text { Assessment } \\
\text { Criteria }\end{array}$} & \multicolumn{2}{|c|}{$\begin{array}{l}\text { Strongly } \\
\text { Agree (5) }\end{array}$} & \multicolumn{2}{|c|}{$\begin{array}{l}\text { Somehow } \\
\text { Agree (4) }\end{array}$} & \multicolumn{2}{|c|}{$\begin{array}{l}\text { Neither Agree } \\
\text { or Disagree } \\
\text { (3) }\end{array}$} & \multicolumn{2}{|c|}{$\begin{array}{c}\text { Somehow } \\
\text { Disagree (2) }\end{array}$} & \multicolumn{2}{|c|}{$\begin{array}{c}\text { Strongly } \\
\text { Disagree (1) }\end{array}$} & \multirow[t]{2}{*}{$\overline{\mathbf{x}}$} & \multirow[t]{2}{*}{$\Sigma$} \\
\hline & $\mathbf{N}$ & $\%$ & $\mathbf{N}$ & $\%$ & $\mathbf{N}$ & $\%$ & $\mathbf{N}$ & $\%$ & $\mathbf{N}$ & $\%$ & & \\
\hline Effectiveness & 5 & 27 & 8 & 44 & 1 & 5.5 & 4 & 22.2 & 0 & 0 & 3.7 & 1.1 \\
\hline Ease of use & 7 & 38.8 & 6 & 33 & 1 & 5.5 & 4 & 22.2 & 0 & 0 & 3.8 & 1.1 \\
\hline $\begin{array}{l}\begin{array}{l}\text { Suitability to } \\
\text { environment }\end{array} \\
\end{array}$ & 6 & 33 & 5 & 27 & 2 & 11.1 & 4 & 22.2 & 1 & 5.5 & 3.6 & 1.3 \\
\hline
\end{tabular}

Table 5 - Door panels responses

Colored Lights. With relatively low variables $(\boldsymbol{\sigma}=\mathbf{1} \& \mathbf{1 . 1})$ and a high steady mean, the responses of the participants were the highest in terms of the assessment criteria for this solution in comparison with other interventions. Some of the participants were uncertain 
whether the colored lights would attract the residents and/or create confusion. Others commented that all visitors should understand how the system works in order for it to be effective. The majority of answers emphasized on the intervention's suitability to the environment. As stated by a nurse, "I like this one cause you never know what's on the other side, and you can't have windows".

\begin{tabular}{|c|c|c|c|c|c|c|c|c|c|c|c|c|}
\hline \multirow{2}{*}{$\begin{array}{l}\text { Assessment } \\
\text { Criteria }\end{array}$} & \multicolumn{2}{|c|}{$\begin{array}{c}\text { Strongly } \\
\text { Agree (5) }\end{array}$} & \multicolumn{2}{|c|}{$\begin{array}{l}\text { Somehow } \\
\text { Agree (4) }\end{array}$} & \multicolumn{2}{|c|}{$\begin{array}{l}\text { Neither Agree } \\
\text { or Disagree } \\
\text { (3) }\end{array}$} & \multicolumn{2}{|c|}{$\begin{array}{c}\text { Somehow } \\
\text { Disagree (2) }\end{array}$} & \multicolumn{2}{|c|}{$\begin{array}{c}\text { Strongly } \\
\text { Disagree (1) }\end{array}$} & \multirow[t]{2}{*}{$\overline{\mathbf{x}}$} & \multirow[t]{2}{*}{$\Sigma$} \\
\hline & $\mathbf{N}$ & $\%$ & $\mathbf{N}$ & $\%$ & $\mathbf{N}$ & $\%$ & $\mathbf{N}$ & $\%$ & $\mathbf{N}$ & $\%$ & & \\
\hline Effectiveness & 7 & 38.8 & 7 & 38.8 & 3 & 16.6 & 0 & 0 & 1 & 5.5 & 4 & 1 \\
\hline Ease of use & 8 & 44.4 & 5 & 27.7 & 4 & 22.2 & 0 & 0 & 1 & 5.5 & 4 & 1.1 \\
\hline $\begin{array}{l}\text { Suitability to } \\
\text { environment }\end{array}$ & 9 & 50 & 5 & 27.7 & 2 & 11.1 & 1 & 5.5 & 1 & 5.5 & 4.1 & 1.1 \\
\hline
\end{tabular}

Table 6 - Colored lights responses

Video Call. The majority of respondents somehow agreed that this interventions is effective, easy to be use and suitable to the environment. The standard deviation was also low $(\boldsymbol{\sigma}=\mathbf{1})$. The participants suggested that nurses use a wearable device to conduct the video calls as they might not be in the nursing station at the time of the elopement. One participant thought that this intervention might attract the residents to the door if they enjoyed having a conversation. Another respondent doubted this solution's effectiveness with argumentative patients.

\begin{tabular}{|c|c|c|c|c|c|c|c|c|c|c|c|c|}
\hline \multirow[t]{2}{*}{$\begin{array}{l}\text { Assessment } \\
\text { Criteria }\end{array}$} & \multicolumn{2}{|c|}{$\begin{array}{l}\text { Strongly } \\
\text { Agree (5) }\end{array}$} & \multicolumn{2}{|c|}{$\begin{array}{l}\text { Somehow } \\
\text { Agree (4) }\end{array}$} & \multicolumn{2}{|c|}{$\begin{array}{l}\text { Neither Agree } \\
\text { or Disagree } \\
\text { (3) }\end{array}$} & \multicolumn{2}{|c|}{$\begin{array}{c}\text { Somehow } \\
\text { Disagree (2) }\end{array}$} & \multicolumn{2}{|c|}{$\begin{array}{c}\text { Strongly } \\
\text { Disagree (1) }\end{array}$} & \multirow[t]{2}{*}{$\overline{\mathbf{x}}$} & \multirow[t]{2}{*}{$\Sigma$} \\
\hline & $\mathbf{N}$ & $\%$ & $\mathbf{N}$ & $\%$ & $\mathbf{N}$ & $\%$ & $\mathbf{N}$ & $\%$ & $\mathbf{N}$ & $\%$ & & \\
\hline Effectiveness & 2 & 11.1 & 10 & 55.5 & 3 & 16.6 & 2 & 11.1 & 1 & 5.5 & 3.5 & 1 \\
\hline Ease of use & 2 & 11.1 & 9 & 50 & 3 & 16.6 & 3 & 16.6 & 1 & 5.5 & 3.4 & 1 \\
\hline $\begin{array}{l}\text { Suitability to } \\
\text { environment }\end{array}$ & 3 & 16.6 & 8 & 44.4 & 4 & 22.2 & 2 & 11.1 & 1 & 5.5 & 3.5 & 1 \\
\hline
\end{tabular}

Table 7 - Video call responses 
The Hologram. The majority of participants were in the mid to mid-high ranges in terms of the assessment criteria of the hologram. Also, the most common remark made regarding this intervention was the uncertainty about its usefulness as a deterrent and about the expense. There were some concerns about hallucinations and some uncertainty regarding the automated responses capabilities.

\begin{tabular}{|c|c|c|c|c|c|c|c|c|c|c|c|c|}
\hline \multirow[t]{2}{*}{$\begin{array}{l}\text { Assessment } \\
\text { Criteria }\end{array}$} & \multicolumn{2}{|c|}{$\begin{array}{l}\text { Strongly } \\
\text { Agree (5) }\end{array}$} & \multicolumn{2}{|c|}{$\begin{array}{l}\text { Somehow } \\
\text { Agree (4) }\end{array}$} & \multicolumn{2}{|c|}{$\begin{array}{c}\text { Neither Agree } \\
\text { or Disagree } \\
\text { (3) }\end{array}$} & \multicolumn{2}{|c|}{$\begin{array}{c}\text { Somehow } \\
\text { Disagree (2) }\end{array}$} & \multicolumn{2}{|c|}{$\begin{array}{c}\text { Strongly } \\
\text { Disagree (1) }\end{array}$} & \multirow[t]{2}{*}{$\overline{\mathbf{x}}$} & \multirow[t]{2}{*}{$\Sigma$} \\
\hline & $\mathbf{N}$ & $\%$ & $\mathbf{N}$ & $\%$ & $\mathbf{N}$ & $\%$ & $\mathbf{N}$ & $\%$ & $\mathbf{N}$ & $\%$ & & \\
\hline Effectiveness & 1 & 5.5 & 5 & 27.7 & 5 & 27.7 & 3 & 16.6 & 4 & 22.2 & 2.7 & 1.2 \\
\hline Ease of use & 1 & 5.5 & 6 & 33.3 & 5 & 27.7 & 4 & 22.2 & 2 & 11.1 & 3 & 1.1 \\
\hline $\begin{array}{l}\text { Suitability to } \\
\text { environment }\end{array}$ & 3 & 16.6 & 3 & 16.6 & 5 & 27.7 & 3 & 16.6 & 4 & 22.2 & 2.8 & 1.3 \\
\hline
\end{tabular}

Table 8 - The hologram responses

High-Pitched Alarm. Because a similar alarm is occasionally used in the facility where the surveys were conducted, the participants were able to draw on their experiences. In fact, there was a lot of controversy and disagreement about this noisy intervention. The chart below shows that equal numbers of respondents provided contradictory answers. More importantly, the standard deviation was the highest in this case $(\boldsymbol{\sigma}=\mathbf{1 . 4 - 1 . 6})$ indicating high variances in the carers' perspectives. Also, the comments accompanied the answers showed that alarming the caregivers of elopement attempts is very beneficial, however adding more noise to the environment is not favorable. One participant noted, "the alarm was easy for us as it was an instant alert", while another one stated, "everyone will go crazy at the end of the day". Also, the respondents reported that the system worked with some patients but not with all wanderers. 


\begin{tabular}{|c|c|c|c|c|c|c|c|c|c|c|c|c|}
\hline \multirow{2}{*}{$\begin{array}{l}\text { Assessment } \\
\text { Criteria }\end{array}$} & \multicolumn{2}{|c|}{$\begin{array}{c}\text { Strongly } \\
\text { Agree (5) }\end{array}$} & \multicolumn{2}{|c|}{$\begin{array}{l}\text { Somehow } \\
\text { Agree (4) }\end{array}$} & \multicolumn{2}{|c|}{$\begin{array}{l}\text { Neither Agree } \\
\text { or Disagree } \\
\text { (3) }\end{array}$} & \multicolumn{2}{|c|}{$\begin{array}{c}\text { Somehow } \\
\text { Disagree (2) }\end{array}$} & \multicolumn{2}{|c|}{$\begin{array}{c}\text { Strongly } \\
\text { Disagree (1) }\end{array}$} & \multirow[t]{2}{*}{$\overline{\mathbf{x}}$} & \multirow[t]{2}{*}{$\Sigma$} \\
\hline & $\mathbf{N}$ & $\%$ & $\mathbf{N}$ & $\%$ & $\mathbf{N}$ & $\%$ & $\mathbf{N}$ & $\%$ & $\mathbf{N}$ & $\%$ & & \\
\hline Effectiveness & 4 & 22.2 & 5 & 27.7 & 1 & 5.5 & 3 & 16.6 & 5 & 27.7 & 3 & 1.6 \\
\hline Ease of use & 4 & 22.2 & 4 & 22.2 & 3 & 16.6 & 3 & 16.6 & 4 & 22.2 & 3 & 1.5 \\
\hline $\begin{array}{l}\text { Suitability to } \\
\text { environment }\end{array}$ & 2 & 11.7 & 5 & 29.4 & 2 & 11.7 & 3 & 17.6 & 5 & 29.4 & 2.7 & 1.4 \\
\hline
\end{tabular}

Table 9 - High-pitch alarm responses

Trompe L'Oeil Cliff. Most participants considered the visual illusions to be somehow not effective and not easy to be used. Moreover, there were equal numbers of respondents who somehow disagreed and strongly disagreed with the suitability of this intervention to the environment. While there was a high variability in responses $(\boldsymbol{\sigma}=\mathbf{1 . 4})$, it was clear from the carers' comments that such deceptive solutions would be very upsetting and frightening, and cause behavioral problems. As indicated by an informant, "they are already hallucinating and seeing scary things!" Others thought this intervention to be ineffective because of the residents' lack of judgment and they might decide to jump in. Therefore, it could increase the risk of falls.

\begin{tabular}{|c|c|c|c|c|c|c|c|c|c|c|c|c|}
\hline \multirow{2}{*}{$\begin{array}{l}\text { Assessment } \\
\text { Criteria }\end{array}$} & \multicolumn{2}{|c|}{$\begin{array}{l}\text { Strongly } \\
\text { Agree (5) }\end{array}$} & \multicolumn{2}{|c|}{$\begin{array}{l}\text { Somehow } \\
\text { Agree (4) }\end{array}$} & \multicolumn{2}{|c|}{$\begin{array}{l}\text { Neither Agree } \\
\text { or Disagree } \\
\text { (3) }\end{array}$} & \multicolumn{2}{|c|}{$\begin{array}{c}\text { Somehow } \\
\text { Disagree (2) }\end{array}$} & \multicolumn{2}{|c|}{$\begin{array}{c}\text { Strongly } \\
\text { Disagree (1) }\end{array}$} & \multirow[t]{2}{*}{$\overline{\mathbf{x}}$} & \multirow[t]{2}{*}{$\Sigma$} \\
\hline & $\mathbf{N}$ & $\%$ & $\mathbf{N}$ & $\%$ & $\mathbf{N}$ & $\%$ & $\mathbf{N}$ & $\%$ & $\mathbf{N}$ & $\%$ & & \\
\hline Effectiveness & 3 & 16.6 & 0 & 0 & 2 & 11.1 & 7 & 38.8 & 6 & 33.3 & 2.2 & 1.4 \\
\hline Ease of use & 3 & 17.6 & 2 & 11.7 & 3 & 17.6 & 5 & 29.4 & 4 & 23.5 & 2.7 & 1.4 \\
\hline $\begin{array}{l}\text { Suitability to } \\
\text { environment }\end{array}$ & 3 & 18.7 & 0 & 0 & 3 & 18.7 & 5 & 31.2 & 5 & 31.2 & 2.4 & 1.4 \\
\hline
\end{tabular}

Table 10 - Trompe l'oeil cliff responses

\subsubsection{Survey Section Two}

The following chart (Table-11) presents the results of intervention ranking as indicated by the survey participants. The displayed figures represent the percentage of scores mean of the sample. Video wall stations were ranked the first with a mean of 5.4 out of 7 which contribute 
to $77.7 \%$. Next, the door panels were ranked the second with a mean of 5.1 which contribute to $72 \%$. The colored lights interventions were ranked the third with a mean of 4.9 which contribute to $70 \%$. The negative interventions were considered the least favored deterrents. The high-pitched alarm was the second last with a mean of 2.9 and $42 \%$, and the tromp l'oeil cliff was the last with a mean of 2.2 and $32.4 \%$.

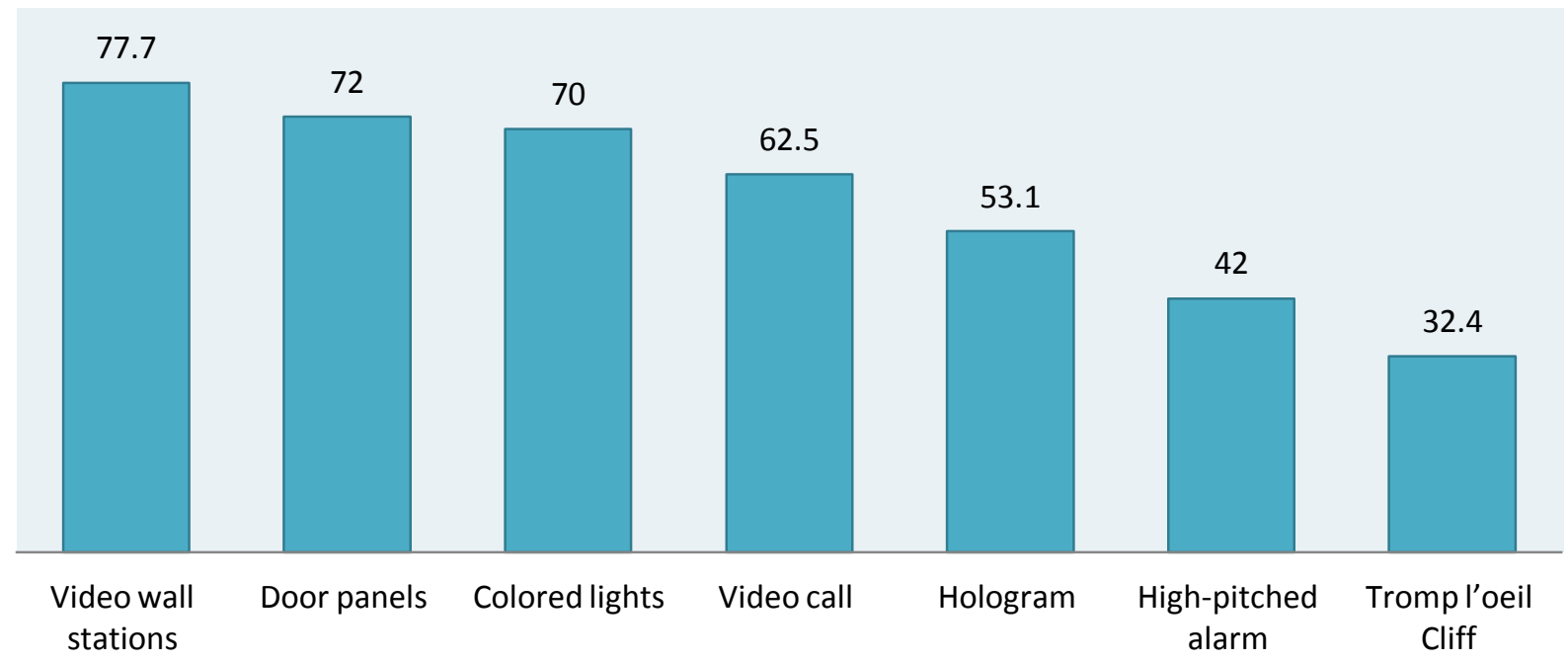

Table 11 - Interventions preference ranking

\subsection{SUMMARY}

Through the methods of in depth interviews, a workshop and a survey, recurring themes about the exit-seeking behavior, the wanderers and the deterring interventions emerged. The research main themes and findings include:

Persons with AD don't make for an homogeneous population. In addition to dementia, the patients undergo various aging symptoms. In fact, because each person has a unique nature, the patients have different interests and are affected by different triggers. Thus, what works with one individual wouldn't necessarily work with all. Furthermore, each person will go 
through the different stages of the disease, hence portraying different behaviors and interests as the dementia progresses.

Two categories of exit-seeking were identified in the research: direct and indirect. However not every exit-seeking attempt is a successful one because of wandering management approaches utilized in institutional care. Yet these attempts are associated with increased levels of negative feelings (agitation, frustration). Building on the research participants' narratives, dementia residents could manage to sneak out of a secured unit with physical barriers by shadowing and/or tricking caregiver and/or visitors.

In order to effectively manage exit-seeking, multiple approaches are needed to accommodate the diverse profiles of patients and deter different types of wandering. The suggested interventions can be organized under two labels: distractions and door solutions. Distractions could deviate the wanderer away from the egress door by providing alternative purposes and attractions. Accordingly, distractions should be positive and build on every patient's interest. In addition, they should be scattered around the facility to provide an interesting trip for the residents. On the other hand, door solutions could deter wandering by concealing the exit, which is the exit-seeker's main objective. The doors should be disguised to not invite the residents to walk through. Also, they should be unattractive and blend well with the surrounding environment, so they wouldn't attract the residents to the doorway. However, exit controls should comply with the city fire department codes.

In general, any proposed exit-seeking intervention should take into account the residents remaining cognition, present skills and current interests. In addition, the interventions shouldn't require much maintenance. Also, they shouldn't add extra demands for the caregivers and affect the patients negatively. 


\section{CHAPTER 5}

\section{DISCUSSION}

As the phenomenon of wandering of people with AD continues to be a problem in LTC facilities, researchers are constantly looking for solutions that preserve the residents' safety while at the same maintain their wellbeing. Because assistive technologies have been found to have the potential to manage exit-seeking, the goal of this study was to investigate how the appropriate design of technological interventions could contribute to dangerous wandering management. However, after gathering and analyzing the data, the thesis direction changed slightly. The data showed that technology-based interventions are not very favorable in institutional care. Yet, the research participants revealed an interest in low-tech wandering management solutions. Accordingly, this study has expanded to include non-technological approaches such as the door camouflage, which was found to have a great impact on deterring wandering. Thereafter, the thesis main and sub-questions evolved as follows:

The main question of this research was "How can technology be introduced in the LTC environment to effectively deter the exit seeking behavior of dementia residents?" The question developed to:

Q- How could the wandering behavior of persons with AD be deterred effectively in LTC settings?

In addition, the first sub-question was "Which dementia-related factors and caregiver issues need to be taken into account when designing assistive technologies to deter exit-seeking?" and changed to be: 
SQ1- Which dementia-related factors and caregiver issues need to be taken into account when designing exit-seeking interventions?

No modifications were made to the second and third sub-questions:

SQ2- What are the tools and interventions currently available to deter wandering, how effective are they and why/why not?

SQ3- Which objects, activities and elements of the physical environment can capture the exit-seekers' attention and provide a distraction?

This chapter aims to compare and contrast the themes that emerged from the in-depth interviews, the workshop and the survey with the theoretical background presented in the literature review in accordance with the research main and sub-questions. The results of this process form the recommendations and guidelines for designing and/or improving the exitseeking interventions.

\subsection{DESING RECOMMENDATIONS}

In order to answer the driving question of this thesis "How could the wandering behavior of persons with AD be deterred effectively in LTC settings?" the emerged themes are broken into two main categories: Recommendations for multiple interventions that build on case-specific wandering scenarios and general recommendations that should be taken into account when designing wandering solutions for institutional care. These sub-sections provide an interesting opportunity to discuss the research sub-questions in relation to previous literature: 


\subsubsection{The Need For Muliple Interventions}

It has been found both in this study and in literature that the population of $\mathrm{AD}$ patients is not homogenous (Silverstein et al, 2002). First of all, in addition to aging symptoms, dementia patients have different personalities and interests according to the interviewees. Second, the workshop participants added to the previous the fact that each person will relate to different triggers as he/she goes through different stages of the disease. Third, the concept of the Video Wall Stations was ranked the highest in the survey, probably because it has the ability to provide something for every resident in the facility and has the flexibility to change and accommodate the patients' current and future needs over time. In fact, the respondents suggested personalizing the projection of each station based on different residents' profiles. Others suggested providing an interest for each resident in each station. Forth, the reasons for which residents exit-seek occur vary from one case to another. In fact, it has been established in this study that understanding why wandering taking place is required in order to address it properly.

In effect, there was a common understanding among the participants that no deterrent is perfectly effective with all residents. In fact, this supports the Alzheimer's Society of BC (2013) warning that no one thing is going to ensure the safety of a person with dementia. Also, by determining what may contribute to this behavior, it may be possible to figure out ways to manage it (Alzheimer's Society of BC, 2013). Accordingly, it is necessary to provide multiple wandering management solutions in nursing homes to accommodate different profiles of wanderers and different scenarios of exit-seeking, both the direct and indirect. 


\subsubsection{Direct Exit-Seeking Recommendations}

Triggers and goals can lead a person with AD to exit-seek. This behavior has a main drive behind it, hence, it is considered direct. Two problems surfaced in the findings of this research: visitors and egress doors issues. Visitors' alarm and door concealment were identified as possible interventions to deal with these concerns respectively, by answering the first and second sub-questions:

SQ1- Which dementia-related factors and caregiver issues need to be taken into account when designing exit-seeking interventions?

SQ2- What are the tools and interventions currently available to deter wandering, how effective are they and why/why not?

\subsection{Visitors Alarm}

The majority of residents' successful elopement incidents reported in the interviews were accomplished by shadowing and/or tricking visitors or new caregivers. This type of behavior was reported by several authors in the literature (Aud, 2004; Algase et al, 2009). The current approach of dealing with such situations is by hanging the pictures of exit-seekers on the main exit and by being attentive all the time. The workshop participants identified this issue and designed the Colored Lights intervention to address it. This intervention ranked third according to the survey responses. This might be because this concept offers a possible solution to a problem that has not been properly addressed in nursing homes and in the literature. In addition, it provides subtle alarms that wouldn't degrade the exit-seeker. In fact, dehumanizing wandering management solutions were associated with decreased levels of well-being (Wigg, 2010). 


\subsection{Doors Concealment}

As persons with AD seek to fulfill their goals of wandering away from the locked unit, they will be looking for the egress door. The door itself is considered a major exit-seeking trigger. According to the interviews, in order to eliminate these factors, the door camouflage was used in institutional care to hide the main exit and was reported to be a successful method to deter wandering. Similarly, the workshop participants proposed the concept of wall panels to cover the entrance/exit area. This intervention was the second favorite concept ranked by the survey participants. It was also compared to the camouflage in that both can hide a door. Thus, concealing the egress doors seems to deter wandering by taking away the recognition that it is the way out.

It is worth noting that the concept of door camouflage discussed in literature varies from the one found in real practice. The literature suggested covering the exits with the same shade/pattern of the surrounding walls using paint/wallpaper (Alzheimer's Knowledge Exchange, 2010) and covering the panic bar with a cloth barrier (Dickinson et al, 1995). However, only one article was found in literature after conducting this research that investigated the use of murals, which were also found to reduce wandering (Kincaid \& Peacock, 2003). In order to design and effectively conceal a door; the following guidelines emerged from research of this thesis.

\section{Uninviting Camouflages}

It is essential when hiding egress doors to create camouflages that disguise the exit and wouldn't signify that it is the way out. In fact, stop signs were found to be ineffective in both the interviews and the workshop findings. However, door curtains were found to be more 
effective. Perhaps, this is because signs don't provide a complete concealment, while curtains do. Nevertheless, the artists indicated that the topic of bulky pieces of furniture was deemed to be the most effective. They postulated that everyone knows that they can't walk through a bookcase. Likewise, door panels can provide the same indication as no one can walk through a wall. Artists' interviews showed that taking away from the square shape of door and including its elements (e.g. handles, bars and windows) in the artwork contributes to the effectiveness of the camouflage. Relatively similar findings about the visibility of hardware on exit doors, and the opacity of door windows and their contribution to wandering were addressed in literature (Zeisel et al, 1994; Silverstein et al, 2002).

\section{Unattractive Camouflages}

Ideally, the design shouldn't be attractive, or else, it will turn into a center of attraction. Family interviews showed that one patient lost his interest in the camouflage once it was painted darker. Topics such as flowers or cats weren't recommended by the artists because of their abilities to attract residents. Instead, the design should blend with the surrounding environment, in terms of the colors and topics, so that people can pass by without noticing or interacting with it. However, according to the artists, LTC management often request attractive designs. Adding aesthetically appealing details (e.g. books and ornaments) that look huge and heavy so patients wouldn't have the interest to play with them can address this issue. Similarly, the survey participants noted that patients might enjoy interacting with the Video Call intervention; hence, it would turn into an attraction instead of a deterrent.

These findings are comparable with Silverstein et al (2002) suggestions of having the exit and non-exit door match colors to avoid attractions. However, the results do not align with 
Kincaid \& Peacock (2003) study, in which the topic of the murals tested was a fish tank and was designed to be interesting.

\section{Fire Code Regulations}

The biggest challenges affecting egress door interventions are the fire code regulations. The interview participants found that covering the doors with a curtain can be effective in preventing elopement. However, this approach couldn’t be applied in practice due to firerelated laws. The artists reported that accommodating the fire code regulations can negatively influence the design and effectiveness of the door camouflage since they were often asked to make alterations (e.g. adding a peep hole). They stated that decisions taken in this regard are municipal-based and vary from one city to another; hence, broad guidelines cannot be standardized. Accordingly, instead of covering the door handle, the artists painted multiple knobs to make it disappear. Also, they suggested including the exit-signs into the painting. Likewise, previous studies documented these problems in the panic bar cloth cover intervention (Dickinson et al, 1995). Hence, they suggested painting the bar with the same color of the door instead of covering it with a cloth. Furthermore, the literature recommended incorporating keypads upside-down or into the surroundings to deal with this issue (Alzheimer's Knowledge Exchange, 2010).

\subsubsection{Indirect Exit-Seeking Recommendations}

Boredom and random wandering might result in unintentional exit-seeking. Providing distractions was reported to be effective in this context. Accordingly, this section explores the answers of the third sub-question: 
SQ3-Which objects, activities and elements of the physical environment can capture the exitseekers' attention and provide a distraction?

This question is approached through discussions of engaging distractions and their criteria of employment.

\subsection{Engaging Distractions}

According to the interviewees, distractions have been used to redirect the patients' attention and provide them with a new purpose. As a result, the workshop participants designed the concept of video wall stations to be distributed around the facility to provide a trip of interesting and continuous distractions. In the survey this concept was ranked first in comparison to the other ideas that emerged from the workshop. These findings confirmed what the researcher had gathered from the literature review in that a rich stimulating environment can alleviate some of the boredom and restlessness associated with wandering (Coons, 1988; Cluff, 1990), and can provide the necessary distraction for exit-seekers (Dickinson \& Mclainkark,1996). In order to design engaging distractions, the following criteria emerged from the research.

\section{Positive Distractions}

Distractions need to provide positive diversions and build on the residents' personal tastes, personalities and interests. According to the interviews, if patients are happy, they wouldn't be thinking of going back home. In fact, oftentimes, caregivers suggested enjoyable activities to divert residents' attention; otherwise, they wouldn't become engaged. Likewise, the survey respondents considered the Video Wall Stations concept, designed in the workshop, the 
best intervention. This is probably because it provides continuous and enjoyable distractions that have the potential to engage the residents. Also, it presents the residents with a freedom to join stations as they please, without being told what to do. In fact, the concept of the Video Wall Station can be considered an advanced version of the sensory scenes experiment conducted by Cohen-Mansfield and Werner (1998), which was found to increase the level of the participants' pleasure.

In addition, music and other sensory stimulation (light \& odor) can attract the residents' attention and increase their engagement. Accordingly, rooms such as the Snoezelen have been used as a therapy for those who wander. However, over stimulation might make a person with AD agitated and confused. Similarly, the literature recommended providing the right amount of sensory stimulation, striking a careful balance between over-stimulation and deprivation (Zeisel et al, 1994; Day et al, 2000). Thomas (1995, P.39) suggested providing tactile and sensory cues in an attempt to redirect the continuous wanderer and to stop his or her motion and compel him or her to sit. Other positive distractions include: socializing, playing with pets and pet plush, kids, baby dolls and other pastimes and hobbies.

\section{Scattered Distractions}

The interviews results showed a need for having multiple distractions (section 5.1.1). This finding evolved to become the Video Wall Stations in the workshop. The workshop participants suggested distributing these stations in all possible locations around the facility (except the entrance area) to provide continuous distractions and new purposes for the residents. They also emphasized on placing them in all possible hallway corners, where residents usually get confused and enter other patients' room. This finding is comparable to Silverstein et al 
(2002) discussion about reducing the number of decision points in corridors and Dickinson \& Mclain-kark (1996) sugesstion of including activities along the path to encourage the wanderer to rest and perhaps join the group. One possible explanation for the reasons behind ranking the Video Wall Stations the highest, is because they provide an interesting continuous trip for the residents as they pace around the facility. Accordingly, the station can provide a context in which Zeisel et al. (1994) recommendations would be applied; a path with interesting cues provides residents with the motivation to stop and attend to an object, view or experience it, and eventually to move to the next place along the pathway.

\subsubsection{General Recommendations}

This section is concerned about the major themes identified in the study that should be taken into account when designing and/or improving wandering interventions in LTC facilities. All the subsequent arguments provide answers to the first sub-question:

SQ1- Which dementia-related factors and caregiver issues need to be taken into account when designing exit-seeking interventions?

In addition, section 5.1.2.2 elaborates more on the answers of the third sub-questions: SQ3- Which objects, activities and elements of the physical environment can capture the exitseekers' attention and provide a distraction?

\subsubsection{Maintenance Concerns}

Maintenance seemed to be one of the biggest issues in LTC facilities. It has been found in the interviews that LTC officials are reluctant to introduce technological improvements to a facility if they require maintenance. For the same reason, the door camouflage was favored over 
huge size posters; in that it occasionally requires a couple of re-touches to deal with the wear and tear. In the workshop, the participants talked about a staircase entrance with a loose lock that was not repaired for any obvious reason, even though it can be utilized for getting to other unsecured units and can increase the risk of falls. Moreover, the survey respondents revealed some concerns about the malfunctions of the door panels. Perhaps, because of the issue of maintenance, the use of technology has not been favored in LTC settings.

This topic has been commonly addressed in published research about technological interventions. While most of the studies covered it in brief (Carrillo et al, 2009; Dorsten et al, 2009), the findings of this research imply that maintenance is a more serious issue than it seems in the literature. Accordingly, it is safe to postulate that for any intervention to be installed in LTC facilities, it has to require little or no maintenance.

\subsubsection{Relatable and Understandable Interventions}

This analysis about persons with $\mathrm{AD}$ indicates that it is important to align their current skills with their past stories (backgrounds, activities, routines). In other words, the patients need to relate to and understand the intervention in order for it to be effective. First, the interviews showed that the residents can relate to their past better than their present lives. Therefore, the interviewees suggested using distractions inspired from their past life experiences such folding the laundry. Likewise, Dickinson \& Mclain-kark (1996) sugested to provide non-infantizing activites that build on lifetime experiences such as dusting, folding towels, or sorting envelopes. Also, the Alzheimer's Society of BC (2013) recommends considering past skills and interests when presenting activities. The caregivers interviewed indicated that they spend time learning about the new resident backgrounds and preferences in order to suggest activities or distractions 
that patients can relate to. Nevertheless, the workshop participants identified several objects that patients don't relate to normally (section 4.3.3). As a result, these cannot be used as distractions.

Second, the artists recommended checking the background (e.g. ethnicity \& occupation) of facility residents before deciding on the style of the camouflage. Doing so allowed them to create topics, styles and elements that residents can recognize. On this subject, the interviewees reported that patients relate to the content of the camouflages, which can result in triggering unexpected behaviors that connect to their past.

\subsubsection{Disruptive Interventions Complications}

When interventions can do more bad than good to the caregivers or the patients, their use should be avoided. The analysis of the data showed that the negative consequences associated with some interventions affect the likelihood of being adopted and used in LTC settings.

\subsection{For the Caregivers}

Concerns about the use of wearable technologies have been found in this study. Although all family members have considered tagging the patients at some point during the disease, the interview caregivers have found this approach to be burdensome. This might be because the use of wearables can add extra demands on the carers. The workshop participants have explained that the dementia population tends to remove and/or lose these gadgets along with other aid devices (e.g. hearing aid \& dentures). These results support the literature findings about wearable and attach-free devices (Wigg, 2010; Youssef et al, 2007). However, it is worth 
noting that workshop participants kept coming back to the idea of tags and suggested tagging the residents in less noticeable areas and adding new features to the system, more than only identifying a location. Moreover, some suggested the development of farfetched soluble tags and the use of facial ID recognition. It is worth noting that the concept of the soluble tags is similar to the florescent dye tracking developed by Nishigaki et al (2013) in that they stick to the person and cannot be removed or lost.

In addition, the workshop participants noted that LTC caregivers would reject any intervention that can intervene with their performance, movement, and completion of daily tasks. This finding was supported in the survey results as more respondents preferred having the ability to force the door panels to open and close as desired. Similarly, the literature suggested that alarms could have side effects and result in wasting the staff valuable time (Coons, 1988). Also, the respondents ranked negative interventions the lowest because of their abilities to harm the residents physically or emotionally (section 5.1.2.3.2); hence, adding more duties and requirements to the caregivers workload.

\subsection{For the Patients}

The interviews analysis showed that persons with $\mathrm{AD}$ get agitated by noise since they are very sensitive to sounds. In addition, the workshop participants indicated that negative feelings are often associated with wandering. In fact, the relation between agitation and wandering is commonly addressed in literature (Silverstein et al, 2002; Margot-Cattin \& Nygard, 2006). Also, different opinions were noted about the use of negative interventions that might frighten or agitate the residents. However, because an alarm intervention was used by a couple of workshop participants to deter wandering in household settings, it was suggested as a 
solution. Coons (1988) discussed the effectiveness of alarms and associated them with increased agitation. Similarly, the survey responses regarding the alarm itself showed a lot of disagreement about its assessment criteria. However, the alarms along with other negative interventions, such as the Trompe L'Oeil Cliff, were ranked the lowest in the overall consideration. The participants explained that such interventions can have an effect on the wanderers, the staff and other residents. Hussian and Brown (1987) argued that the use of visual barriers have the potential to restrict the non-problematic movement of the residents. Moreover, the survey respondents explained that these interventions might cause agitation, hallucination and over stimulation, and increase the chance of falls. Thus, they could decrease the physical and emotional wellbeing of the residents. Likewise, Wigg (2010) argues that dehumanizing and freighting the residence by halting their ability to exit decrease their quality of life.

\subsection{LIMITATIONS}

As with every research process, a number of limitations affected the validity of this study and its findings. Because persons with $\mathrm{AD}$ are frail individuals suffering deterioration in cognitive capabilities, it was considered inappropriate to interview them regarding their experience with exit-seeking. Accordingly, the results of this study reflected the opinions of those who provided care to the residents and dealt with them on a daily basis. In fact, gathering information from the caregivers of persons with cognitive diseases is very common in literature. Yet, since no observations and/or interventional experiments were conducted, the contribution of this thesis is solely based on anecdotal evidence.

Furthermore, the researcher had limited resources in terms of recruiting participants. Therefore, the sampling method required months of back-and-forth communications. The initial 
plan of the researcher was to focus on the wandering behavior of those who are still living in the community. However, all recruiting strategies utilized yielded no results and no community participants were enlisted. Thus, the focus of this study shifted to deterring wandering in LTC settings. In addition, only two facilities responded to the research invitations and showed a willingness to help and the facility personnel had to arrange for a time within the working hours of the staff for conducting the interviews and the survey. In one case, the researcher had to shorten the interview because the night-shift caregiver was on duty and needed to go back to work. Also, the nursing home management had to contact the family members on behalf of the researcher in order to preserve their privacy. From the recruited interviewees, two family members hadn't experienced wandering in LTC facilities. While they provided valuable insights about the disease, the patients and wandering before admission, they couldn't specifically elaborate on exit-seeking in nursing homes.

In addition, due to the small number of workshop informants, the responses were relatively limited. Therefore, wider participation could have led to more diverse perspectives reflected in the study. On a somewhat related note, all the workshop participants were recruited from the same facility. This provided them with a common ground and a better understanding of the subjects being discussed. Yet, enlisting participants from different facilities could have revealed other concerns and problems.

Lastly, the population targeted in the survey consisted of only those who provide care for the residents in real practice. Thus, it would have been useful to examine the views of the management personnel about adopting the interventions concepts in LTC facilities by including them in the survey. 


\subsection{RECOMMENDATIONS FOR FUTURE RESEARCH}

A previously implied, a number of suggestions could be considered in future research to build on the knowledge gathered in this study. The first recommendation would be to replicate this research in a different setting and consider the wanderers who are still living in the community. This can introduce a new avenue for the design recommendations of exit-seeking interventions. Similarly, recruiting a wider range of participants in the study, especially those with backgrounds in management, would allow for further development and refinement of the design guidelines developed in this research.

In addition, as the findings of this thesis provide groundwork for future studies, it could be utilized as a start point for additional explorations. In particular, the ideas of visitor alarms and door camouflages can be studied further, since they were not adequately addressed in the literature. It is also suggested to develop an evaluative matrix which can properly assess the different criteria of an intervention such as effectiveness, ease of use, suitability to the environment and others. Moreover, future research could investigate how the meaningful activities suggested in the video wall station could change the way residents engage with and relate to the surrounding space.

Lastly, future studies could conduct empirical testing of the results established in this research in order to test if these recommendations will work as anticipated in actual settings. Conducting interventional experiments could help to observe and compare between the results of each intervention instead of solely relaying on anecdotal dimensions. 


\section{CHAPTER 6}

\section{CONCLUSION}

Building on an extensive review of the literature addressing the issue of wandering of persons with $\mathrm{AD}$, it became clear that the potential of technology to deter this behavior hasn't been fully explored. The knowledge gathered from diverse disciplines in previous research formed the basis of this investigation and led to the thesis main and sub-questions. Accordingly, this research was approached from an interdisciplinary perspective, using exploratory methods, to investigate the subject of designing and improving wandering management interventions in LTC facilities. The data gathering procedures started with two sets of in-depth interviews with the formal and informal caregivers of dementia residents. The findings from these methods yielded a need for deeper examinations of the door camouflage approach and shaped the exercises explored in the workshop. Finally, the concepts proposed by the participants in the collaborative workshop were presented in a visual survey in order to collect a wider range of perspectives regarding the adoption of these interventions in LTC facilities. As a result of the data triangulation conducted and the comparison between the emerging themes and the findings from literature, the thesis direction expanded to include non-technological interventions. Moreover, the study provided several key insights into understanding how appropriate design of exit-seeking interventions contribute to better wandering management of persons with AD. Based on these insights, four major conclusions can be drawn.

First, deterring exit-seeking effectively requires a combination of multiple solutions that take into account different profiles of wanderers and various types of exit-seeking. 
Because the population of persons with $\mathrm{AD}$ is not homogenous and every patient is unique in nature; and since each person goes through different stages and portrays different behaviors and interests over the course of the disease, it is important to provide the residents with several triggers and activities to accommodate their diverse personalities and interests. In addition, the reasons behind exit-seeking differ from one case to another. Therefore, the interventions can be categorized into engaging distractions to deal with indirect wandering behaviors and exit controls such as the door concealments and visitors alarms to tackle the issues of direct exitseeking.

Second, distractions and door concealment interventions serve completely opposite goals. Distractions aim to engage the residents by building on their interests and sensory preferences throughout the facility, except at the exit areas. On the other hand, the purpose of hiding the egress door is to take away the indication that it is the way out by making it unattractive and uninviting to walk through.

Third, in order for interventions to be effective, they should build on the residents' past experiences and routines as well as their backgrounds such as their ethnicity and occupation. Accordingly, persons with $\mathrm{AD}$ would have the skills and abilities to understand and relate to them.

\section{Forth, the implications associated with the use of interventions affect their} likelihood of being adopted and installed in LTC facilities. The interventions should have virtually no malfunctions and require minimal maintenance. In addition, they shouldn't add extra duties and demands on the workload of the caregivers. Furthermore, they should not disrupt the carers' performance of their jobs and waste their valuable time. Similarly, 
interventions that could decrease the residents' emotional and physical well-being by causing agitation and hallucinations and by increasing their chances of falls should be avoided.

The information derived from this research paves the path for future interdisciplinary design development research to expand on these findings by utilizing this study as a start point for further explorations. The complied findings and design recommendations of this thesis could act as a tool or a guideline for the professionals concerned about creating and/or improving the features of exit-seeking interventions for persons with AD in LTC facilities. 


\section{BIBLIOGRAPHY}

Algase DL. (1999) Wandering: a dementia-compromised behavior. J Gerontol Nurs. 25(9):1016

Algase, D. L. (2003). Biomechanical activity devices to index wandering behaviour in dementia. American Journal of Alzheimer's Disease and Other Dementias, 18(2), 85-92.

Algase, D. L., Beattie, E. R. a, Antonakos, C., Beel-Bates, C. a, \& Yao, L. (2010). Wandering and the physical environment. American journal of Alzheimer's disease and other dementias, 25(4), 340-6.

Algase, D. L., Moore, D. H., Vandeweerd, C., \& Gavin-Dreschnack, D. J. (2007). Mapping the maze of terms and definitions in dementia-related wandering. Aging \& mental health, 11(6), $686-98$.

Altus, D. E., Mathews, R. M., Xaverius, P. K., Engelman, K. K., \& Nolan, B. a. D. (2000). Evaluating an electronic monitoring system for people who wander. American Journal of Alzheimer's Disease and Other Dementias, 15(2), 121-125.

Alzheimer's Association (2013). About Dementia. Retrieved November 17, 2013, From http://www.alz.org/what-is-dementia.asp

Alzheimer Association. (2013). Disaster Planning in Residential Care Settings. Retrieved April 7, 2013, from www.alz.org/national/documents/topicsheet_disasterprep.pdf

Alzheimer Association. (2012). Wandering and Getting Lost. Retrieved October 23, 2012, From http://www.alz.org/care/alzheimers-dementia-wandering.asp

Alzheimer Association. (2013). Wandering and Getting Lost. Retrieved October 1, 2013, from http://www.alz.org/alzheimers_disease_what_is_alzheimers.asp

Alzheimer's Knowledge Exchange (2010). Dementia Friendly Design Considerations: Doorways. Retrieved April, 23, 2013, From http://www.akeresourcecentre.org/files/Design/Doorways\%20K2P_v9\%20updated\%20feb2 013.pdf

Alzheimer's Society of BC (2013). Exit Diversion. Retrieved December 6, 2013, From http://www.alzheimerbc.org/getdoc/6e567132-7e41-46fb-92f0-54f5f32948e0/WanderingInformation-Kit.aspx 
Alzheimer's Society of BC (2013). Exit Diversion. Retrieved December 6, 2013, From http://www.alzheimerbc.org/getdoc/1e32a61d-a00b-4294-969f-

daa4b0ec7a9d/Wandering.aspx

Alzheimer Society of Canada (2007). Restraints. Retrieved November 17, 2013, From http://www.alzheimer.ca/ /media/Files/national/brochures-toughissues/Tough_Issues_Restraints_2007_e.ashx

Alzheimer Society of Canada (2010). Rising tides. Retrieved October 12, 2012, From http://www.alzheimer.ca/on/ /media/Files/national/Advocacy/ASC_Rising\%20TideExecutive\%20Summary_Eng.ashx

Alzheimer Society of Canada (2012a). About Dementia. Retrieved September 20, 2012, From Http://www.Alzheimer.Ca/En/On/About-Dementia/Dementias/What-Is-Dementia/FactsAbout-Dementia

Alzheimer Society of Canada (2012b). Managing Wandering. Retrieved September 20, 2012, From http://www.alzheimer.ca/en/suroit/We-can-help/Living-Safely/managingwandering? $\mathrm{p}=1$

Alzheimer Society of Canada (2013a). Safely Home. Retrieved July 12, 2013, From http://www.alzheimer.ca/en/Living-with-dementia/Day-to-day-living/Safety/Safely-Home

Alzheimer Society of Canada (2013b). Understanding Behaviour. Retrieved October 1, 2013, From http://www.alzheimer.ca/en/About-dementia/Understanding-behaviour

Alzheimer Society of Canada (2013c). What is Alzheimer's disease. Retrieved October 1, 2013, from http://www.alzheimer.ca/en/About-dementia/Alzheimer-s-disease/What-is-Alzheimers-disease

Alzheimer Society of Toronto (2013). About Dementia. Retrieved November, 17 2013, From http://www.alzheimertoronto.org/ti_Restraints.htm

Alzheimer Society of UK (2013). Moving and walking about. Retrieved November 17, 2013, From http://www.alzheimers.org.uk/site/scripts/documents_info.php?documentID=152

Aud, M. a. (2004). Dangerous wandering: elopements of older adults with dementia from longterm care facilities. American journal of Alzheimer's disease and other dementias, 19(6), 361-8.

BKRC Art Effects (2013). Exit Diversion. Retrieved November 27, 2013, From http://bkrcarteffects.com/content/exit-diversion 
Braekhus, A., Oksengard, A.R., Engendal, K., Laake, K. (1998) Social and depressive stress suffered by spouses of patients with mild dementia. Scandinavian Journal of Primary Health Care, 16(4):242-246.

Brawley, E. (1992). Alzheimer's disease: designing the physical environment. American Journal of Alzheimer's Disease and Other Dementias, 7(1), 3-8.

Buchanan, J.A. and Fisher, J.E. (2002) Functional assessment and noncontingent reinforcement in the treatment of disruptive vocalization in elderly dementia patients, Journal of Applied Behavior Analysis, 35, 99-103

Bui, Y. N. (2009). How to write a master's thesis. Thousand Oaks, CA: Sage.

Calkins, M. P. ( 1988). Design for dementia. Owings Mills, MD: National Health

Carrillo, M. C., Dishman, E., \& Plowman, T. (2009). Everyday technologies for Alzheimer's disease care: Research findings, directions, and challenges. Alzheimer's \& dementia : the journal of the Alzheimer's Association, 5(6), 479-88.

Carswell, W., McCullagh, P. J., Augusto, J. C., Martin, S., Mulvenna, M. D., Zheng, H., ... Jeffers, W. P. (2009). A review of the role of assistive technology for people with dementia in the hours of darkness. Technology and health care: official journal of the European Society for Engineering and Medicine, 17(4), 281-304.

Cash, M. (2003). Assistive technology and people with dementia. Reviews in Clinical Gerontology, 13(4), 313-319.

CBC News (2011). Designing spaces for Alzheimer's patients. Retrieved October 12, 2012 From http://www.cbc.ca/news/health/story/2011/02/22/f-audio-goldman-interview-zeiselalzheimer.html

Chen, D., Wactlar, H., Chen, M. Y., Gao, C., Bharucha, A., \& Hauptmann, A. (2008, August). Recognition of aggressive human behavior using binary local motion descriptors. In Engineering in Medicine and Biology Society, 2008. EMBS 2008. 30th Annual International Conference of the IEEE (pp. 5238-5241). IEEE.

Cluff, P. J. (1990). Alzheimer's disease and the institution: Issues in environmental design. The American Journal of Alzheimerk Core and Related Disorders and Research, 5(3). 23-32

Cohen-Mansfield, J., \& Werner, P. (1998). The effects of an enhanced environment on nursing home residents who pace. The Gerontologist, 38(2), 199-208.

Community Care Access Center (2013). Eligibility and admission. Retrieved October 23, 2013, from http://healthcareathome.ca/centraleast/en/Getting-Care/Getting-Long-TermCare/Eligibility-and-Admission 
Coons, D. ( 1988). Wandering. The AmericanJournol of Alzheimerk Care and Related Disorders and Research, 3(1), 3 1-36

Creswell, J. W. (2013). Qualitative Inquiry \& Research Design: Choosing among Five Approaches. Thousand Oaks, Ca: Sage Publications.

Day, K., Carreon, D., \& Stump, C. (2000). The therapeutic design of environments for people with dementia: a review of the empirical research. The Gerontologist, 40(4), 397-416.

Desai, A.K., \& Grossberg, G.T. (2001). Recognition and management of behavioral disturbances in dementia. Primary Care Companion to the Journal of Clinical Psychiatry, 3(3), 93-109

Diaz-Ramirez, A., Murrieta, F. N., Atempa, J. a., \& Bonino, F. a. (2013). Non-intrusive Tracking of Patients with Dementia Using a Wireless Sensor Network. 2013 IEEE International Conference on Distributed Computing in Sensor Systems, 1(13), 460-465.

Dickinson, J., \& Mclain-kark, J. (1996). Wandering Behavior Associated with Alzheimer' s Disease and Related Dementias : Implications for Designers. Journal of Interior Design, 22(1), 32-38.

Dickinson, J. I., McLain-Kark, J., \& Marshall-Baker, A. (1995). The effects of visual barriers on exiting behavior in a dementia care unit. The Gerontologist, 35(1), 127-130.

Dorsten, A. M., Sifford, K. S., Bharucha, A., Mecca, L. P., \& Wactlar, H. (2009). Ethical perspectives on emerging assistive technologies: insights from focus groups with stakeholders in long-term care facilities. Journal of Empirical Research on Human Research Ethics: An International Journal, 4(1), 25-36.

Fisher, J.E. and Swingen, D.N. (1997) Contextual factors in the assessment and management of aggression in dementia patients, Cognitive and Behavioral Practice, 4, 171-90.

Flaherty, G., \& Scheft, J. (1995) Law enforcment, Alzheimer's Disease and the lost elder. Cambridge, MA: Alzheiemr's Association, Massachuset Chapter.

Fleming, R., Forbes, I., \& Bennett, K. (2003). Adapting the ward - for people with dementia. Sydney: NSW Department of Health.

Foxwell, L. G. (1993-1994). Elopement--exposure and control. The Journal of long term care administration, 21(4), 8.

Fratiglioni, L., Winblad, B., \& Von Strauss, E. (2007). Prevention of Alzheimer's Disease and Dementia. Major Findings from the Kungsholmen Project. Physiology \& Behavior, 92(1-2), 98-104 
Gori, G., Pientini, S., \& Vespa, A. (2001). The selection of meaningful activities as a treatment for day-care in dementia. Archives of Gerontology and Geriatrics, 33, 207-212.

Greiner, C., Makimoto, K., Suzuki, M., Yamakawa, M., \& Ashida, N. (2007). Feasibility study of the integrated circuit tag monitoring system for dementia residents in Japan. American journal of Alzheimer's disease and other dementias, 22(2), 129-36.

Hamilton, C. (1993). The use of tape patterns as an alternative method for controlling wanderers'exiting behavior in a dementia care unit. Unpublished master's thesis. Blacksburg: Virginia Polytechnic Institute and State University.

Heim K.M. (1986) Wandering behavior. Journal of Gerontological Nursing 12, 4-7.

Hewawasam, L. C. (1996). The use of two-dimensional grid patterns to limit hazardous ambulation in elderly patients with Alzheimer's disease. Nursing Times Research, 1(3), 217227.

Hoey, J., Plötz, T., Jackson, D., Monk, A., Pham, C., \& Olivier, P. (2011). Rapid specification and automated generation of prompting systems to assist people with dementia. Pervasive and Mobile Computing, 7(3), 299-318.

Houston, A. M., Brown, L. M., Rowe, M. a, \& Barnett, S. D. (2011). The informal caregivers' perception of wandering. American journal of Alzheimer's disease and other dementias, 26(8), 616-22.

Hughes, J. C., \& Louw, S. J. (2002). Electronic tagging of people with dementia who wander: ethical considerations are possibly more important than practical benefits. BMJ: British Medical Journal, 325(7369), 847.

Hanington, B. \& Martin, B. (2012). Universal Methods of Design: 100 Ways to Research Complex Problems, Develop Innovative Ideas, and Design Effective Solutions. Rockport Publishers.

Hussain, R. A.,\& Brown, D. C. (1987). Use of two-dimensional grid to limit hazardous ambulation in demented patients. Journal of Gerontology, 42, 558-560.

Hussian R. A., Davis R. L., (1985): Responsive Care: Behavioral Interventions with Elderly Persons. Champaign, IL: Research Press

Kim, K.-J., Hassan, M. M., Na, S.-H., \& Huh, E.-N. (2009). Dementia Wandering Detection and Activity Recognition Algorithm Using Tri-Axial Accelerometer Sensors. Proceedings of the 4th International Conference on Ubiquitous Information Technologies \& Applications, 1-5. 
Lai, C. K. Y. (2003). Wandering behaviour in people with dementia. Journal of advanced nursing, 44(2), 173-182.

Lawton, M. P., Fulcomer, M., \& Kleban, M. (1984.). Architecture for the mentally impaired elderly. Environment and Behaviour, 16: 730-757.

Library of Parliament (2012). Canada's Aging Population and Public Policy: 1. Statistical Overview. Retrieved May 1, 2013, From

http://www.parl.gc.ca/content/lop/researchpublications/2011-63-e.pdf

Library of Parliament (2012). Canada's Aging Population and Public Policy: 3. The Effects on Health Care. Retrieved May 1, 2013, From http://www.parl.gc.ca/Content/LOP/ResearchPublications/2011-122-e.pdf

Library of Parliament (2012). Canada's Aging Population and Public Policy: 6. The Effects on Home Care. Retrieved May 1, 2013, From http://www.parl.gc.ca/Content/LOP/ResearchPublications/2012-03-e.pdf

Lin, C. C., Chiu, M. J., Hsiao, C. C., Lee, R. G., \& Tsai, Y. S. (2006). Wireless health care service system for elderly with dementia. Information Technology in Biomedicine, IEEE Transactions on, 10(4), 696-704.

Lucero, M. (2002). Intervention strategies for exit-seeking wandering behavior in dementia residents. American Journal of Alzheimer's Disease and Other Dementias, 17(5), 277-280.

Ludwick, D. A., \& Doucette, J. (2009). Adopting electronic medical records in primary care: lessons learned from health information systems implementation experience in seven countries. International journal of medical informatics, $78(1), 22-31$.

Marshall, M. (2000). ASTRID: A guide to using technology within dementia care. London: Hawker Puplications, 31.

Martino-Saltzman, D., Blasch, B. B., Morris, R. D., \& McNeal, L. W. (1991). Travel behavior of nursing home residents perceived as wanderers and nonwanderers. The Gerontologist, 31(5), 666-672.

Melillo K: Wandering and technology devices. Helping caregivers ensure the safety of confused older adults. J Gerontol Nurs. 1998; 24(8): 32-38.

Miskelly, F. (2004). A novel system of electronic tagging in patients with dementia and wandering. Age and ageing, 33(3), 304-306.

Morchadze, L., Margvelashvili, V., \& Lobzhanidze, T. (2009). Investigation of Stomatologic Status of Middle-Aged and Elderly People in Western Georgia. Georgian Med News (177), $30-4$ 
Moustakas, C. (1994). Phenomenological Research Methods. Thousand Oaks, Ca: Sage Publications.

Muller, Claudia; Wan, Lin; Wulf, V. (2013). Dealing with Wandering in Institutional Care : Exploring the Field. In 7th International Conference on Pervasive Computing Technologies for Healthcare and Workshops (pp. 101-104).

Mulvenna, D, M., \& Nugent, C, D. (2010). Supporting People with Dementia Using Pervasive Health Technologies, London: Springer

Namazi K.H., Rosner T.T.\&Calkins M.P. (1989) Visual barriers to prevent ambulatory Alzheimer's patients from exiting through an emergency door. The Gerontologist, 29, 699702.

Nishigaki, Y., Tanaka, K., Kim, J., \& Nakajima, K. (2013). Development of an image processing support system based on fluorescent dye to prevent elderly people with dementia from wandering. In Conference proceedings : ... Annual International Conference of the IEEE Engineering in Medicine and Biology Society. IEEE Engineering in Medicine and Biology Society. Conference (Vol. 2013, pp. 7302-5)

Noell, E. (1995/1996). Design in nursing homes: Environment as a silent partner in caregiving. Generations, Winter, 19(4),14-19.

Nygard, L. (2004). Responses of persons with dementia to challenges in daily activities: A synthesis of findings from empirical studies. The American journal of occupational therapy, 58(4), 435-445.

Ontario Retirement Communities Association (2009). About The ORCA Accreditation Program. Retrieved June 1, 2012, From Http://www.Orcaretirement.Com/Public/Master.Php?Page=Res.

Peter A. Lichtenberg, Daniel L. Murman, Alan M. Mellow (2004). Handbook of Dementia: Psychological, Neurological, and Psychiatric Perspectives, Hoboken, NJ: John Wiley \& Sons

Pickard, A. J (2007). Research methods in information. London: Facet Publishing.

Price, J. D., Hermans, D. G., \& Grimley Evans, J. (2001). Subjective barriers to prevent wandering of cognitively impaired people. The Cochrane Database of Systematic Reviews, 1 .

Reddy, S. M., Chakrabarti, D., \& Karmakar, S. (2012). Emotion and interior space design: an ergonomic perspective. Work: A Journal of Prevention, Assessment and Rehabilitation, 41, 1072-1078. 
Rubin, E. H., Morris, J. C., Storandt, M., \& Berg, L. (1987). Behavioral changes in patients with mild senile dementia of the Alzheimer's type.Psychiatry research, 21(1), 55-62.

Rodriguez, J. (1993) Resident falls and elopement: Cost and controls. Nursing Homes, 42: 1617

Sanders, E. B., \& Stappers, P. J (2008). Co-creation and the new landscapes of design. Retrieved June 1, 2012, From http://www.maketools.com/articlespapers/CoCreation_Sanders_Stappers_08_preprint.pdf

Silverstein N, Flaherty G, Tobin T: Dementia and Wandering Behavior: Concern for the Lost Elder. New York: Springer, 2002.

Sixsmith, A., Hine, N., Neild, I., Clarke, N., Brown, S., \& Garner, P. (2007). Monitoring the well-being of older people. Topics in Geriatric Rehabilitation,23(1), 9-23.

Sternberg, E. M. (2009). Healing Spaces: The Science of Place and Wellbeing, London: Belknap Press of Harvard University Press

Suchman, L. A. (1987). Plans and situated actions: the problem of human-machine communication. Cambridge university press.

Tellis-Nayak, V. (2007). A person-centered workplace: the foundation for person- centered caregiving in long-term care. Journal of the American Medical Directors Association, 8, 4654

Tilly, J., \& Reed, P. (2008). Falls, wandering, and physical restraints: a review of interventions for individuals with dementia in assisted living and nursing homes. Alzheimer's Care Today, 9(1), 45-50.

Teri, L. (1997). Behavior and caregiver burden: Behavioral problems in patients with Alzheimer disease and its association with caregiver distress. Alzheimer Disease and Associated Disorders.

Thomas D. W. (1995) Wandering: a proposed definition. J Gerontol Nurs. 21: 35-41.

Thomas D. W. (1997). Understanding the wandering patient: A continuity of personality perspective. J Gerontol Nurs. 23(1): 16-24.

Torrington, J. (2006). What has architecture got to do with dementia care?: Explorations of the relationship between quality of life and building design in two EQUAL projects. Quality in Ageing and Older Adults, 7(1), 34-48.

United Nation Population Division. (2004). World Population in 2300. UN Department of Economic and Social Affairs 
Van Hoof, J., \& Kort, H. S. M. (2009). Supportive living environments: A first concept of a dwelling designed for older adults with dementia. Dementia, 8(2), 293-316.

Welsh, S., Hassiotis, A., O’Mahoney, G., \& Deahl, M. (2003). Big brother is watching you--the ethical implications of electronic surveillance measures in the elderly with dementia and in adults with learning difficulties. Aging \& mental health, 7(5), 372-375

Wigg, J. M. (2010). Liberating the wanderers: using technology to unlock doors for those living with dementia. Sociology of Health \& Illness, 32(2), 288-303.

Wimo A, Winblad B, Grafstrom M. (1999), The social consequences for families with Alzheimer's disease patients: Potential impact of mew drug treatment. International Journal of Geriatric Psychiatry, (14):338 - 47.

Windsor-Essex Project Lifesaver (2013). Overview. Retrieved May 4, 2013, From http://www.windsor-essexprojectlifesaver.com/

Yao, L., \& Algase, D. (2006). Environmental ambiance as a new window on wandering. Western journal of nursing research, 28(1), 89-104.

Youssef, M., Mah, M., \& Agrawala, A. (2007, September). Challenges: device-free passive localization for wireless environments. In Proceedings of the 13th annual ACM international conference on Mobile computing and networking (pp. 222-229). ACM.

Zajonc, R. B. (1980). Feeling and thinking preferences need no inferences. American Psychologist, 35, 151-175.

Zeisel, J., Silverstein, N. M., Hyde, J., Levkoff, S., Lawton, M. P., \& Holmes, W. (2003). Environmental correlates to behavioral health outcomes in Alzheimer's special care units. The Gerontologist, 43(5), 697-711. 


\section{APPENDIX A - EXPERTS INTERVIEWS}

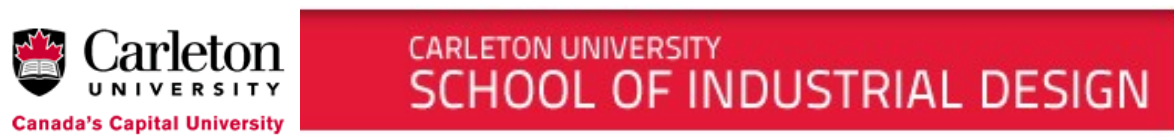

CONSENT FORM

\section{INVESTIGATING EXIT-SEEKING INTERVENTIONS FOR RESIDENTS WITH ALZHEIMER'S DISEASE IN INSTITUTIONAL CARE}

$\mathrm{I}$, (participant's name), understand that I am

being asked to participate in this study that forms part of Dea Attar required Masters' thesis work at the School of Industrial Design, Carleton University. The purpose of the study is to make recommendations and set up the guidelines for improving the features of assistive technological solutions for persons with Alzheimer's' disease.

It is my understanding that this interview will cover the following subjects or topics:

- Persons with Alzheimer's disease Wandering behavior

- Wandering prevention tools review and comparison

- The relationship between the patients and the interior space

The researcher has explained the purpose and the process of this study. I have been given the opportunity to ask questions, which the researcher has addressed to my satisfaction.

I understand that I am free to withdraw my consent and discontinue my participation in this study at any time prior to or at any point during the interview and until March the 15th. I understand that I can choose to answer only the questions that I wish to answer. I can ask to have any data that I have contributed removed from the study if I withdraw.

I understand that the interview will be audio-taped and then transcribed.

I understand that the audio-recordings and transcripts will be kept in a password protected files and can only be accessed by the research and her supervisor. The data will be kept for 2 years and then be deleted permanently.

I understand that all information obtained in this study will be kept strictly confidential and anonymous unless permission is given by the interviewee to the researcher for a specific context.

I agree that researcher may publish documents that contain quotations by me under a made-up name and I will remain anonymous. 
The results of this study will be presented collectively and no individual participants will be identified without their permissions.

To thank you for volunteering, small gift baskets will be provided to all participants in appreciation of their time and effort.

By signing this consent form, you are indicating that you fully understand the above information and agree to participate in this study.

Participant's signature

Date:

Researcher's signature:

Date:

If you have any questions or concerns about this study, please contact Dea Attar by email at deaattar@cmail.carleton.ca, and/or Lois Frankel by e-mail at lois_frankel@carleton.ca.

This research has been reviewed and approved by Carleton University Research Ethics Board Tel: (613) 520-2517

1325 Dunton Tower, Carleton University

1125 Colonel By Drive, Ottawa, Ontario, Canada K1S 5B6 


\section{PARTICIPANTS}

4 Caregivers In-person

1 Activity Coordinator In-person

2 Program Managers In-person

1 Founder-Director By phone 


\section{INTERVIEW QUESTIONS}

1. How long have you been working with dementia and Alzheimer's disease patients?

2. a) What is wandering and how would it affect the quality of life?

b) In general, which of the following behaviors can wandering be associated with, please explain your answers and provide example?

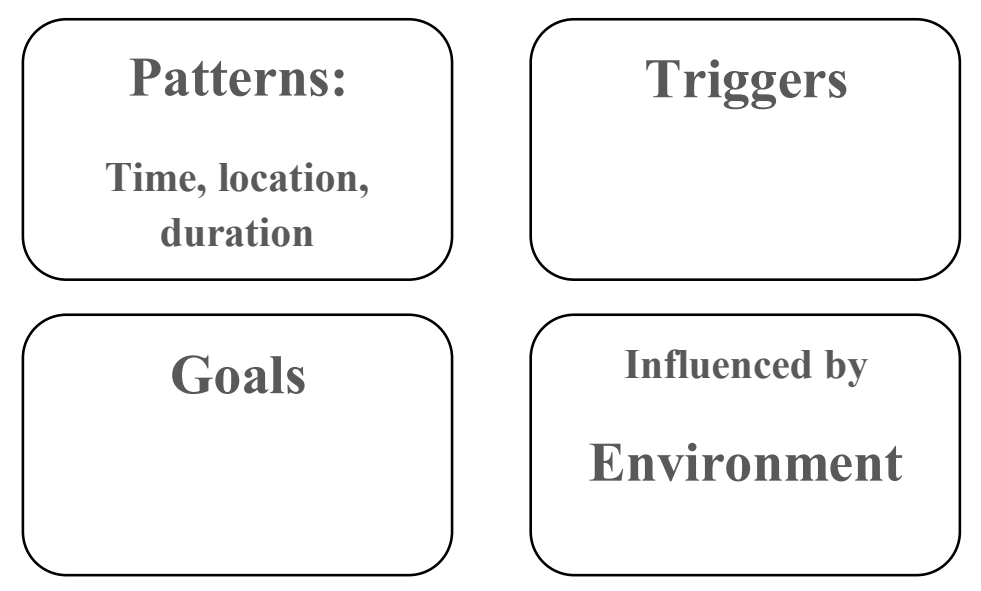

c) Is there a difference between wandering at home and wandering in long-term care facilities?

3- a) What are the wandering prevention tools available for home care and institutional care?

b) Review these prevention tools (cards) in terms of:

- The context in which each tool is used

- The effectiveness of each tool

- The limitations of each tool

- Specific design elements that make each tool user friendly or not

- How often is each tool used, and by who

- What can be done to improve each tool

- Provide a ranking of tools popularities with explanations 


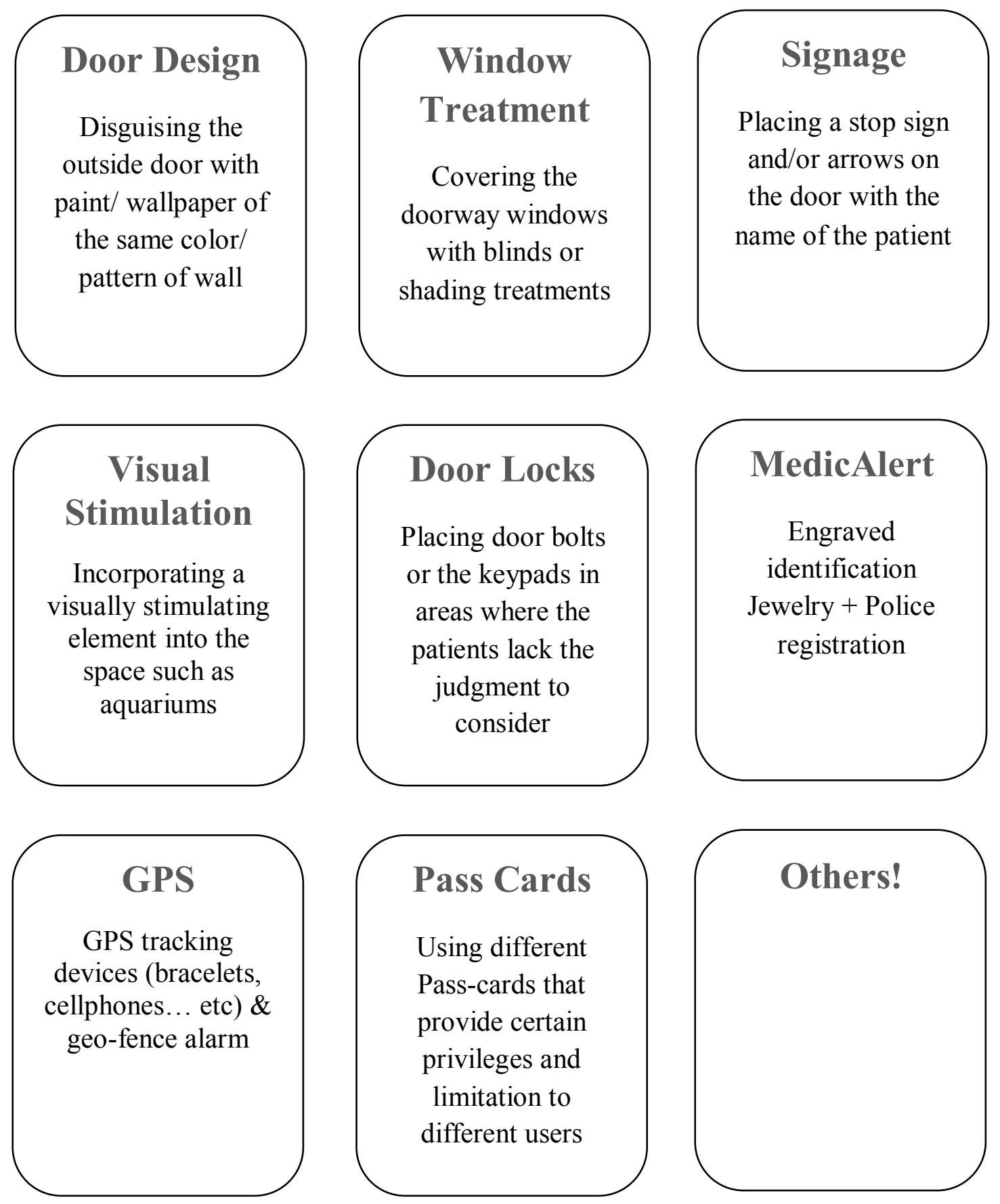

4- a) Which of the following do patients show interest in? Please provide explanations?
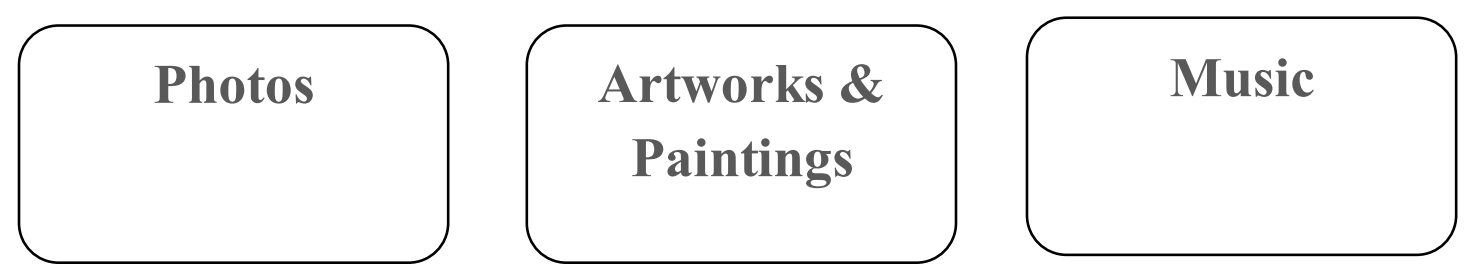

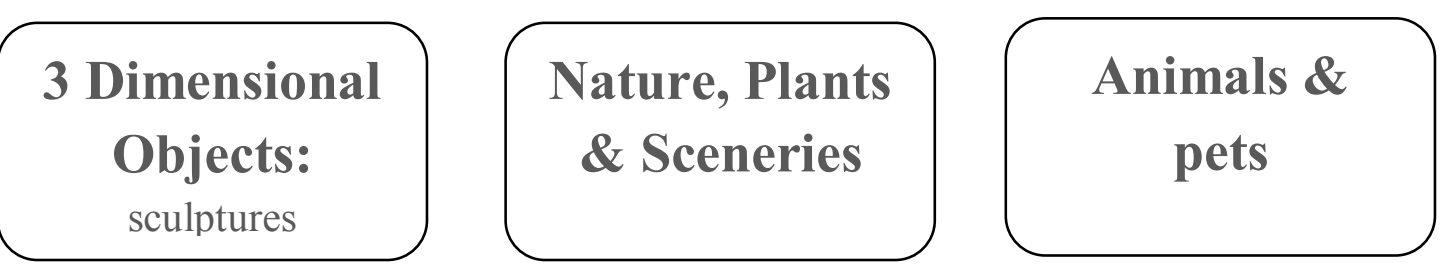

\section{TV shows:}

Hockey, ballet, cooking

b) What elements of the environment/ interior space can patients get frustrated with?

c) Which of the following elements are patients more sensitive to? Please arrange them in order and provide examples
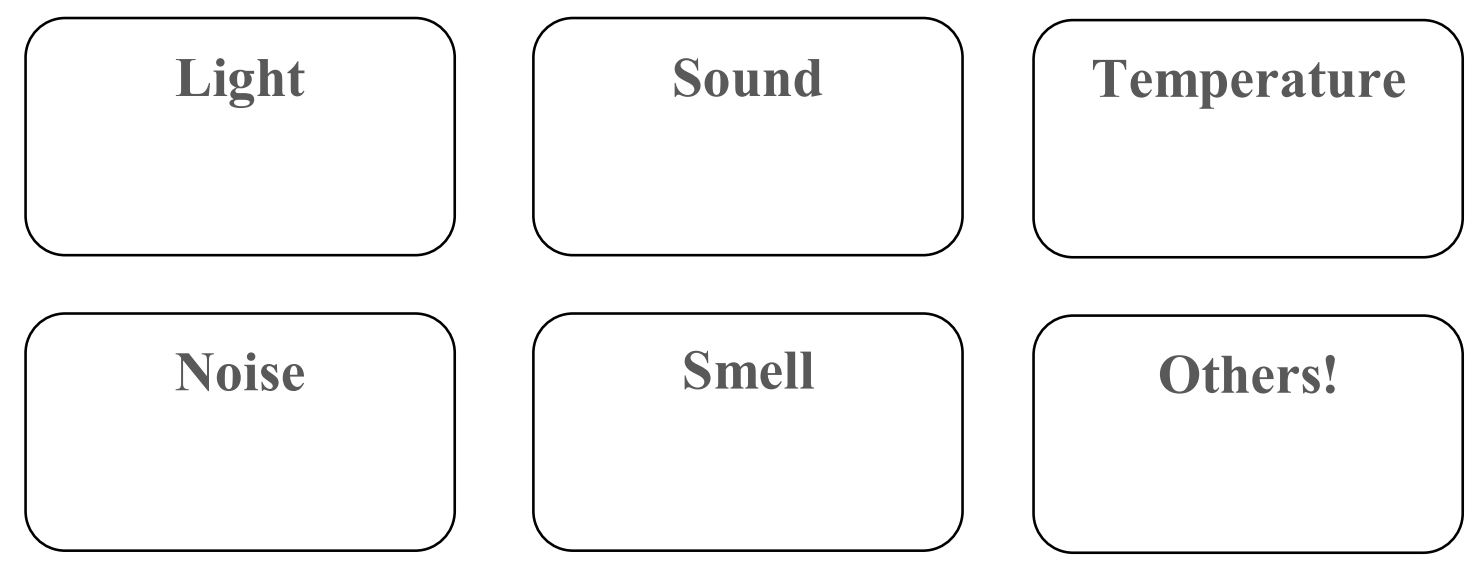

d) What type of activities do patients enjoy doing or participating in?

5- What do persons with AD wear on daily basis (including accessories and jewelry)? 


\section{APPENDIX B - FAMILY INTERVIEWS}

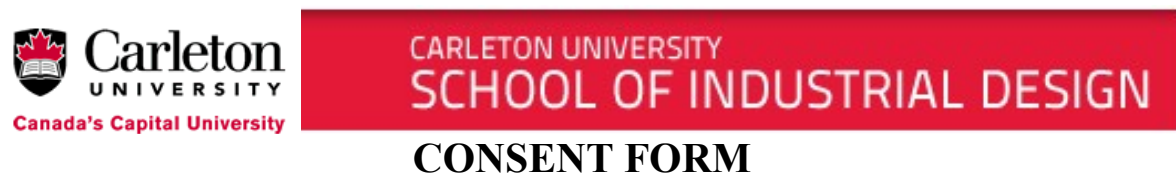

\section{INVESTIGATING EXIT-SEEKING INTERVENTIONS FOR RESIDENTS WITH ALZHEIMER'S DISEASE IN INSTITUTIONAL CARE}

$\mathrm{I}$, (participant's name), understand that I am being asked to participate in this study that forms part of Dea Attar required Masters' thesis work at the School of Industrial Design, Carleton University. The purpose of the study is to make recommendations and set up the guidelines for improving the features of assistive technological solutions for persons with Alzheimer's' disease.

It is my understanding that this interview will cover the following subjects or topics:

- What is wandering for caregivers?

- Objects of interest to persons with Alzheimer's disease

- The relationship between persons with Alzheimer's disease, the technology and the physical space

The researcher has explained the purpose and the process of this study. I have been given the opportunity to ask questions, which the researcher has addressed to my satisfaction.

I understand that I am free to withdraw my consent and discontinue my participation in this study at any time prior to or at any point during the interview and until April the 10th. I understand that I can choose to answer only the questions that I wish to answer. I can ask to have any data that I have contributed removed from the study if I withdraw.

I understand that the interview will be audio-taped and then transcribed.

I understand that the audio-recordings and transcripts will be kept in a password protected files and can only be accessed by the research and her supervisor. The data will be kept for 2 years and then be deleted permanently.

I understand that all information obtained in this study will be kept strictly confidential and anonymous unless permission is given by the interviewee to the researcher for a specific context. 
I agree that researcher may publish documents that contain quotations by me under a made-up name and I will remain anonymous.

The results of this study will be presented collectively and no individual participants will be identified without their permissions.

To thank you for volunteering, $\$ 10$ gift-cards will be provided to all participants in appreciation of their time and effort.

By signing this consent form, you are indicating that you fully understand the above information and agree to participate in this study.

Participant's signature

Date:

Researcher's signature:

Date:

If you have any questions or concerns about this study, please contact Dea Attar by email at deaattar@cmail.carleton.ca, and/or Lois Frankel by e-mail at lois_frankel@carleton.ca.

This research has been reviewed and approved by Carleton University Research Ethics Board

Tel: (613) 520-2517

1325 Dunton Tower, Carleton University

1125 Colonel By Drive, Ottawa, Ontario, Canada K1S 5B6 


$\begin{array}{lll}1 & \text { Daughter } & \text { AD } \\ 2 & \text { Sons } & \text { AD } \\ 1 & \text { Daughter } & \text { VD } \\ 1 & \text { Spouse } & \text { AD }\end{array}$




\section{INTERVIEW QUESTIONS}

1- a) How would you define Alzheimer's disease?

b) How would you compare your life before and after your loved one was diagnosed with AD? (Routines, work, activities)

c) Arrange the following consequences based of their seriousness, please explain why.
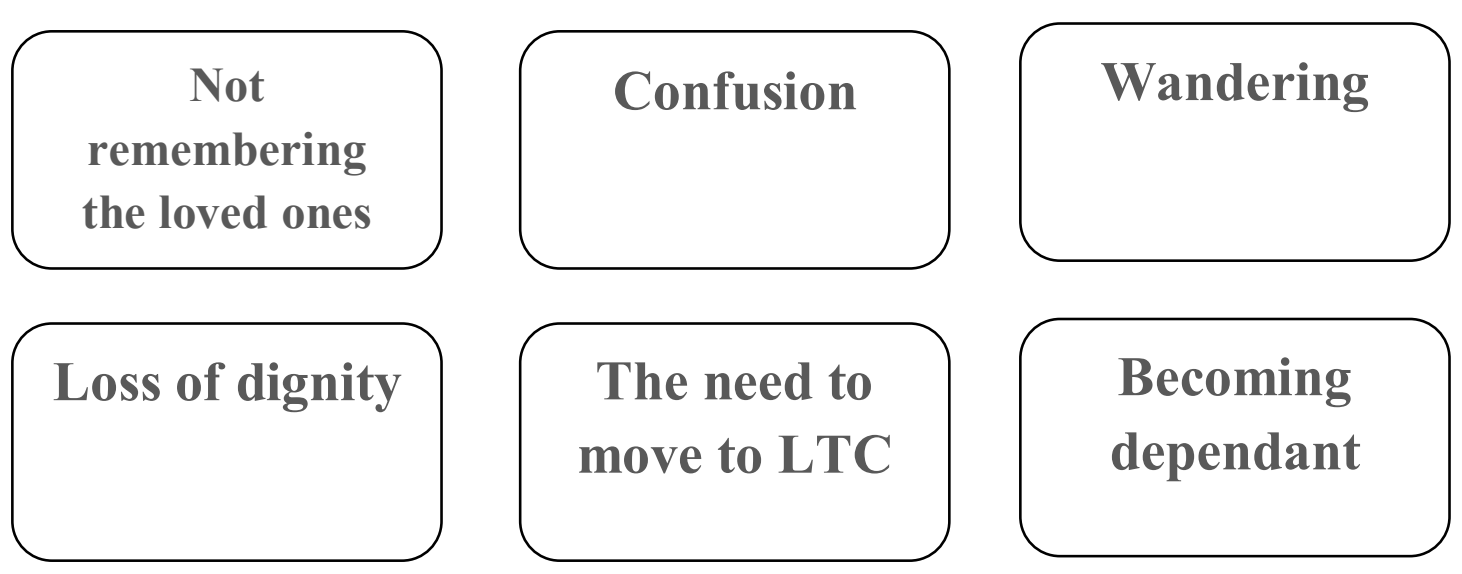

2- a) How would you define wandering?

b) How many times does your loved one wander per day/week/month?

c) On averages, which of the following behaviors can your loved one wandering be associated with, please explain your answers?

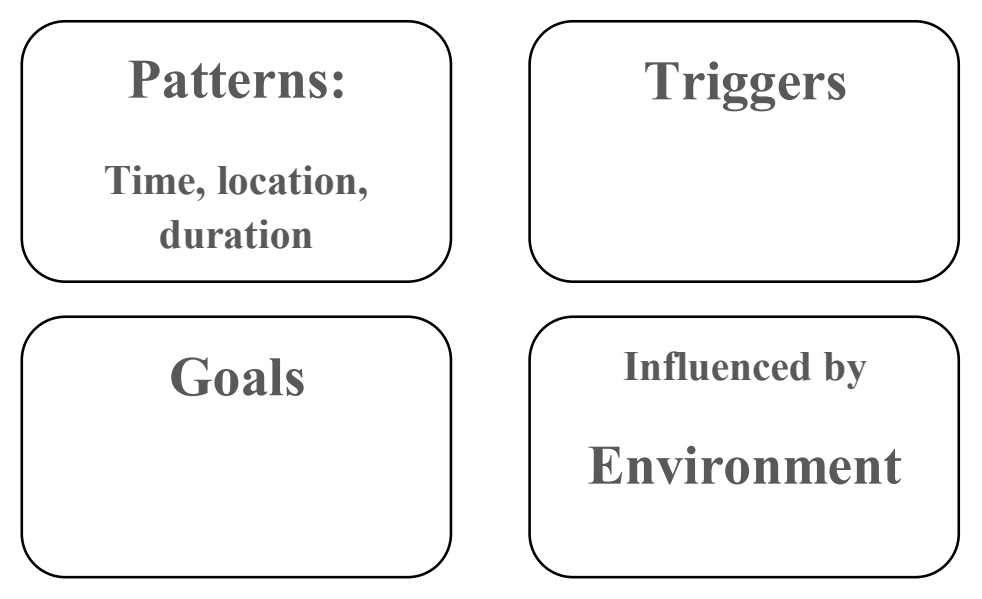


d) What do you do when your family member wanders? / To cope with the disease, what type of interventions or interior modifications do you use?

3- Which of the following elements is your partner more sensitive to? Please arrange them in order and provide examples
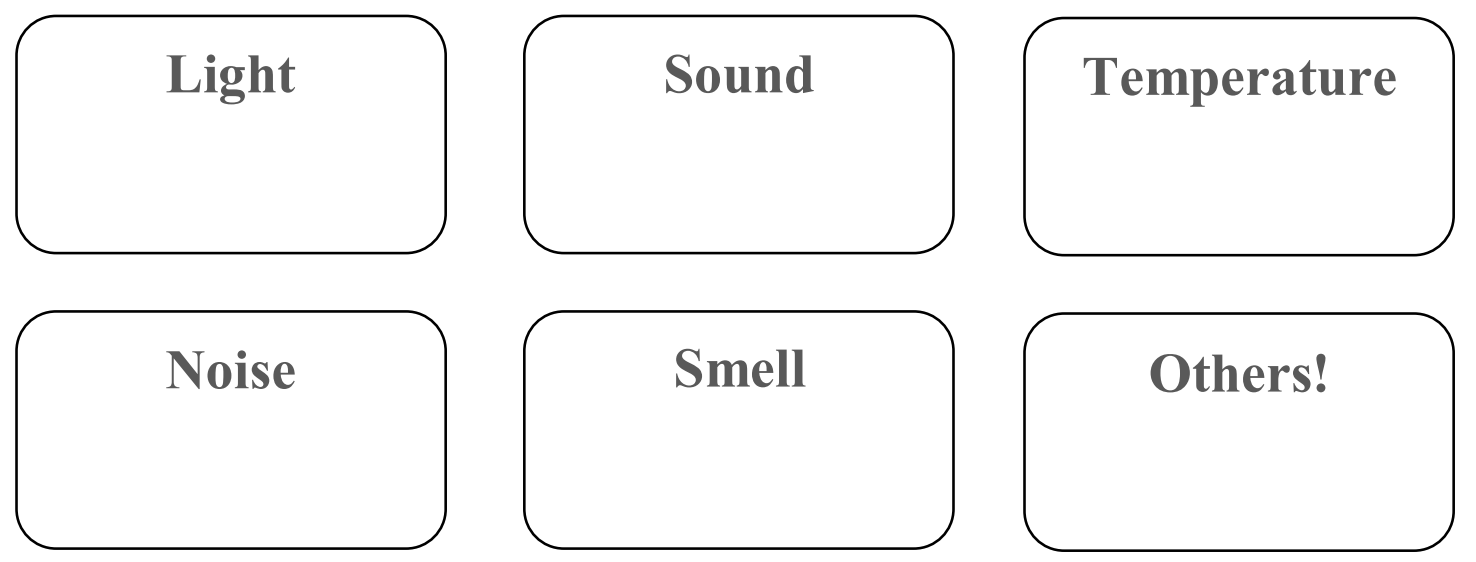

4- Which of the following does your partner show interest in? Please arrange them in order and explain why?
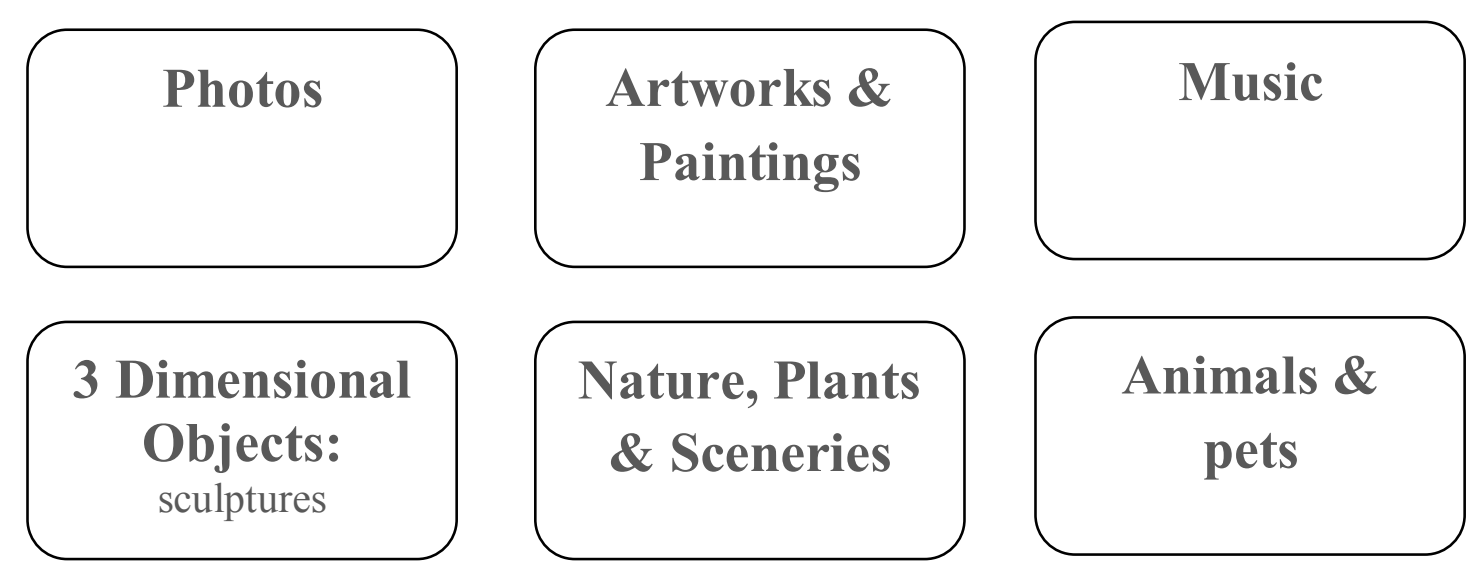

TV shows:

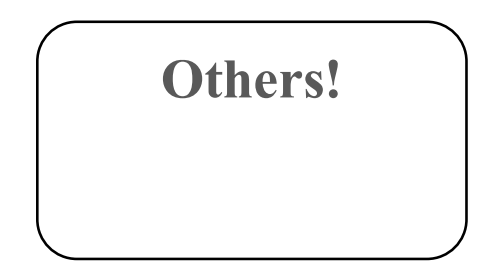

Hockey, ballet, cooking shows

5- What type of activities does your partner enjoy?

6- a) Which of the following gadgets do you (you and your loved one) own and use: 

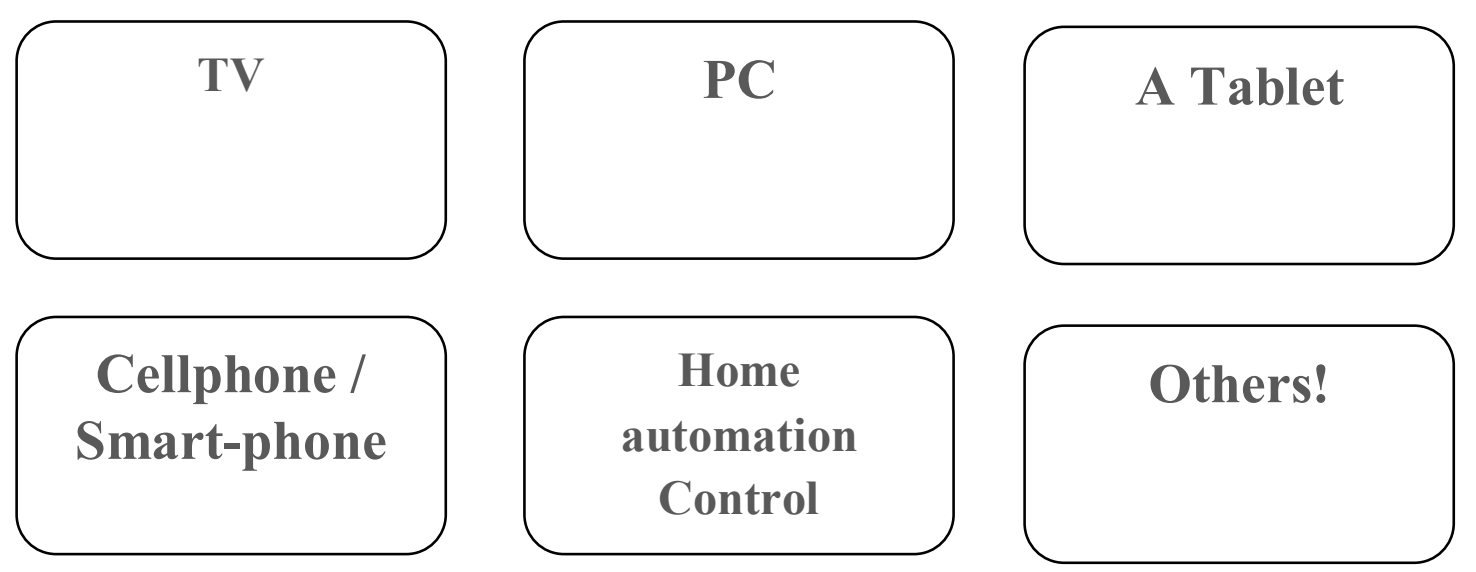

b) How do you feel about using the technology (Love VS. hate)? Please explain why

7- What does your partner wear on daily basis (including accessories and jewelry) 


\section{APPENDIX C - ARTISTS INTERVIEWS}

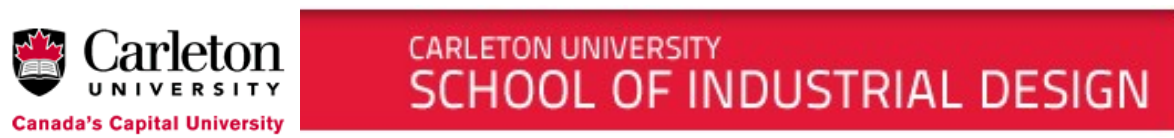

CONSENT FORM

\section{INVESTIGATING EXIT-SEEKING INTERVENTIONS FOR RESIDENTS WITH ALZHEIMER'S DISEASE IN INSTITUTIONAL CARE}

$\mathrm{I}$, (participant's name), understand that I am being asked to participate in this study that forms part of Dea Attar required Masters' thesis work at the School of Industrial Design, Carleton University. The purpose of the study is to make recommendations and set up the guidelines for improving the features of assistive technological solutions for persons with Alzheimer's' disease.

It is my understanding that this interview will cover the topic of door camouflage.

The researcher has explained the purpose and the process of this study. I have been given the opportunity to ask questions, which the researcher has addressed to my satisfaction.

I understand that I am free to withdraw my consent and discontinue my participation in this study at any time prior to or at any point during the interview and until April the 10th. I understand that I can choose to answer only the questions that I wish to answer. I can ask to have any data that I have contributed removed from the study if I withdraw.

I understand that the interview will be audio-taped and then transcribed.

I understand that the audio-recordings and transcripts will be kept in a password protected files and can only be accessed by the research and her supervisor. The data will be kept for 2 years and then be deleted permanently.

I understand that all information obtained in this study will be kept strictly confidential and anonymous unless permission is given by the interviewee to the researcher for a specific context.

I agree that researcher may publish documents that contain quotations by me under a made-up name and I will remain anonymous.

The results of this study will be presented collectively and no individual participants will be identified without their permissions. 
By signing this consent form, you are indicating that you fully understand the above information and agree to participate in this study.

Participant's signature

Date:

Researcher's signature:

Date:

If you have any questions or concerns about this study, please contact Dea Attar by email at deaattar@cmail.carleton.ca, and/or Lois Frankel by e-mail at lois_frankel@carleton.ca.

This research has been reviewed and approved by Carleton University Research Ethics Board

Tel: (613) 520-2517

1325 Dunton Tower, Carleton University

1125 Colonel By Drive, Ottawa, Ontario, Canada K1S 5B6

PARTICIPANTS

2 Professional Artists By phone

1 Amateur Artist + Caregiver In-person 


\section{INTERVIEW QUESTIONS}

1. Can you give me a short overview of your experience with dementia and Alzheimer's?

2. Can you explain to me the technique of disguising the doors with camouflage?

3. Who initiate the call of covering a certain door with paintings?

4. How do you choose which door is one you need to cover?

5. How do you choose the topic of the camouflage painting?

6. Is there some sort of analysis you do before choosing the topic, the layout, the dimensions and the expansion of the painting?

7. Why do you choose performing real paintings rather than huge size photograph of the same topic?

8. How do you deal with the issue of the door handles?

9. How do you deal with the issue of the exit sign that are required by the city law?

10. How do you deal with the door frame issue?

11. In your opinion, how effective is the door camouflage in deterring wandering?

12. Over the past couple years, you have performed numerous door designs, which ones were the most effective and for what reasons?

13. Have you ever done this camouflage in the households of people with Alzheimer's or is it mainly for long-term care?

14. I noticed that the paintings are so detailed; the books, the ornaments, the plats. Is there a reason for it?

15. I noticed that the camouflage drawing and painting styles are similar to the first colored print newspaper (early to mid the 20st century). Is there a reason for it?

16. How do you maintain the camouflage?

17. What is the best way to address the door camouflages so the patients wouldn't notice the doors? Can you provide me with recommendations/ considerations? 


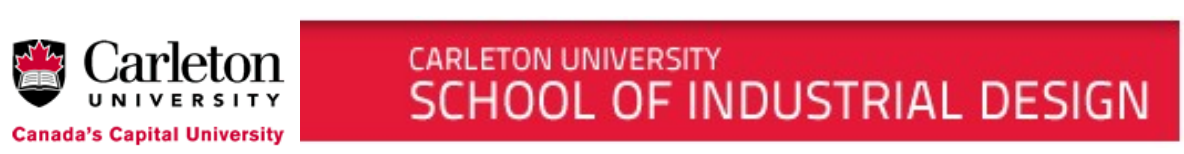

CONSENT FORM

\section{INVESTIGATING EXIT-SEEKING INTERVENTIONS FOR RESIDENTS WITH ALZHEIMER'S DISEASE IN INSTITUTIONAL CARE}

$\mathrm{I}$, (participant's name), understand that I am being asked to participate in this study that forms part of Dea Attar required Masters' thesis work at the School of Industrial Design, Carleton University. The purpose of the study is to make recommendations and set up the guidelines for improving the features of assistive technological solutions for persons with Alzheimer's' disease.

It is my understanding that this workshop will cover the following subjects or topics:

- What is wandering to caregivers?

- How do they deal with it?

- How can they be helped when it occurs?

The researcher has explained the purpose and the process of this study. I have been given the opportunity to ask questions, which the researcher has addressed to my satisfaction.

I understand that I am free to withdraw my consent and discontinue my participation in this study at any time prior to or at any point during the workshop and until August the 31st. I understand that I can choose to participate in the activities that I wish to collaborate in and answer only the questions that I wish to answer. I can ask to have any data that I have contributed removed from the study if I withdraw.

I understand that all information obtained in this study will be kept strictly confidential and anonymous unless permission is given by the interviewee to the researcher for a specific context.

I understand that this workshop will be video recorded for the purpose of analyzing the data only and no video of me will be published or accessed by anyone except of the researcher and her supervisor.

I understand that the video-recordings will be kept in a password protected files and can only be accessed by the research and her supervisor. The data will be kept for 2 years and then be deleted permanently. 
I agree that researcher may publish documents that contain quotations by me under a made-up name and I will remain anonymous.

The results of this study will be presented collectively and no individual participants will be identified without their permissions.

To thank you for volunteering, parking/bus fees will be covered in appreciation of the participants' time and effort.

By signing this consent form, you are indicating that you fully understand the above information and agree to participate in this study.

Participant's signature

Date:

Researcher's signature:

Date:

If you have any questions or concerns about this study, please contact Dea Attar by email at deaattar@cmail.carleton.ca, and/or Lois Frankel by e-mail at lois_frankel@carleton.ca.

This research has been reviewed and approved by Carleton University Research Ethics Board

Tel: (613) 520-2517

1325 Dunton Tower, Carleton University

1125 Colonel By Drive, Ottawa, Ontario, Canada K1S 5B6 


\section{PARTICIPANTS}

1 Daughter + Volunteer Caregiver

VD

1 Son

AD

1 Son + Volunteer Caregiver

$A D$

1 Granddaughter + Formal Caregiver

$A D$ 


\section{EXERCISE INSTRUCTIONS}

\section{Exercise one - the WHY exercise}

Why do people with AD [Alzheimer's Disease] exit seek?

1) Check the CAUSES cards and rank them with your partner based on their likelihood to be the reasons behind exit seeking.

2) Open discussion between groups.

\section{Exercise two - the HOW exercise}

How do people with AD exit seek?

1) As a pair, choose the TWO highly-ranked CAUSES of exit seeking to continue with throughout the workshop.

2) With your partner, prepare two stories in which a person with $\mathrm{AD}$ exit seeks because of the reasons you've chosen earlier. (Plan to act out the scenarios using the dementia mock-up unit for the next task)

Note: - The scenarios start point: reasons behind exit-seeking

- The scenarios persona: an Alzheimer's disease patient

3) Act out the scenarios using the mock-up unit to the other group and explain how you usually deal with this behavior (solutions, interventions, reactions... etc). 
What type of stuff can people with AD relate to?

1) With your partner, check the STUFF cards and differentiate between the STUFF that residents relate to SPONTANEOUSLY and the STUFF that REQUIRE CAREGIVERS GUIDANCE.

Relate means Process with or without the guidance of caregiver; respond to; capture their attention

2) Rank these cards within each of the previous categories based on their effectiveness

3) Open discussion between groups

\section{Exercise four - the MAGIC exercise}

If you were to design a magic solution/tool to deter exit-seeking, what would it do?

1) Building on the STUFF you've pointed out their effectiveness in the $3^{\text {rd }}$ exercise, design two magical tools that can deter the two exit seeking scenarios you've portrayed in the $2^{\text {nd }}$ exercise:

- What would your magical solutions be?

- What are their functions?

- How would they work in context?

- What sort of input(s) they require to work and what sort of output(s) they generate?

2) Using the craft materials provided, make a rough mock-up of your magical tools.

3) Act out your magic scenarios using the dementia mock-up unit and make sure you point out the magical solutions locations (e.g. stationary, mobile or wearable). You can also illustrate by drawing a story board. 


\section{APPENDIX E - VISUAL SURVEY}

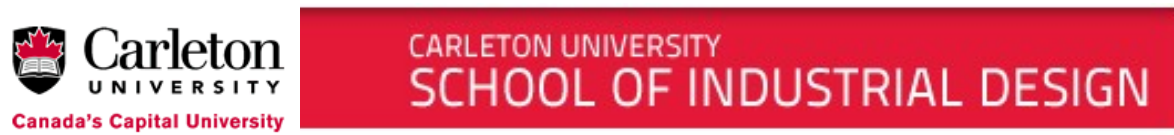

CONSENT FORM

\section{INVESTIGATING EXIT-SEEKING INTERVENTIONS FOR RESIDENTS WITH ALZHEIMER'S DISEASE IN INSTITUTIONAL CARE}

This study is a part of a Master's thesis that investigates how assistive technologies can be designed to deter the exit seeking behavior of those who suffer from Alzheimer's disease and other dementias in Long-term care facilities, and at the same time match the needs and expectations of caregivers and family members.

Your participation in this study is voluntary. You may choose not to participate or not to answer any question. If you decide to participate in this research, you may withdraw at any time during the survey or after and until October the $15^{\text {th }}$.

All information obtained in this study will be kept strictly confidential and anonymous. The results of this questionnaire will be presented collectively and no individual participants will be identified without their permissions.

The survey will take approximately 15 minutes to complete.

The survey will be audio-taped and then transcribed as you will be asked to think aloud when answering the questions.

By signing this consent form, you are indicating that you fully understand the above information and agree to participate in this study.

Participant's Name

Participant's signature

Date:

If you have any questions or concerns about this study, please contact the research Dea Attar by email at deaattar@cmail.carleton.ca, and/or Professor Lois Frankel by e-mail at lois_frankel@carleton.ca.

This research has been reviewed and approved by Carleton University Research Ethics Board 
Professor Andy Adler, Chair

Tel: (613) 520-2517

1325 Dunton Tower, Carleton University

1125 Colonel By Drive, Ottawa, Ontario, Canada K1S 5B6

10 Personal Support Workers

6 Registered Nurses

2 Healthcare Assistants 


\section{SURVEY QUESTIONS}

\section{A) Please complete the following information}

- Occupation/ position:

- Years of experience:

- Gender:

- Age:

- Highest level of education:

- How do you assess your familiarity with technology?

\begin{tabular}{|c|c|c|c|c|}
\hline Very familiar & & & & Not Familiar \\
\hline $\mathbf{5}$ & $\mathbf{4}$ & $\mathbf{3}$ & $\mathbf{2}$ & $\mathbf{1}$ \\
\hline$\circ$ & 0 & 0 & 0 & 0 \\
\hline
\end{tabular}

- What sort of devices/appliances do you regularly use?

(Digital camera, Mp3 player, Smartphone, GPS, house security system... etc)

B) Please examine each of the following scenarios and share your opinion about theses interventions in terms of... 


\section{1- Intervention: DOOR PANELS}
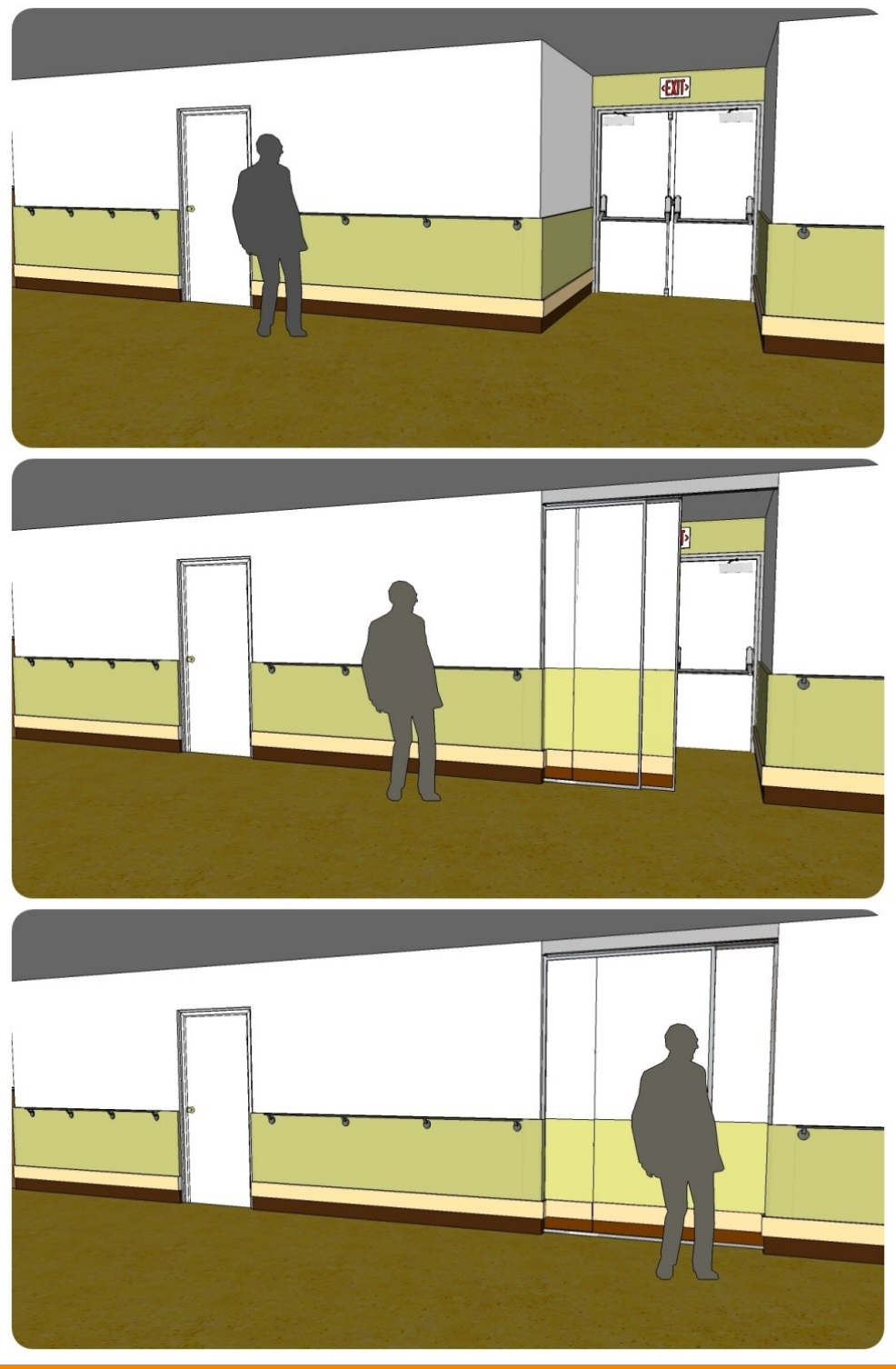

Strongly agree

5

Effectiveness

Ease of use

Suitability to environment

$\circ$
$\circ$
$\circ$

Strongly disagree

- What would you change about it? 


\section{2- Intervention: TROMPE L'OEIL CLIFF}
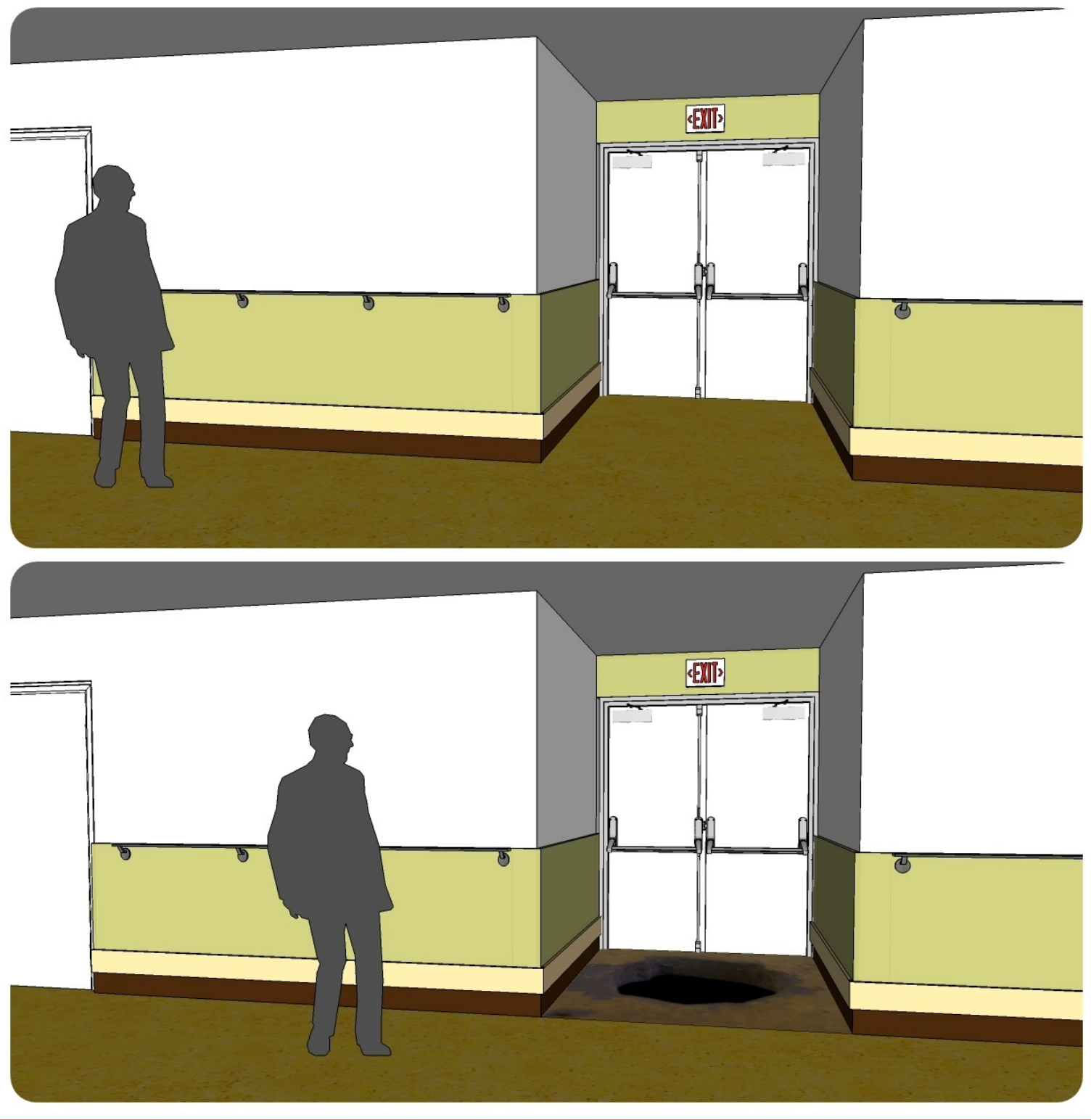

Strongly agree

5

Effectiveness

Ease of use

Suitability to environment

0
0
0

0
0
0

- What would you change about it? 


\section{3- Intervention: A HOLOGRAM}
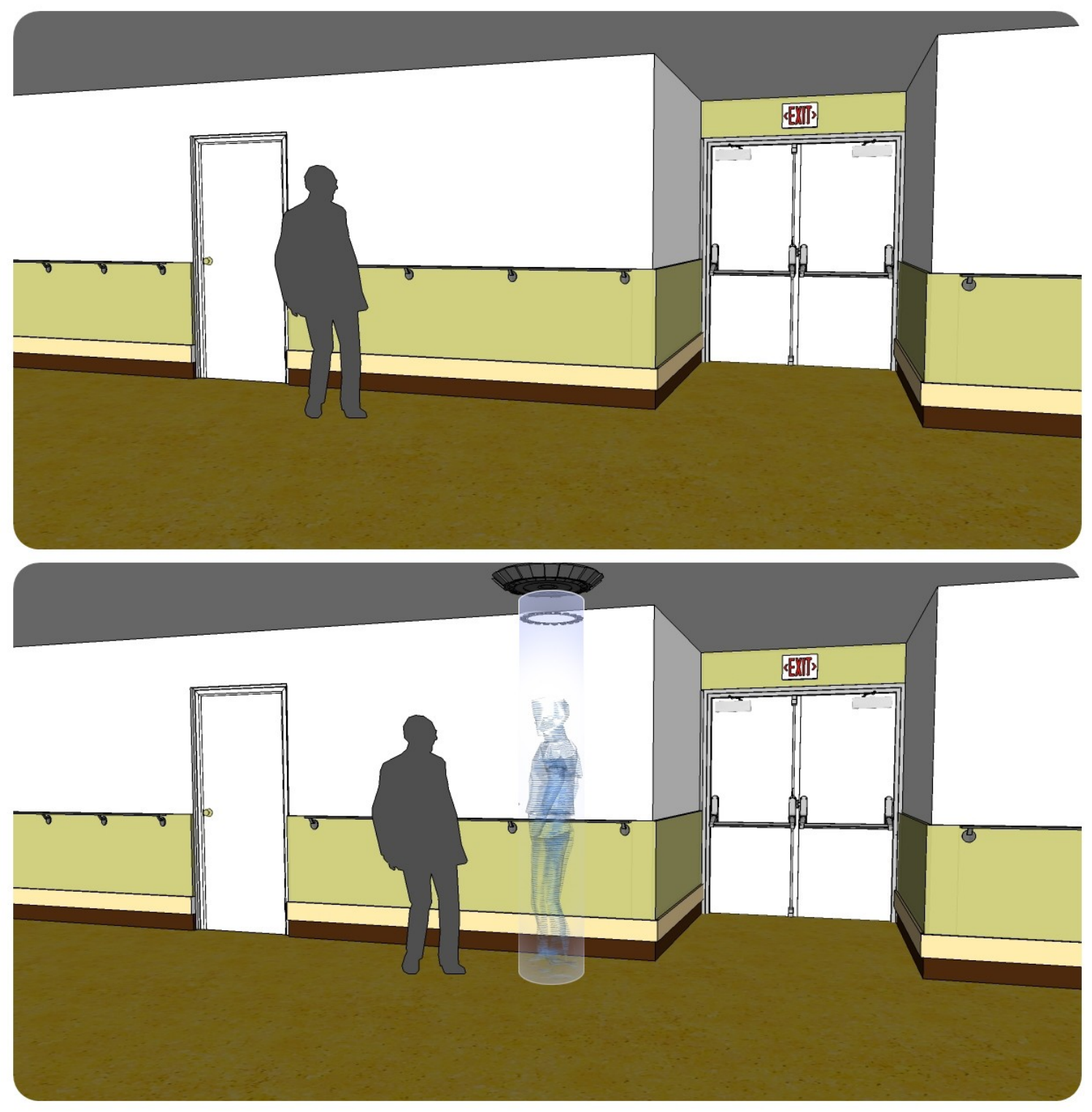

Strongly agree

5

Effectiveness

Ease of use

Suitability to environment
4

3

0
0
0

○
Strongly disagree

- What would you change about it? 


\section{4- Intervention: HIGH-PITCHED ALARM}
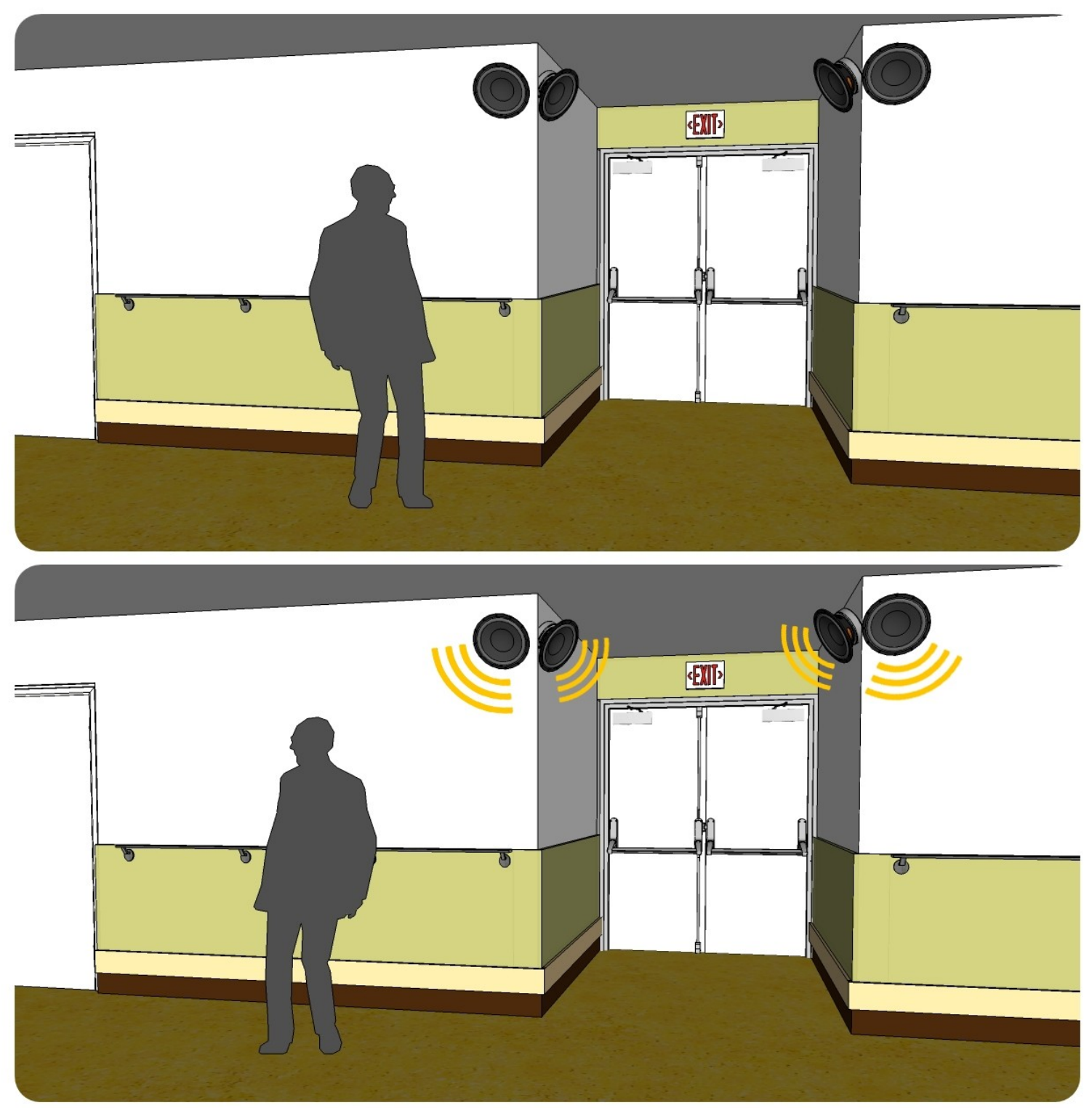

Strongly agree

5

Effectiveness

Ease of use

Suitability to environment

0
0
0

4

3

Strongly

disagree

2

1

○

○

0

0

0

○

$\circ$

$\circ$

- What would you change about it? 


\section{5- Intervention: COLORED LIGHTS}
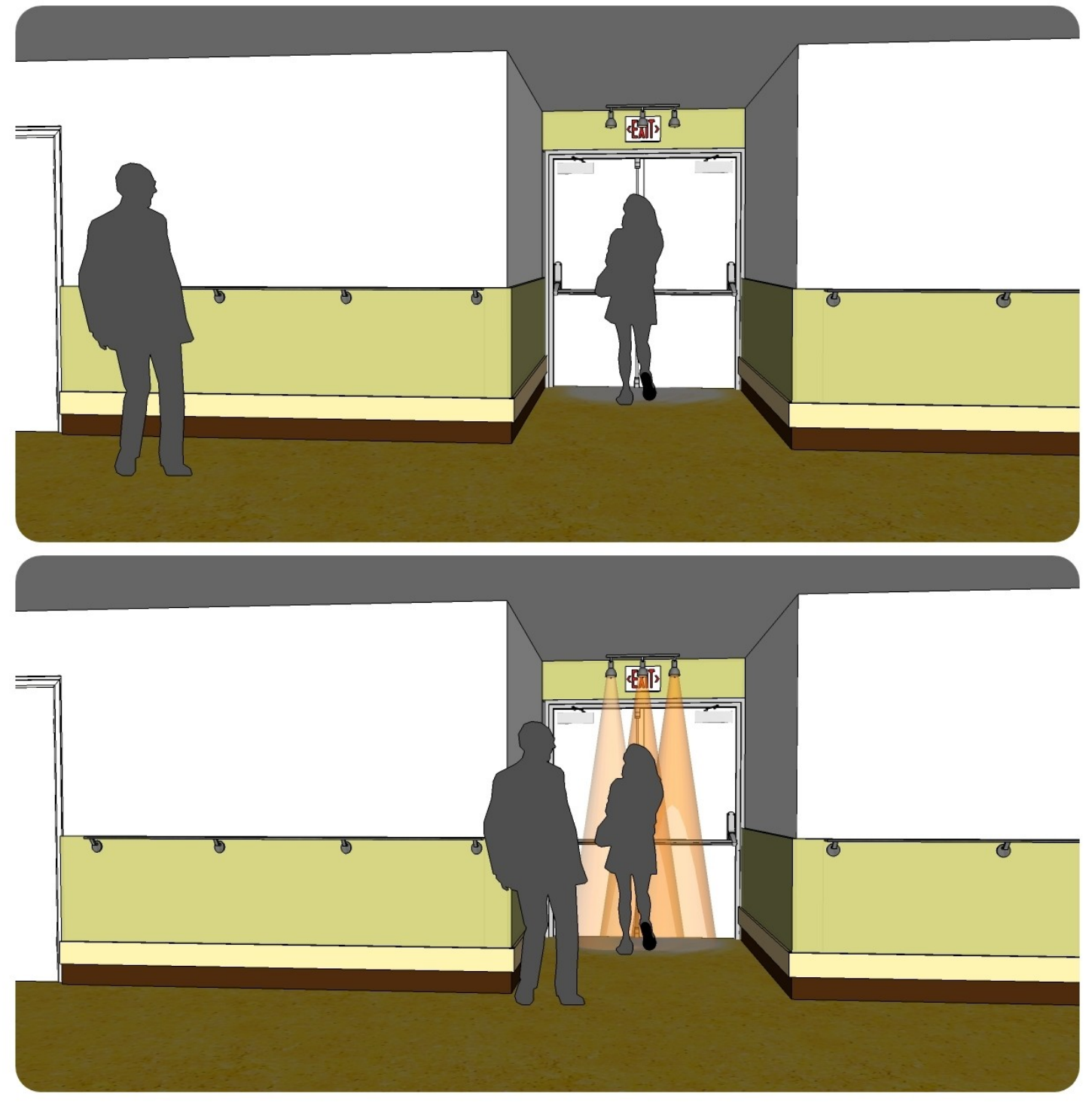

Strongly agree

5

Effectiveness

Ease of use

Suitability to environment

0
0
0

4

3

Strongly

disagree

2

1

0

$\circ$

○

0

○

0

○

$\circ$

$\circ$

- What would you change about it? 
6- Intervention: VIDEO CALL
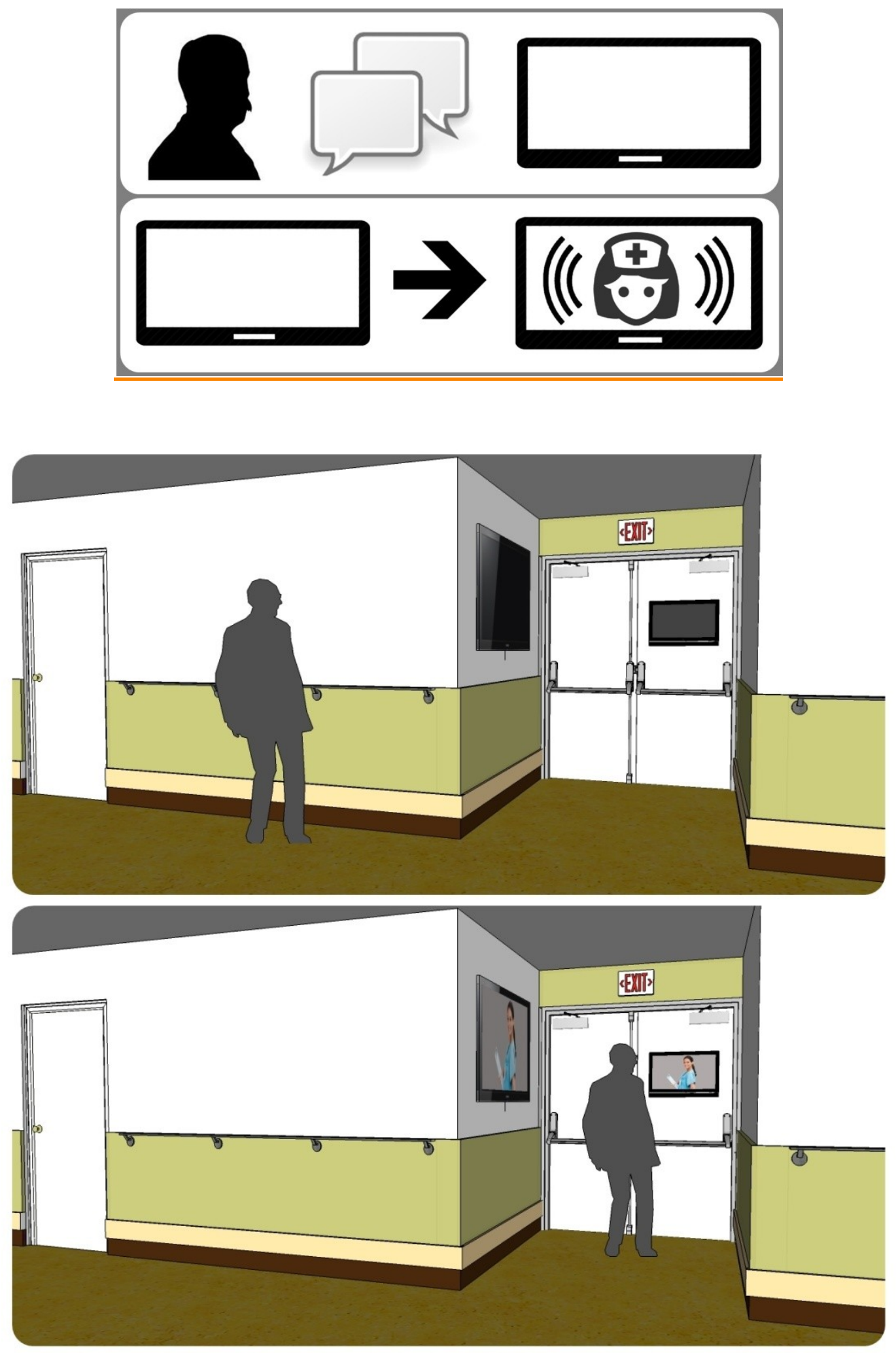
Strongly agree

5

4

Strongly disagree

- What would you change about it?

\section{7- Intervention: VIDEO WALL STATIONS}
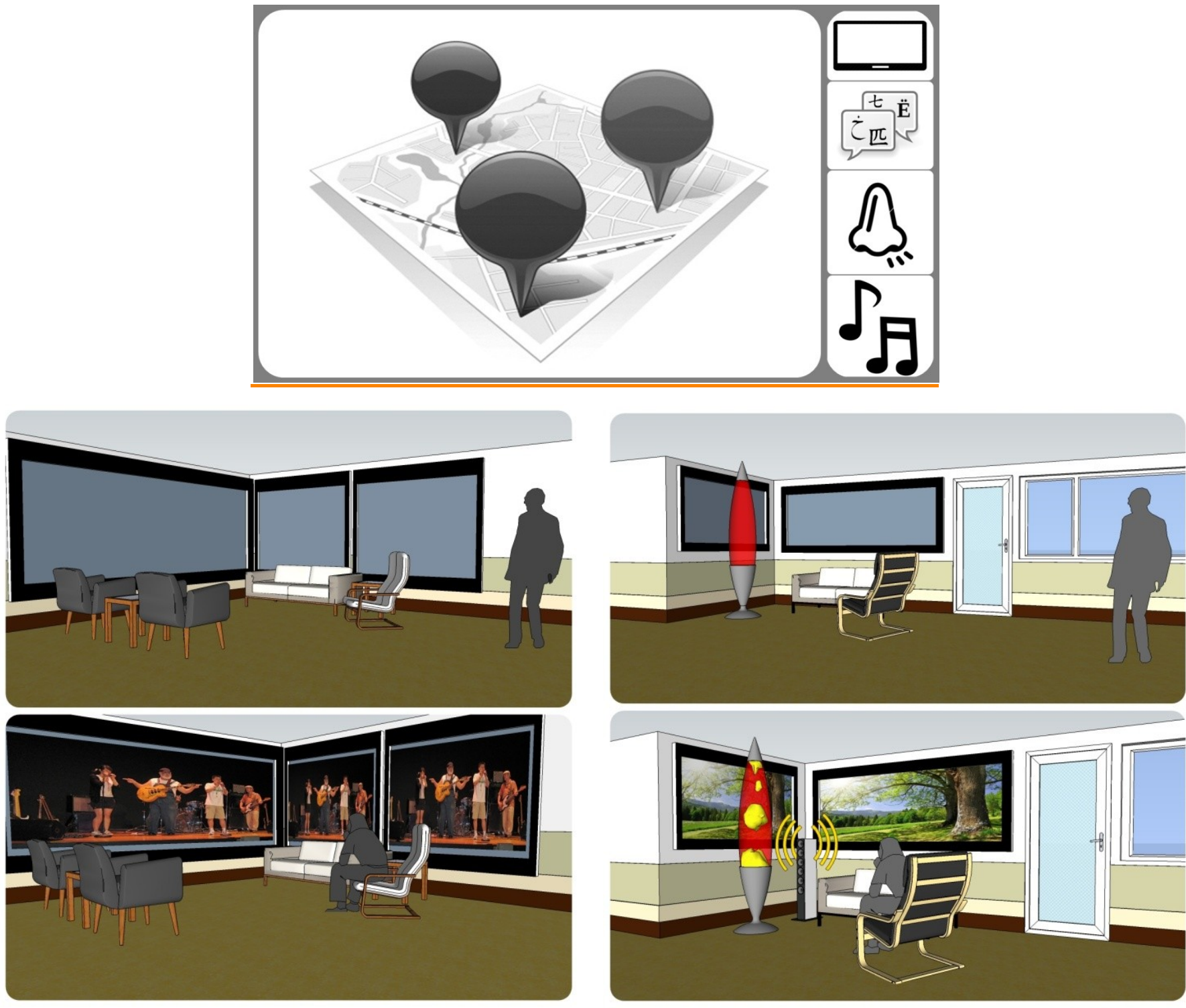


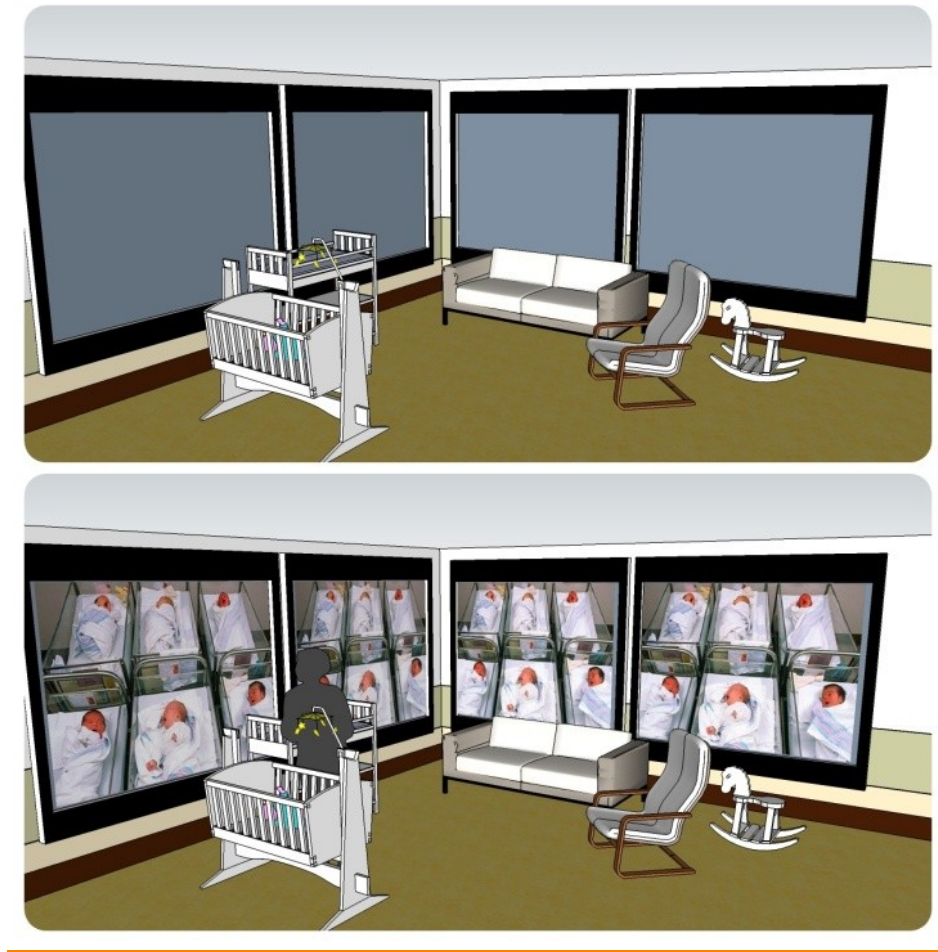

Strongly agree

5

Effectiveness

Ease of use

Suitability to environment

- What would you change about it?

- Possible Projections:

\begin{tabular}{|c|c|c|c|c|c|}
\hline & $\begin{array}{c}\text { Very Useful } \\
5\end{array}$ & 4 & 3 & 2 & $\begin{array}{c}\text { Not } \\
\text { Useful } \\
1\end{array}$ \\
\hline Pop-up Band & ० & 0 & 0 & 0 & o \\
\hline Huge Size Snoezlen & o & 0 & 0 & O & o \\
\hline A Nursery & o & o & o & o & o \\
\hline Wedding & o & 0 & 0 & 0 & o \\
\hline Restaurant & 0 & 0 & 0 & 0 & 0 \\
\hline
\end{tabular}

Strongly disagree

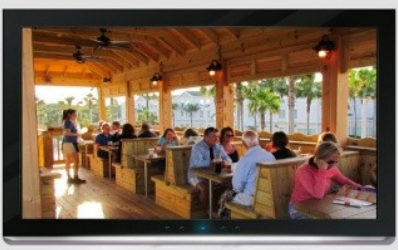

$\begin{array}{ccc}3 & 1 \\ \circ & 0 & 0 \\ 0 & 0 & 0 \\ 0 & 0 & 0\end{array}$




\begin{tabular}{c|c|c|c|c|c|}
\hline Homeland Sceneries & 0 & 0 & 0 & 0 & 0 \\
\hline Party & 0 & 0 & 0 & 0 & 0 \\
\hline Someone asking for help & 0 & 0 & 0 & 0 & 0 \\
\cline { 2 - 5 }
\end{tabular}

- Possible Functions:

\begin{tabular}{|c|c|c|c|c|c|}
\hline & $\begin{array}{c}\text { Very Useful } \\
5\end{array}$ & 4 & 3 & 2 & $\begin{array}{c}\text { Not } \\
\text { Useful } \\
1\end{array}$ \\
\hline $\begin{array}{c}\text { Suitable - personalized } \\
\text { Odor }\end{array}$ & 0 & O & o & ○ & o \\
\hline $\begin{array}{c}\text { Personalized Generic } \\
\text { Music }\end{array}$ & O & O & O & O & O \\
\hline Automated Conversations & 0 & o & o & 0 & O \\
\hline $\begin{array}{l}\text { Ability to understand } \\
\text { languages }\end{array}$ & O & O & ○ & ○ & ○ \\
\hline $\begin{array}{l}\text { Ability to understand } \\
\text { patient's own vocabularies }\end{array}$ & O & o & O & ○ & ○ \\
\hline
\end{tabular}


C) Please the rank the ideas based on their usefulness.

\section{DOOR PANELS}
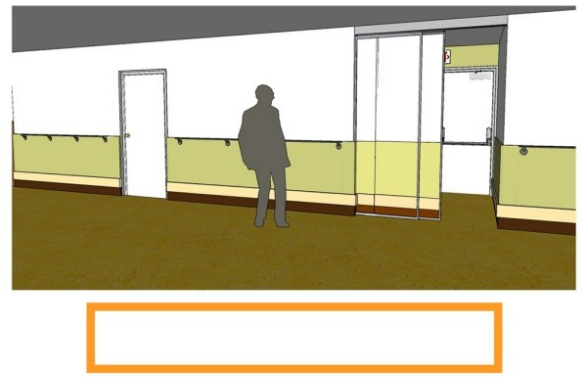

A HOLOGRAM
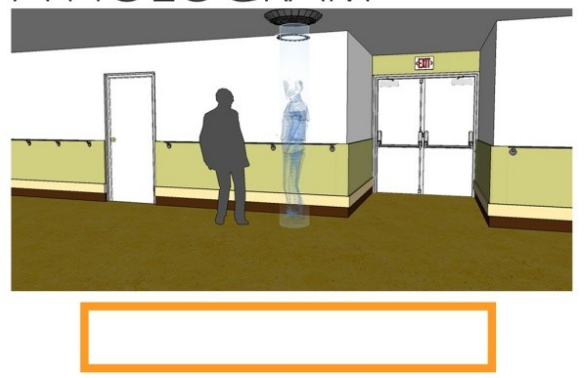

COLORED LIGHTS
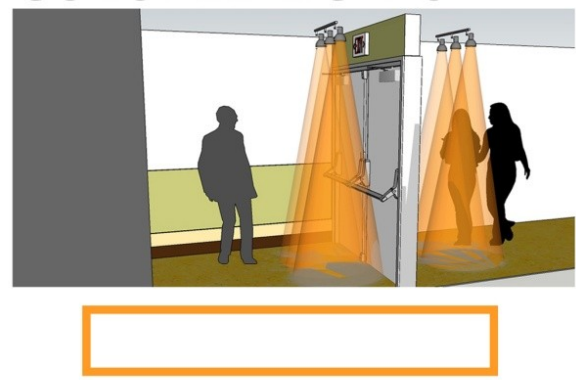

VIDEO WALL STATIONS

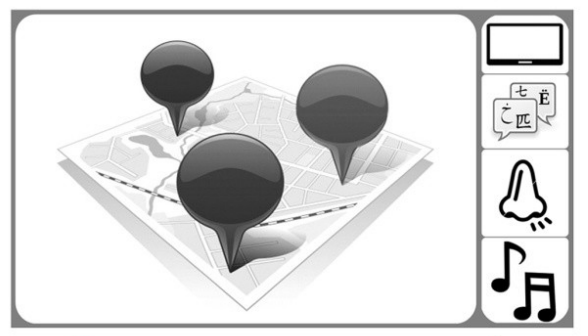

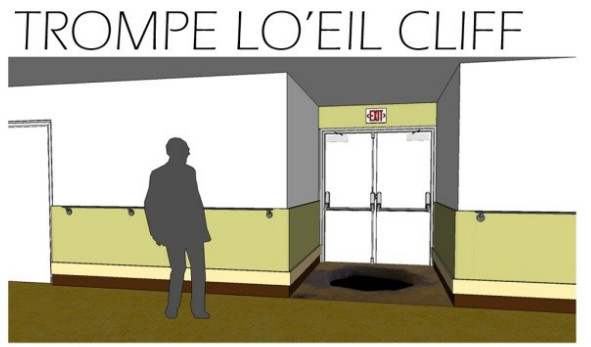

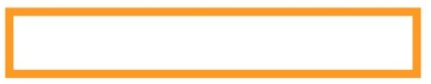

HIGH-PITCHED ALARM
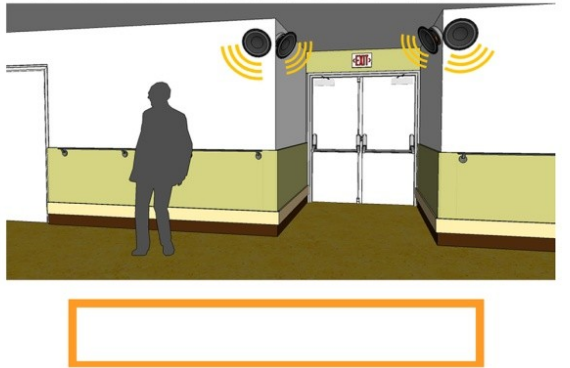

VIDEO CALL
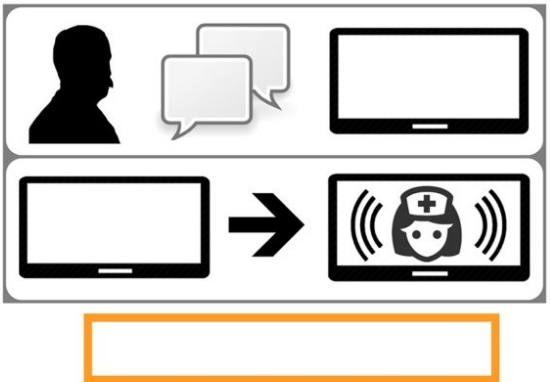


\section{APPENDIX F - INTERVIEWS FINDINGS}

\section{AFFINITY DIAGRAM}

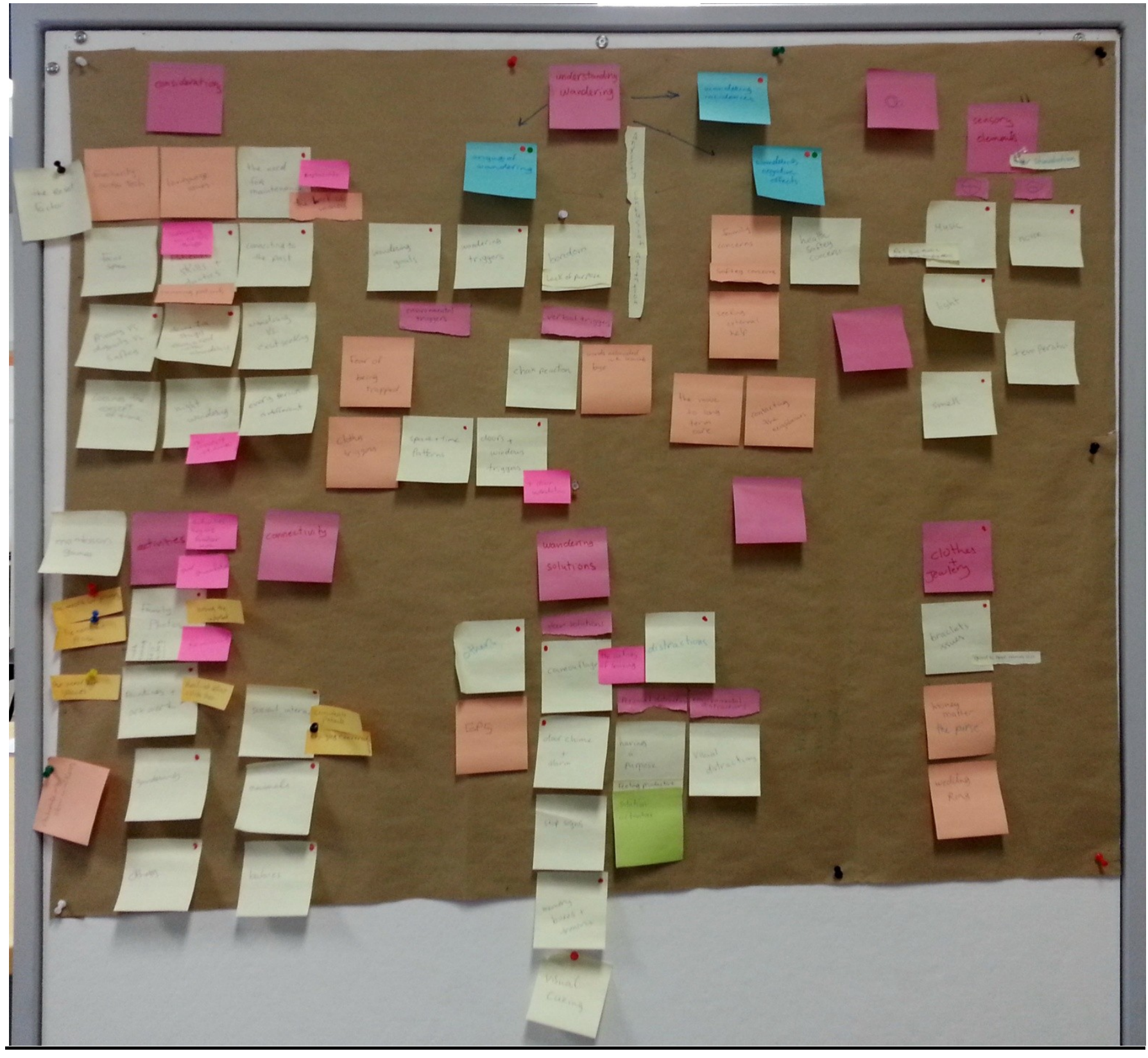




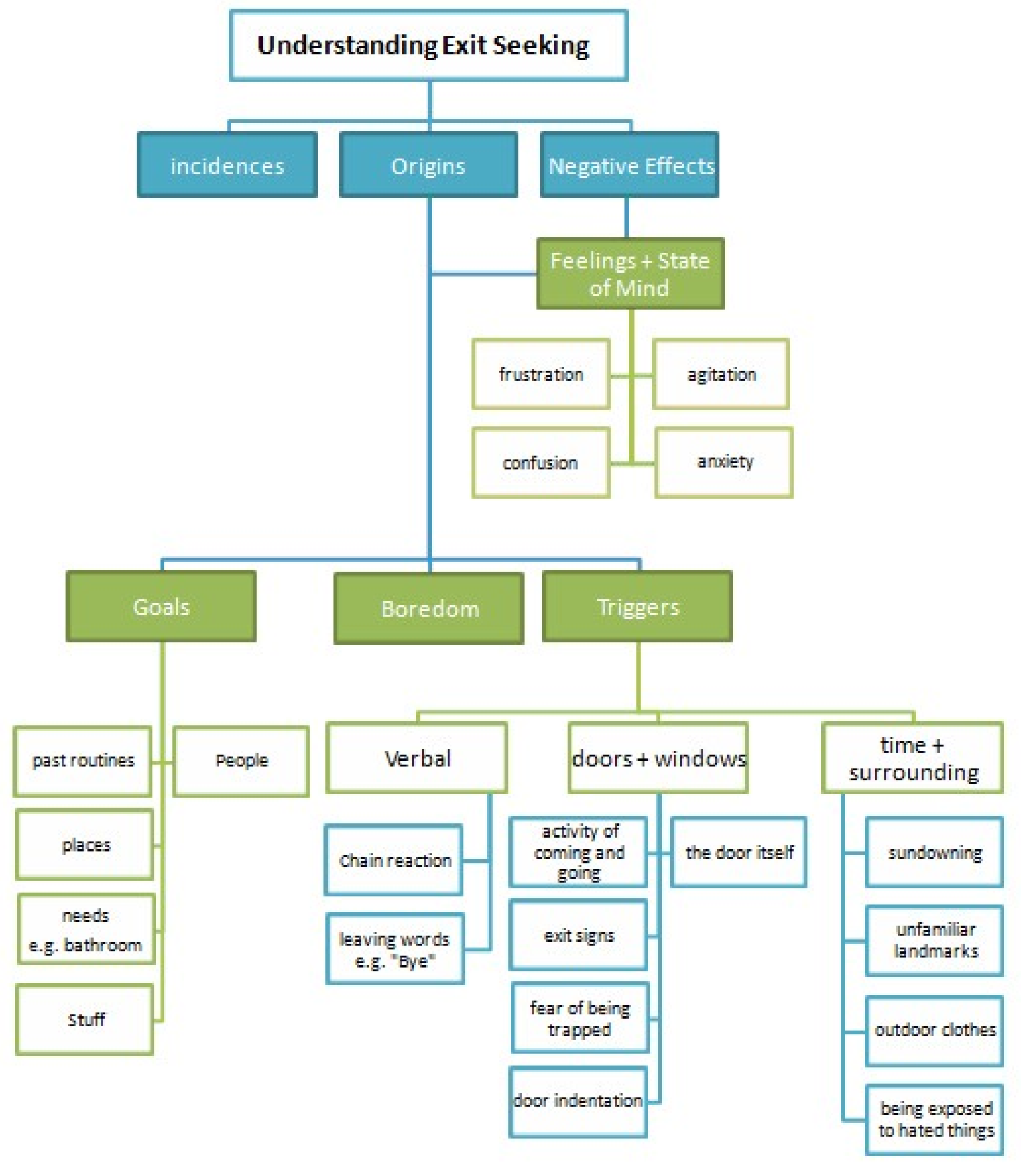




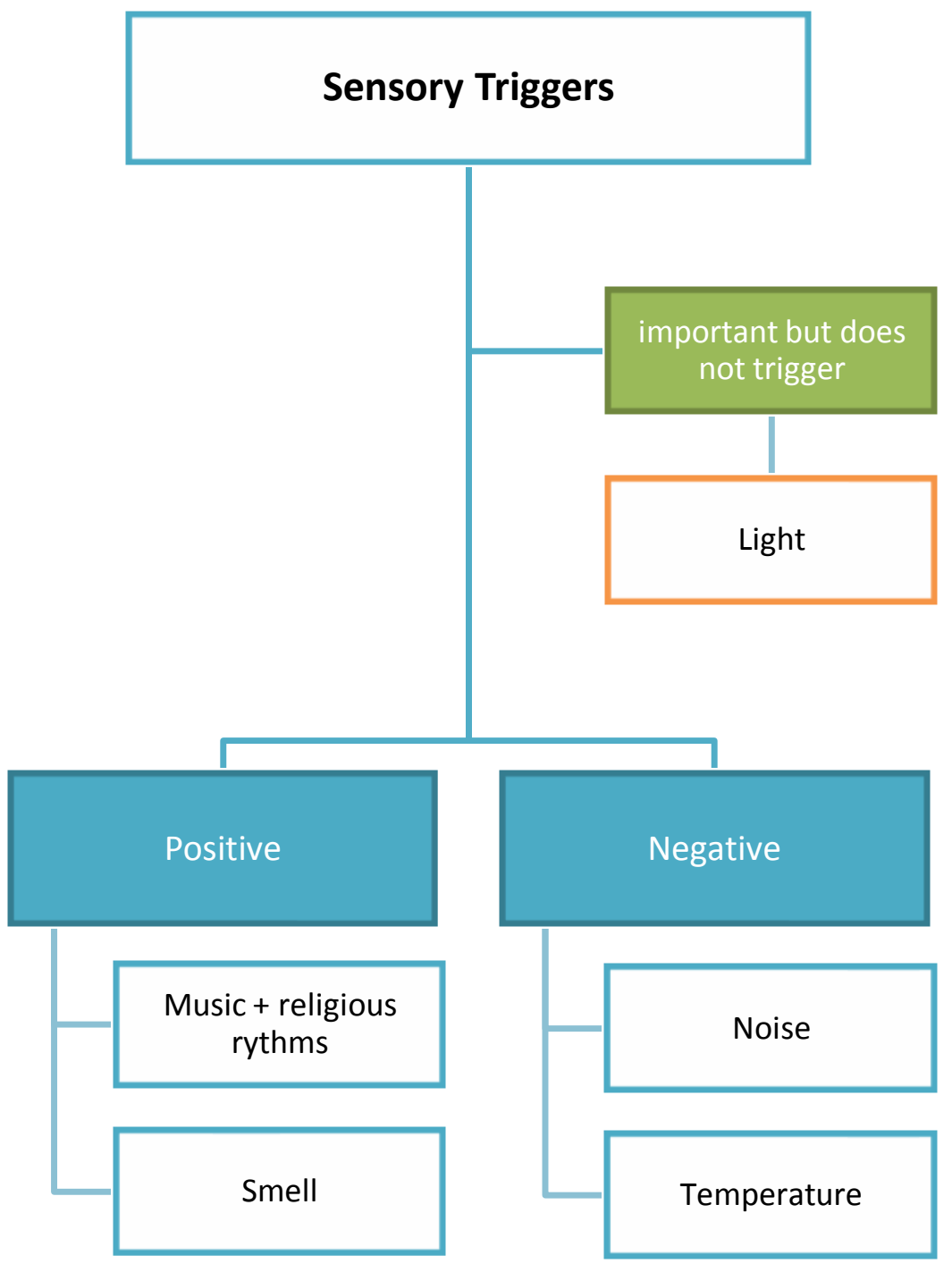




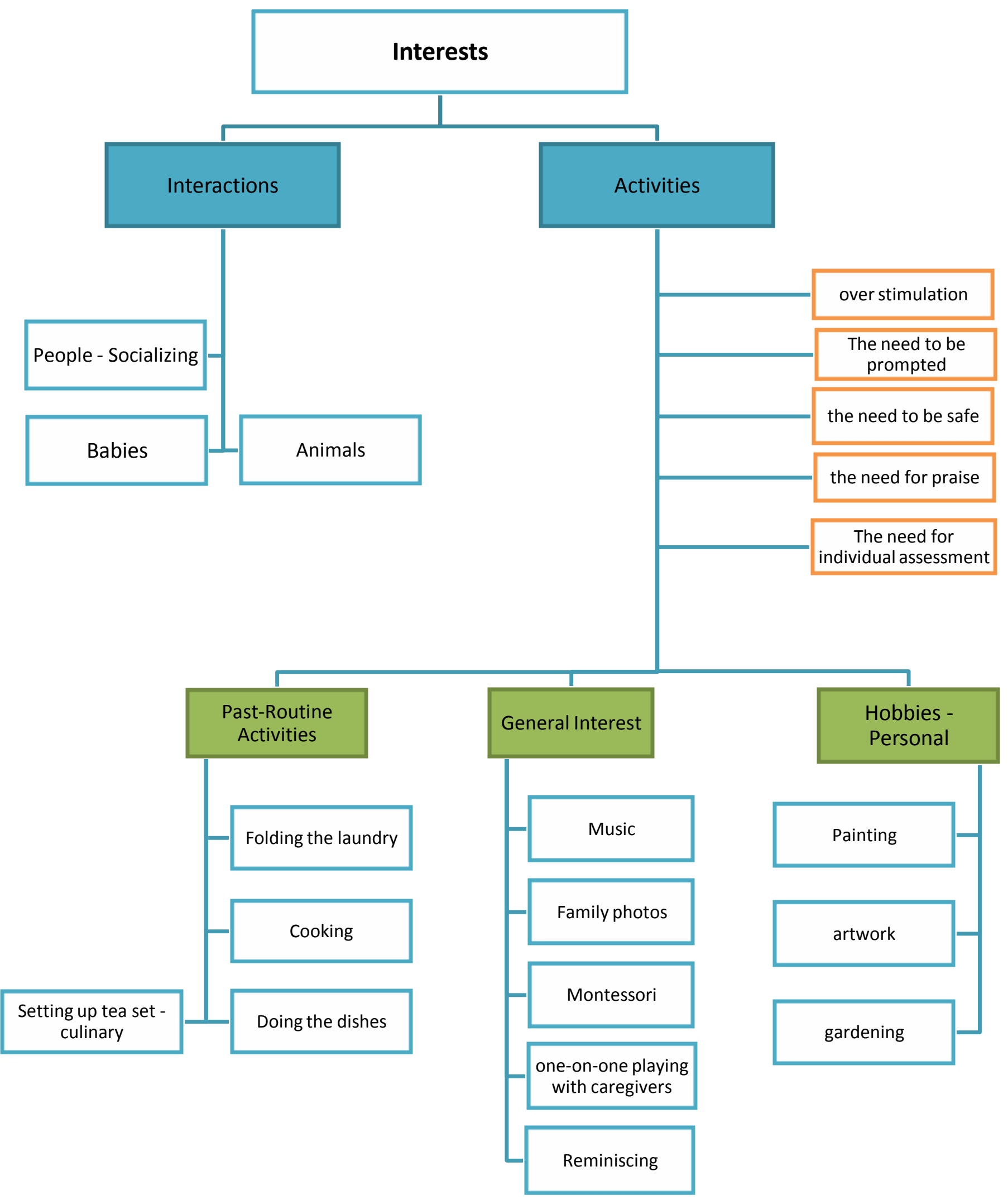




\section{APPENDIX G - WORKSHOP FINDINGS}

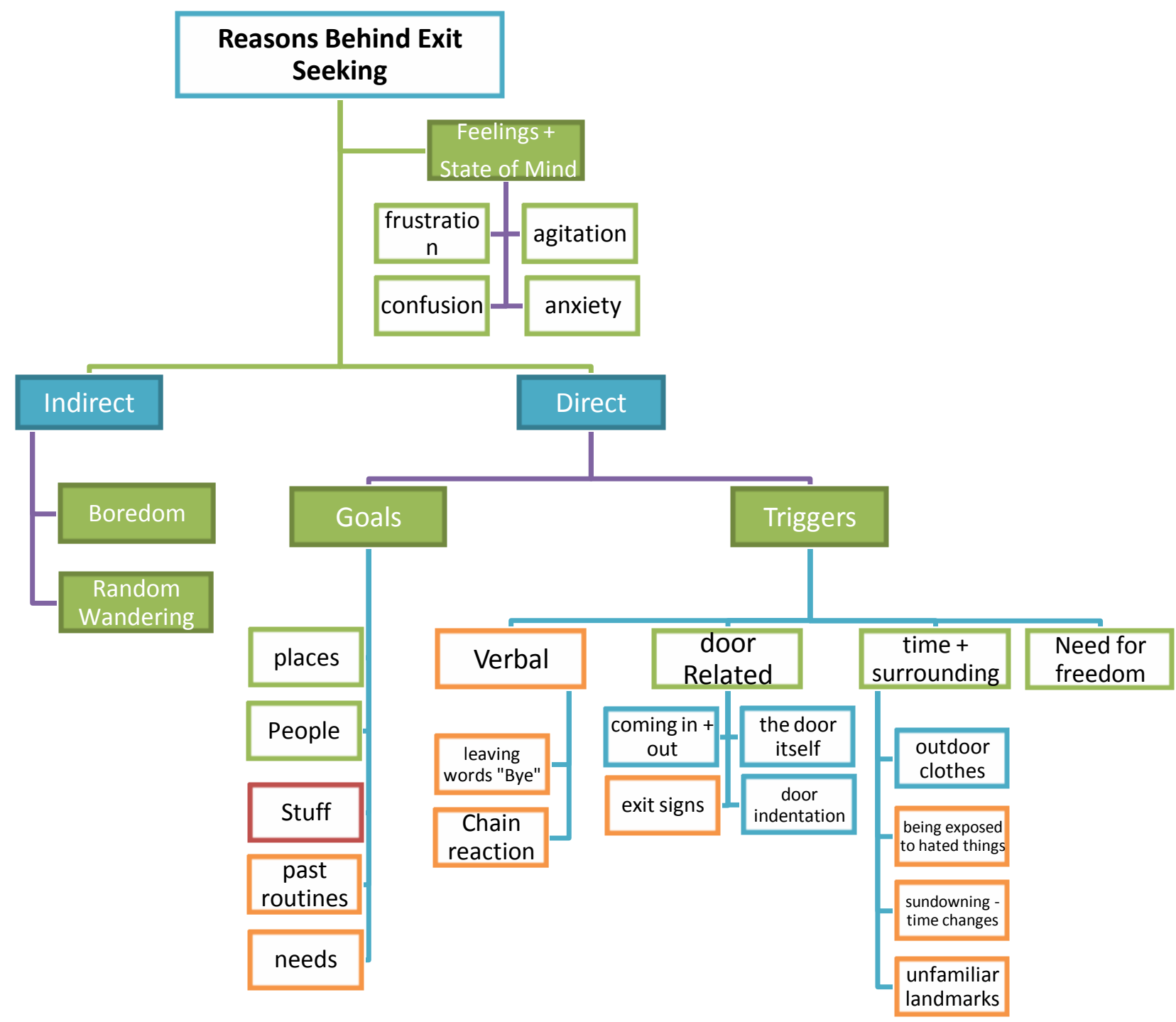




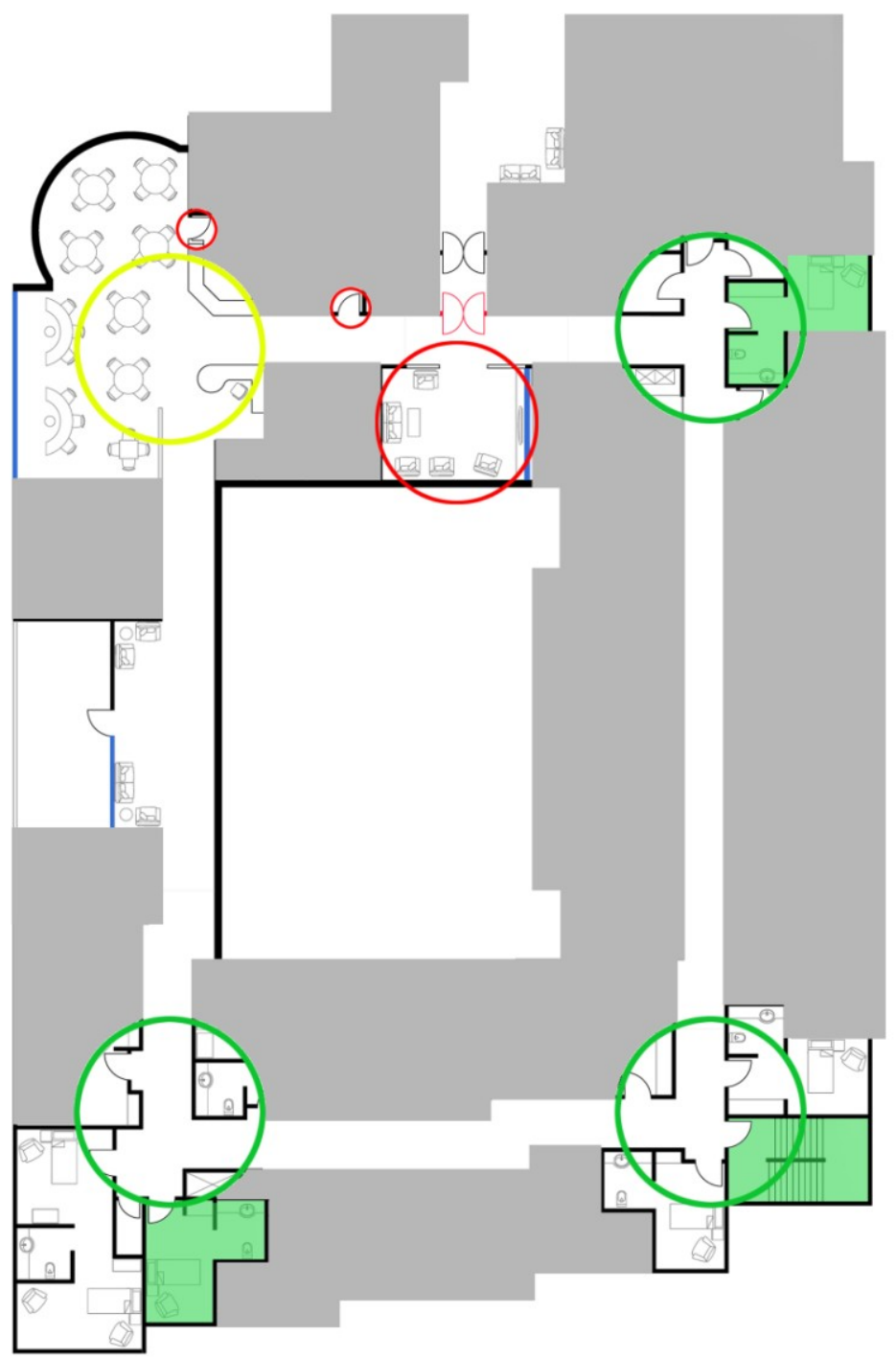

The distribution of distractions around the facility

Problematic doors/door locations that often trigger residents into exit-seeking An appropriate location and room purpose as is

Problematic rooms that can benefit from the use of video wall stations 


\section{APPENDIX H - SURVEY FINDINGS}

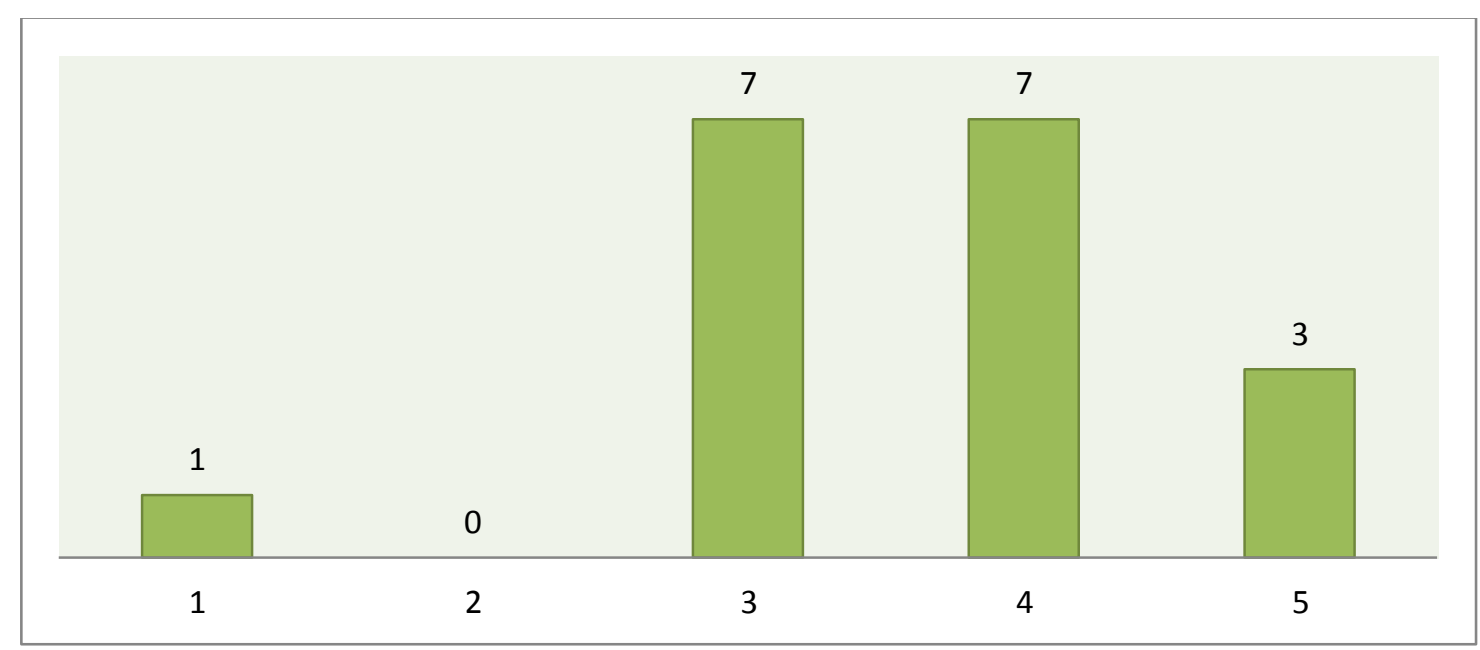

The caregivers responses to the first survey question, their familiarity with technology. An even number of caregivers (seven) indicated that they are somehow familiar with the technology and not familiar nor unfamiliar with technology.

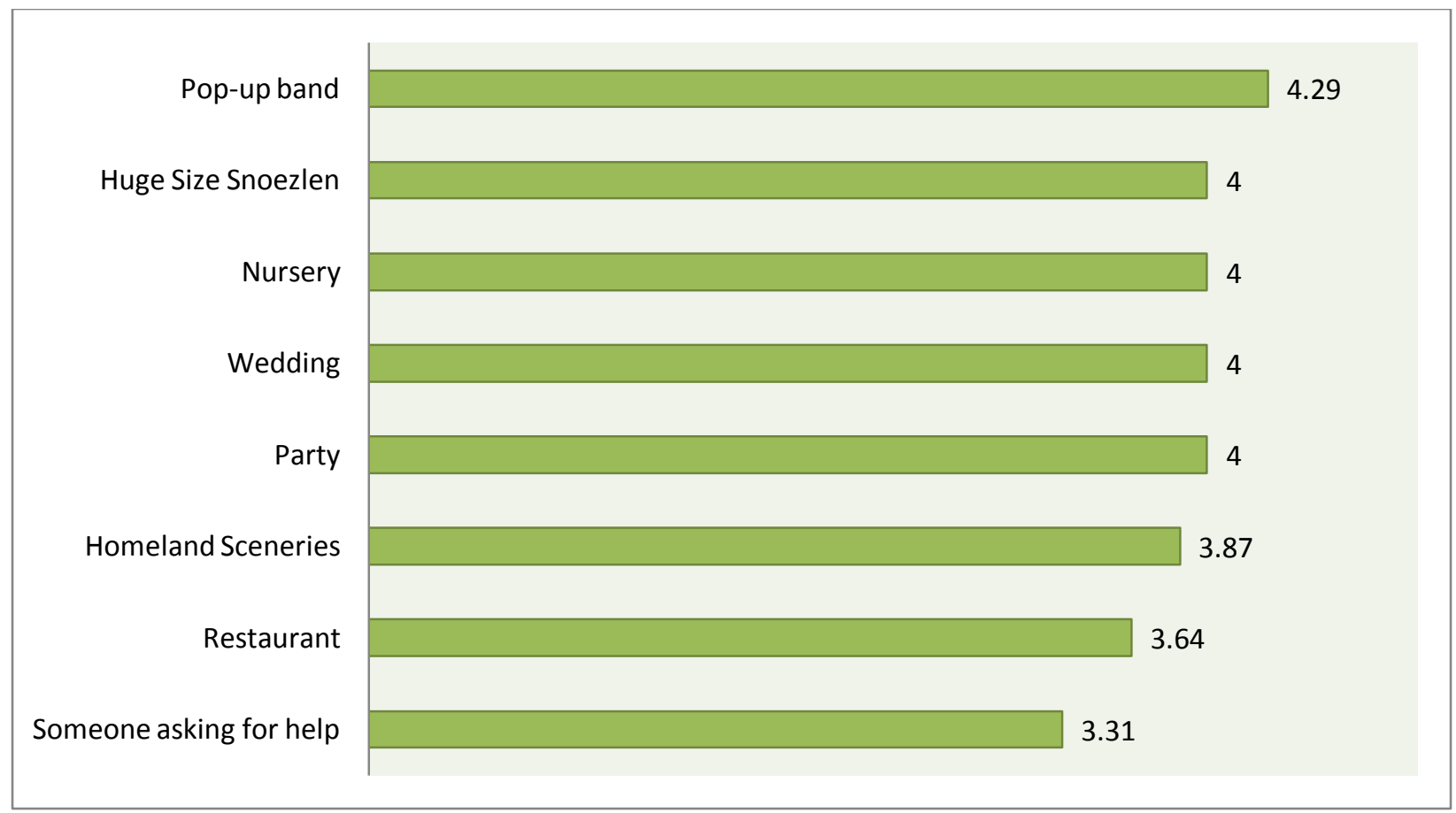

Possible topic projections for video wall station interventions. The pop up band was the most popular, while someone asking for help was the least favored (negative). 


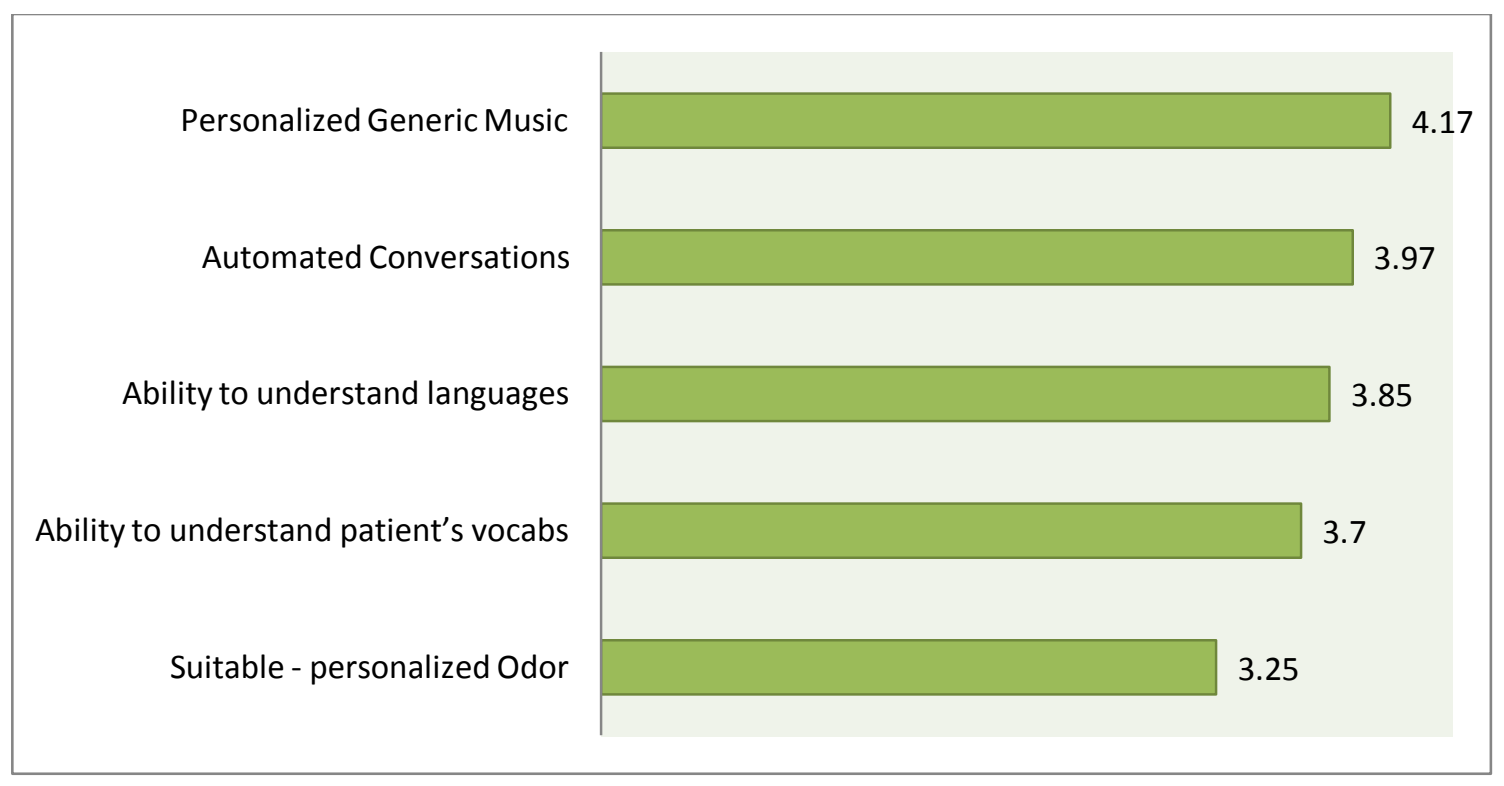

Video Wall Stations Possible Functions. The stations ability to play personalized generic music received most answers. However, the stations ability to omit a fabricated smell received the least support. This is because allergy related reasons.

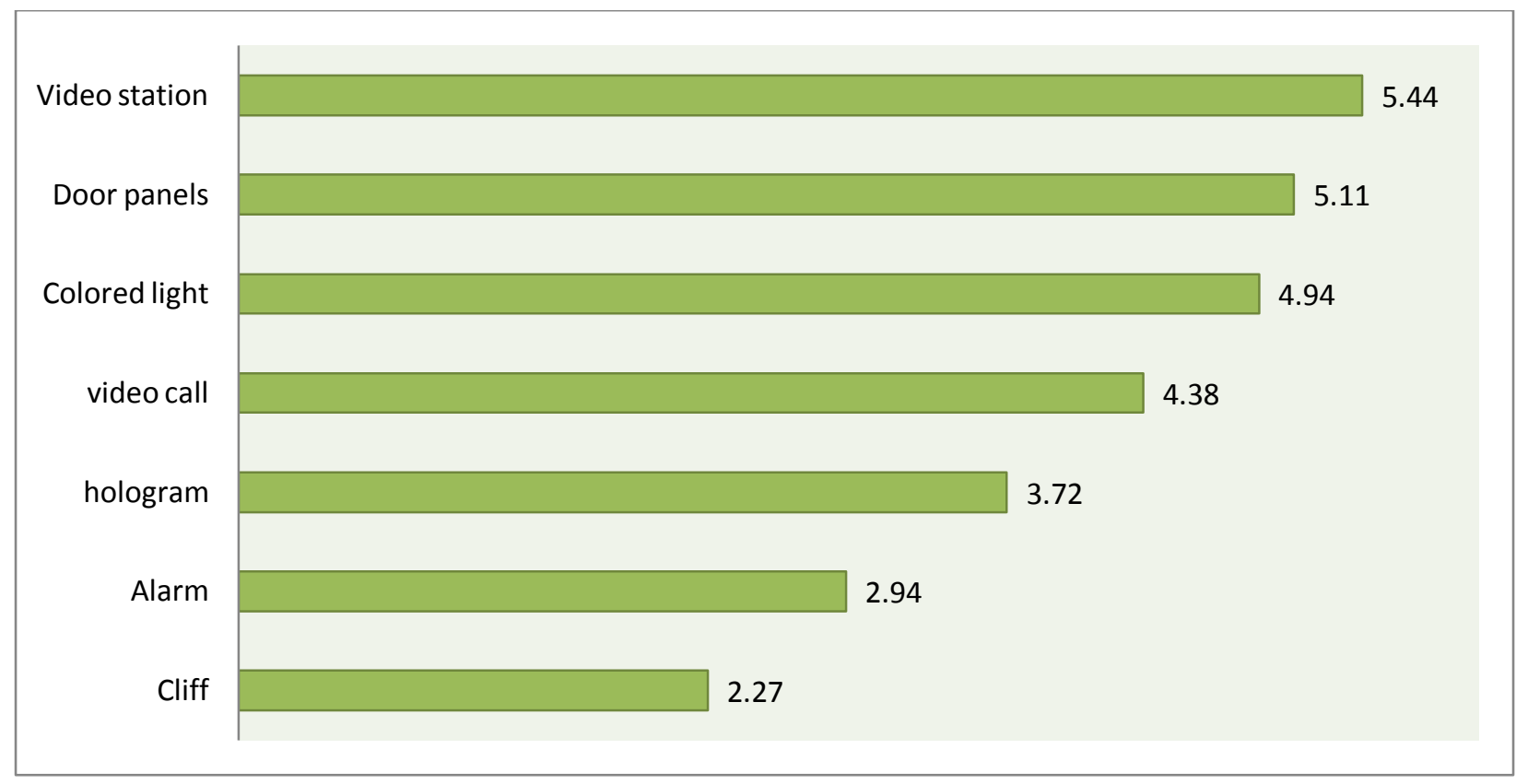

Exercise number three: the ranking task. As discussed in the thesis, the video wall stations received most responses, followed by the door panels, then the colored lights. The trompe l'oeil cliff and the high-pitched alarm were the least favored by the survey participants. 